Redesigning housing for older people in China

BY

\title{
Chang Cui
}

\begin{abstract}
A thesis
submitted to the Victoria University of Wellington

in fulfilment of the requirements for the degree of

Interior Design of Architecture
\end{abstract}

Victoria University of Wellington 


\section{Abstract}

In the 1980 s and early 1990 s, due to the rapid growth of the real estate industry at the time, this time saw a trend towards the commoditization of homes. Driven by the interests of real estate, the excessive pursuit of volume ratio emerged in residential construction, which often sacrificed function to achieve profit maximization. As a result, there were a series of spatial design problems.

Despite this, there are still many older people living in these low-quality dwellings that are no longer suitable for their life. Firstly, the construction of a large number of apartments and nursing homes for older people is a huge and expensive project in China. From the perspectives of finance, and the urgency of accommodating older people, the investment in the reconstruction of older dwellings is potentially lowercost than new buildings, and the scope of application is wide. Secondly, influenced by traditional culture, older people prefer to live near or together with their relatives in familiar surroundings. Therefore, the rational redesign of old dwellings can alleviate some of the living pressure on older people.

The thesis focuses on the living environment of older people over 60 years of age who are currently living in old dwellings from 1980s and has ability of self-care. The aim is to improve the current living environment of older people, redesign the existing poor conditions of their old dwellings, and provide better living quality for their future life. Furthermore, it is also to create new possibilities in the field of ageing-friendly renovation of old dwellings in China in the future. The thesis investigates the background of the research subjects and selects suitable subjects for redesign. The thesis provides a reference for how to improve older dwellings for older people using Universal Design principles. 


\section{Table of Contents}

Abstract.

\section{List of Illustrations}

Introduction 4

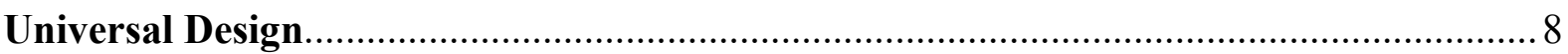

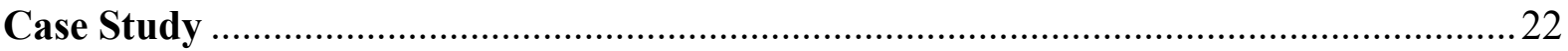

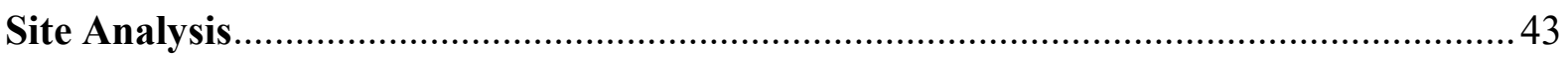

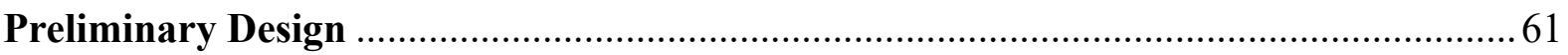

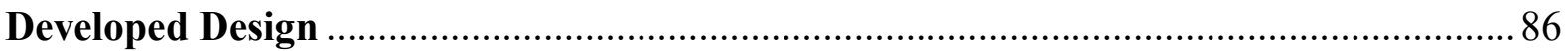

Conclusion

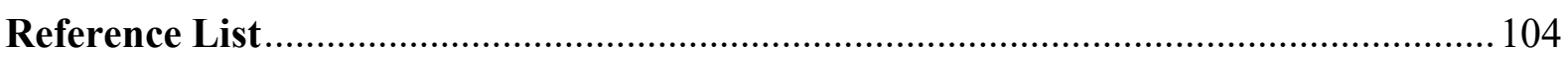

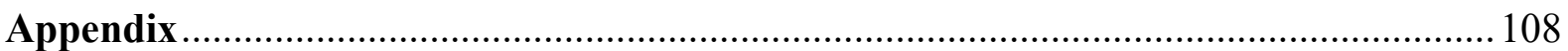




\section{Introduction}

This thesis is a redesign strategy study of older people's living conditions based on aging in China. At the end of the twentieth century, the proportion of older people over 60 years of age in China reached 10\%. According to China's sixth population census, $13.26 \%$ of China's total population is over 60 years old. Furthermore, this increases in the older population has two aspects: the many existing older people and the aging population's rapid development.

With the rapid development of China's urbanization, a large number of young people have left their hometowns for school or work. This has led to the creation of a large number of empty-nest families. The young population's tendency to be overconcentrated in developed regions leads to a large number of empty nesting families. Furthermore, the problem of "providing the aged" has become a common phenomenon. To address some of the problems faced daily by some Chinese older people, this thesis draws on useful design concepts and case studies to redesign dwellings to be more suitable for Chinese older people, extending the time they can live independently and the use of their homes.

Due to China's generally low per capita income, many older people and their families do not have sufficient financial stability. Many older people from the middle and lower classes do not have enough income to support a better living environment. Also, China's social security system for older people and medical care is still inadequate. To ensure that most older people can have a high-quality living environment, the government promotes the home care model's development for older people - one of the reasons why the government promotes the home care model based on traditional Chinese culture. Older Chinese people tend to associate the value of their existence with family relationships. As a result, many older people are reluctant to live in nursing homes and other institutions. 
The aim of this thesis is to select a typical dwelling from the 1980s-90s and redesign it to better support older people's lives, including reorganizing functional areas and activity lines to better meet the essential functions of older people's retirement life at a reasonable cost. This research combines the following components: a review of relevant literature, including an overview of universal design an analysis of case studies, a field survey of Chinese dwellings, on-site interviews with dwelling users, and the redesign of an existing apartment.

The range of dwellings studied was residential dwellings from the 1980s to the 1990s. The target population was older people over 60 who live in these dwellings. This thesis will explore the current and future housing needs they face in their old age from their perspective. Universal design concepts are used to help identify, synthesize, and improve existing housing problems. The universal design of old dwellings can prolong the reality of independent living for older people, thereby reducing the pressure on society caused by the aging of the population, saving social resources, reducing labor consumption, and improving the older people's quality of life.

This thesis aims to explore a universal design model in older people housing that is suitable for the Chinese context. Efforts are made to achieve the sustainable use of older housing and social development so that dwelling design can best meet the older people's needs and provide the necessary assistance for them to live comfortably.

The study began in May of 2020 with a review of the literature on Universal Design theory, the physiological and psychological changes in older people, which to summarize its key points and laying the theoretical foundations for the design chapters. 
In July and August of 2020, the research started with investigation of international examples of universal design, which to summarize its merits and providing new, upto-date ideas for the design phase, as well as providing relevant design practice experience.

After August in 2020, the research started with investigation of old dwellings in the surrounding area of researcher's city that were eligible for the study. The researcher contacted the owners by telephone and agreed with them in writing to obtain permission of study. This involved field photography, house mapping and a written interview with the owner. The conducting the interview and documentation of the apartment were approved by the Human Ethics Committee at the university.

A detailed site visit to the renovated house was carried out. The researcher explored new options for the renovation based on previous theories and case studies. The author's findings are presented by means of 3D modelling and floor plans.

The main content of this thesis is divided into five chapters:

The Literature Review chapter examines two areas, which are the concept, principle, the feasibility of the universal design theory and the relationship of universal design with barrier-free design. It define and classify concepts and analyze the physical, psychological characteristics and needs of older people, the daily activities of older people, and other issues;

The Case Studies chapter reviews five examples of older people's dwellings. It summarized that the needs of the older people and disabled for indoor space and the principles, methods and significance of the general design of the interior space through the study of international older people housing cases; 
The Site Analysis chapter examines two areas. The first area describes the existing dwellings in China from the 1980s to the 1990s and analyzes their spatial features, indoor environments, and dwellings' problems. The second area collects information on the targeted dwellings and conducting a questionnaire survey of the dwelling owners through fieldwork;

The Preliminary Design chapter examines the redesign of targeted dwelling based on a universal design from seven functional areas which are kitchen, bedroom, study, living room, dining room, front lobby and bathroom. The redesign's content includes improving the spatial functions, human movement, lighting, ventilation, and noise transmission of the targeted dwelling. The spatial relationships, dimensions, and object positions were redrawn from the original floor plan.

The Developed Design chapter examines two areas, which are interior finish, furnishing and lighting. Based on the preliminary design review, more detail on specific furniture design will be shown in this chapter, including examining color, materiality, and surface textures. Issues related to improvements in light, ventilation, and noise transmission also will be included. 


\section{Universal Design}

This chapter starts with an introduction to universal design (UD), and will focus on the core concepts of UD referred to Ronald Mace's handbook. It also analyzes the significance of UD for senior housing and suggests guidelines in chapter 1.2.

\section{A.The Basic Principles of Universal Design}

\subsection{The concept of universal design}

The concept of Universal Design was first proposed in 1985. It refers to "design that is irrelevant to name, gender, ability, and suitable for everyone." (J.W Rowe). The International Universal Design Center revised this definition in 1988 to introduce modifications related to maximum allowable range, regardless of gender, age, and ability, suitable for everyone to use the environment or product design. (J.W Rowe, 1987, \&1997, p-147-149). UD emphasizes that at the beginning of the design, the essential and priority objects, such as barrier-free design which makes home accessible and safe to use for everyone in a house, should not be compromised in any case. Limited to the current state of the person, UD should look at the user with a dynamic perspective. The user's existing physical ability, along with increased age, should be considered to make the designed space and environment more suitable for lifetime use.

As a set of design procedures, UD enables development strategies, promoting the improved quality of life. In the process of developing the set of design principles, the motto of UD is successful aging. Successful aging includes: 


\section{a. a low probability of diseases and disorder-associated disability;}

b. a high degree of body and cognitive functioning; and

c. a lively engagement in lifestyles (J.W Rowe, 1987, \&97).

During the aging process, older people try to maintain their day-to-day functions with freedom and independence (J.M. Guralnik, 1996). "To seek independence is considered to be an essential factor as it facilitates autonomy and control over their utilities, finally end with life satisfaction and well-being" (J.E Hertz, 2002, p.166). The benefits of well-being resulting from UD include a better mindset, low stress, high life expectancy and low health care costs. (K.E. Thorpe, 2012). In addition, UD needs to consider older people residing in a community with activities in their homes, social groups, religious places, recreational centers and daily household tasks and personal activities (such as banking, purchasing and appointments, etc.). At the outset, planning and designing of buildings for the older people should show respect and care towards elders for their rest of the life.

The key reason for proposing UD is to provide access to all spaces in the planned area without stigma (M.F. Story, 1998). By enhancing the life quality UD can enable individuals to complete day to day activities with safety, freedom and less struggle. Universal Design promotes building access for older people without stigmatization. 


\subsection{The principle of universal design}

Ronald Mace (1997) of North Carolina State University and a group of expert teams consisting of architects, designers, researchers of environmental design and engineers further developed UD principles in 1997. Their global design handbook set standards and provided examples so consumers would have a clear understanding of the design end products and environments. The seven essential principles of Universal Design are:

\section{a. Principle 1. Equitable use}

Principle 1 deals with designing for diverse abilities promoting universal accepted utilities that should not show disrespect to gender, sex, and age groups. The guidelines of principle 1 further consist of avoiding stigma with user provisions related to privacy, safety. Correspondingly, security provides an equal opportunity for all kinds of users.

\section{b. Principle 2 Flexibility in use}

This principle concentrates on accommodation individual preference and abilities. It refers to adaptability to support different user needs.

\section{c. Principle 3 Simple and intuitive use}

This principle supports users to understand the designs regardless of experience, knowledge, and language proficiency. This principle reduces 
the unnecessary complexity of features. This includes the compliance of user expectations and intuition, the accommodation of language skills with a wide range, the arrangement of information with its importance, the effective feedback and prompting during the process.

\section{d. Principle 4 Perceptible information}

Principle 4 relates to effective communication of necessary information to the user, irrespective of ambient and user sensor ability conditions. Additionally, effective communication makes use of different modes of presentation either by verbal, pictorial and tactile means. Even with a variety of techniques or devices used by the residents, the information provided should be comprehensible.

\section{e. Principle 5 Tolerance for error}

Principle 5 minimizes the frequency of accidental or unintended actions. This includes additional safety features like warning systems for errors and hazard-prone areas.

\section{f. Principle 6 Low Physical Effort}

Principle 6 promotes designs that do not require significant physical effort, and reduces the likelihood of fatigue, supports natural body positions, and minimizes repetitive actions. 


\section{g. Principle 7 Size and space for approach and use}

Principle 7 lists suitable sizes for designs that are compatible for the user and options for modifications for all user body sizes and mobility needs. Suitable sizes should assist comfort in the seated or standing positions. It also, accommodates variations in hand and grip size.

Ageing is associated with a natural change in health conditions and body functioning (J.W. Rowe, 1987, p-148). The transformations in the body include loss of muscle mass, the decline in vision, sensory, and cognitive function. (Hedden, 2004; Lang, 2010; Lindenberger, 2009). The natural age-related issues impact on the ability for an active life; and the built environment can either positively or negatively support older people's lives. (Crews, 2006).

Future designs, or renovation of existing buildings, should support individual needs and produce a risk-free environment and promote successful aging (Bowling,2005; Charbonneau, 2002). The residential environments of older people, should improve quality of life, positive attitude of older people, and leading a successful life for them (Guse, 1999). 


\section{B. Analysis of the Needs of Older People}

\subsection{Definition of older people and their needs}

According to the Chinese building design code for older people, and general international standards, those people aged over 60 are treated as senior citizens.

Lawton (1980) suggested that design with minimal physical barriers should pay attention to older people's needs, such as care, safety, and eco-friendly features. Multiple design features should address the physical, mental, and well-being of older people. For developing different standards in nursing, care, and housing, physiological anthropologists can provide unique information for designing environments of elders (Crews, 2005). Anthropological studies focus on developing both exterior and interior fixtures along with visionary and hearing aids related issues, such as lighting, color schemes, audio attributes, and spacing appropriates. In addition to improving older people's memory and sense of emotions, certain therapies can be designed to facilitate this process.

Physical weakness and biological phenomenon in individuals should strictly be monitored. House design for people with long term health issues, may include advice from medical practitioners to provide appropriate facilities according to need. There should be a proper individual-centric study for certain individuals to identify the specific needs that can reduce stress-related issues, less physical activity, and loss of weight (Walston, 2005). While acknowledging the importance of such studies and evaluations, these are beyond the scope and resources of the current thesis project. 
The capacities of older people can be categorized as follows:

\section{a. Self-helping}

Older people who have the ability to self-care are able to perform basic tasks on their own, have a healthy mind, and can move freely. In the Hand Book of Universal Design, Abir Mullick (1993) discussed the importance of planning and designing a building and bathroom environment for older people. Concerning the capabilities of older people and the current bathroom and other requirements within the house, the environment in the home should be designed to support the independent users to operate independently as their first choice. For instance, some older people insist on support in the bathroom, and in most cases, the bathroom is an unsafe and inconvenient place. The designs should anticipate all types of users and more care for older people.

\section{b. Device-helping}

Some older people are more likely to be less dependent than other people and would benefit from using device-based help. Examples of device-help include: automatic dispensers, smart connecting systems, and mechanical wheelchairs. Smart bathroom developments, like IDEA centers by the National Institute on Disability and Rehabilitation Research (NIDRR) of U.S Development of Education, also promote helping devices for the benefit of individuals. 


\section{c. Under nursing}

Some older people will not be able to live independently even with devicebased help, or may be unable to afford such devices and self-helping equipment, due to their cost and other parameters. These people rely on the availability of caring facilities. The Chinese government funds most of the caring centers in China. A combination of nursing and device-based help are mostly required in care residences for people with severe health conditions and long-term diseases. 


\subsection{Psychological and physiological changes of older people}

Yanmin (2018) found that, after the human body began to physically decline, different parts of the human body began to show different degrees of degeneration. Women aged 60 and men aged 65 and older begin to experience physical ageing and may face risk of damage to their bodies during day-to-day activities. Specific examples of decline associated with ageing are identified below:

\section{a. Visual decline}

The lens elasticity of the eye decreases with age, the ciliary muscle's ability to regulate will decline, the number of retinal cells will gradually decrease, and there will be regression phenomena such as blurred vision. Decreased vision can cause older people to have difficulty recognizing objects' shapes and colors and distinguishing small objects. Older people also have an increased chance of eye diseases. Glaucoma, cataracts, and macular degeneration are common visual diseases. In severe cases, night blindness or blindness may occur. The visible decline will lead to the deterioration of the older person's ability to recognize images and colors.

Some of these conditions are improved with increased indoor illuminance by arranging light sources and adding night lighting. An easy-to-recognize light switch is also helpful. 


\section{b. Hearing loss}

The phenomenon of inaudibility caused by the decline of the hearing organs in older people is common. The clinical manifestations are generally lowfrequency resolution difficulties, fast speech rate resolution difficulties, loudness recovery, speech recognition rate, and pure tone difficulty. These are often accompanied by dizziness, drowsiness, tinnitus and other manifestations. Hearing loss can have an impact on the lives of older people. For example, they might not be able to hear the phone or doorbell, or even the alarm. Therefore, hearing loss can cause older people to be less effective interacting with their environment.

Other sensory communication can be used to compensate for the lack of hearing. For example, adding light or vibration cues or haptic-type sensors can promote hearing improvement.

\section{c. Memory loss}

The primary manifestation of the degeneration of the nervous system in older people is forgetfulness, especially the poor ability to remember recent events. Due to memory loss, older people often forget the location of items or other things.

Obvious indications of where objects are located and kept should be included in residential design. For example, legible and transparent design allows older people to see where items located easily. 


\section{d. Cognitive decline}

Due to the degeneration of the nervous system, older people can be slow to respond to things, and their cognitive ability declines with age. The response speed to a sudden situation is slow, meaning that dangerous situations might not be responded to quickly and effectively.

Overly complicated designs and paths should be avoided.

\section{e. Reduced limb flexibility}

With the degeneration of motor nerves and atrophy of tendons and ligaments, the ability of older people to control limbs will decline. Regular exercises such as squatting, bending over, and arm stretching will become more difficult for older people. Therefore, avoid furniture and other objects that are too high or too low. Focus functional design on medium-height areas of the space

\section{f. Decreased muscle capacity}

Imbalanced protein metabolism leads to decreased muscle strength and reduced vitality in older people. Muscle atrophy, reduced concentration, and reduced elasticity will cause older people to not engage in physical labor or long-term sports and other activities. Therefore, it is essential to minimize unnecessary physical activities such as climbing stairs, moving heavy objects, and other indoor cleaning tasks for older people. 


\section{g. Easy to fracture}

As the bone density decreases, the bones of older people gradually weaken, and the bone's regenerative ability and elasticity will deteriorate. Older people are susceptible to bone hyperplasia and osteoporosis, which makes them prone to fractures during exercise and have greater difficulty recovering. Therefore, installing handrails and other auxiliary facilities next to the operating objects when older people perform operating actions is important.

\section{h. Reduced Psychological security.}

As the physiological functions continue to degenerate, the psychology of older people also changes, and they will age and lose their sense of security. For example, older people are more likely to worry about collisions, slipping, or facing unexpected situations without help. Therefore, improving the space's design, choosing the right colors and materials, and installing alarm devices can effectively improve older people's sense of security.

\section{i. Weakened adaptability}

Older people are often reluctant to leave a familiar environment due to slow movements or fear of accidents, and unwillingness to contact with unfamiliar environments, which leads to weakened adaptability to the outside. Therefore, the design of the space needs to consider how to enhance communication between older people and their environment and avoid keeping them in confined and in small spaces for long periods 


\section{j. Feeling of loss}

Older people are more likely to feel alienated from society because of their aging body with slow and restricted movement. Contact between older people after retirement and the community may significantly reduce, and the range of activities also shrinks with age. This change in social role will further exacerbate the negative differences in the psychology perspective of older people. Therefore, where possible, appropriate spaces can be created in residential buildings to allow older people to interact with their neighbors. Examples include translucent balconies, windows and doors, and open courtyards. 


\section{Summary: The feasibility assessment of UD for Older people's Living}

According to the analysis of UD design, Chinese housing design for older people, and the physiological and psychological characteristics of older people, it is necessary to consider older people's current housing needs and anticipate a series of future changes in older people.

Although the main population targeted in this study is the self-care older people, we cannot exclude the possibility that the healthy older people will experience psychological and physical deterioration in the future. Therefore, the core of this study is how to incorporate UD design principles into the existing older people housing design elements, as well as the needs of Chinese older people, in order to come up with a more reasonable, longer life cycle, and more suitable housing design solution for older people.

The research in this chapter is summarized as follows:

Self-helping older people who live alone requires adequately sized rooms and a special design for assistive devices and emergency needs. UD can support the needs of self-helping older people by treating all seniors equally, not only with humane care but also by enhancing their quality of life. At the same time, it can help older people in their future lives.

In practice, there are individual physiological differences between older people. Therefore, the UD design should also take into account the needs of the individual in order to meet them. 


\section{Case Studies}

This chapter will explore the adaptation of various UD strategies and evaluate this.

The selection criteria for these case studies are as follows:

1. are examples of Universal Design

2. are residential projects

3. are less than 20 years old.

The case A, B and C are collected from IHCD (Institute for Human-centred Design), which is an international educational non-profit organization focuses on exploring current practices in UD. The case D is from the Housing for the elderly, which is a project by Yanmin for her parents. 


\section{A.Baldwin Residence}

Type: Renovation

Location: Seattle, Washington, USA

Year Completed: 2006

Designer: Emory R. Baldwin

The Baldwin Residence is a three-story renovated home with apartments for two and three-family. Specific design considerations to support older people, include an entrance opened with a ramp

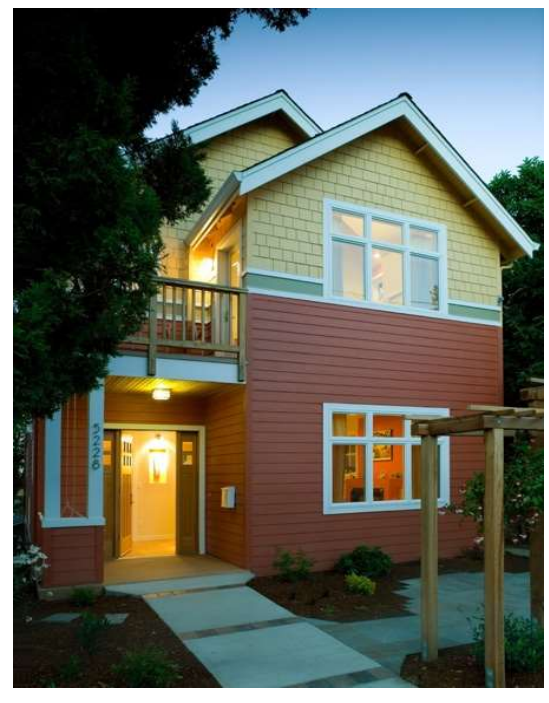

Figure 3.1 Entrance foyer length of $9450 \mathrm{~mm}$ (figure 3.1). The dwelling has no barriers inside on each floor, so the older people and children can move throughout the house with no barriers.

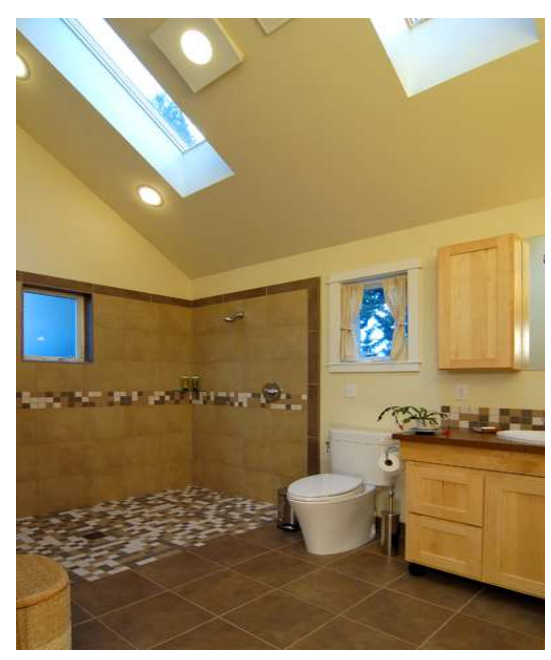

Figure 3.2 Section of sink after the removeable base cabinet is rolled away 


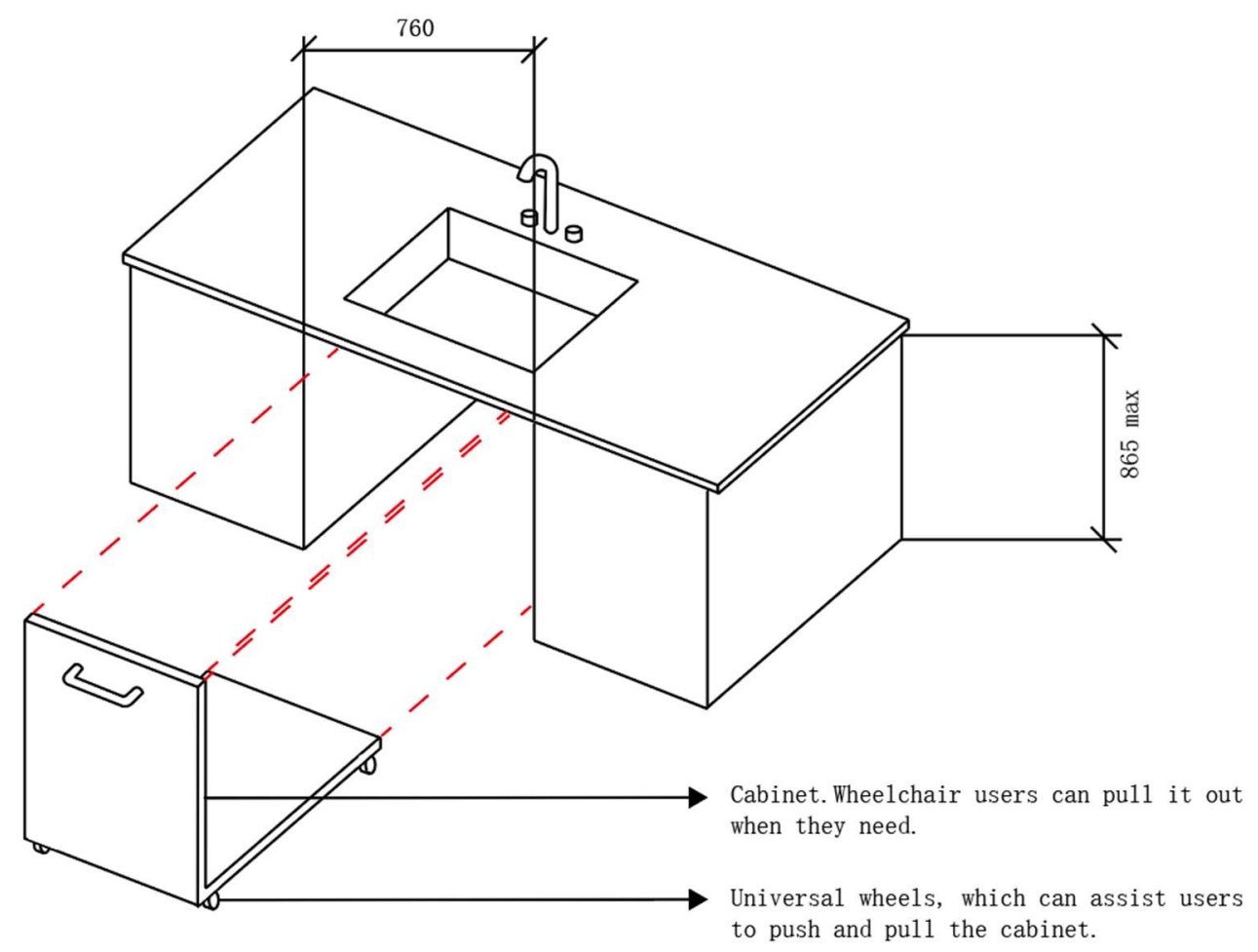

Figure 3.3 Removeable cabinets

Figure 3.2 shows a bathroom interior. The main bathroom is designed for wheelchair access to both the shower and lavatory. The showers are open space without any convex curb design, which allows people to stand on the floor easily. The removable base cabinet near the toilet has lockable casters, which will quickly roll away when the user needs to be a seated position as Figure 3.3 show. To conclude, the building has sufficient features in terms of a whole family. Since

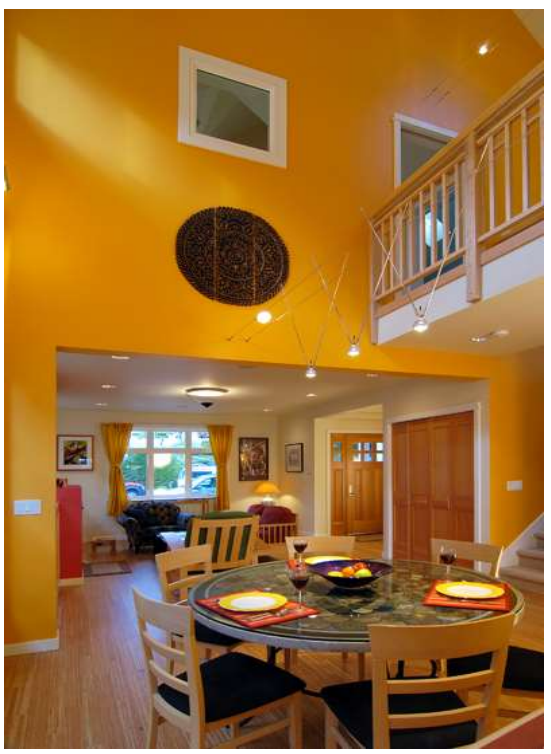

Figure 3.4 Dining adjacent with kitchen the main residents of the building are the Baldwin couple and their two children, and there are no other older users with limited 
mobility, each floor is connected by stairs only (Figure 3.6). From the perspective of older users, this is the most negative aspect of the design. Further interior elevators should be considered if older people or disabled users move in later.

Most doors handles and cupboards have lever handles (Figure 3.4) which are easy to handle and open for children and older people. In addition, some of the doors are single hanged. This is because the flush opening of the door saves space and ensures that the opening action does not interfere with the use of functional areas.

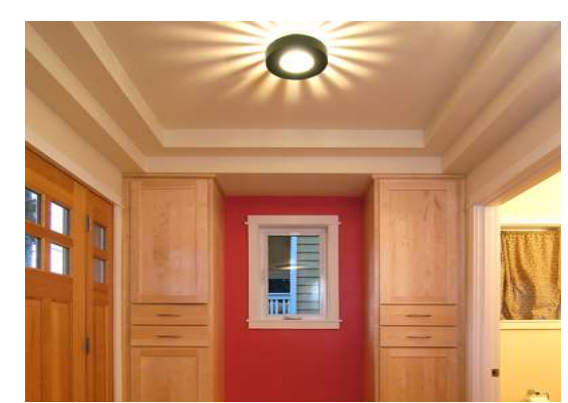

Figure 3.5 Front foyer

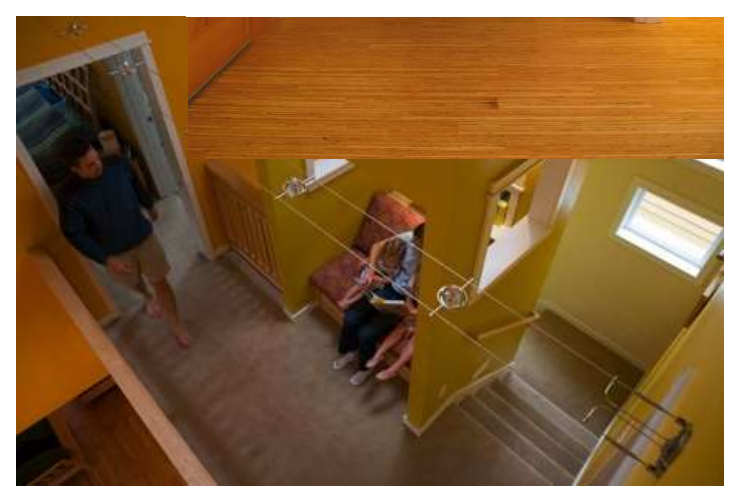

Figure 3.6 Reading room and stair 


\section{B. Taubate House}

Type: New Construction

Location: Taubate, Brazil

Year Completed: 2003

Designer: Sandra Perito

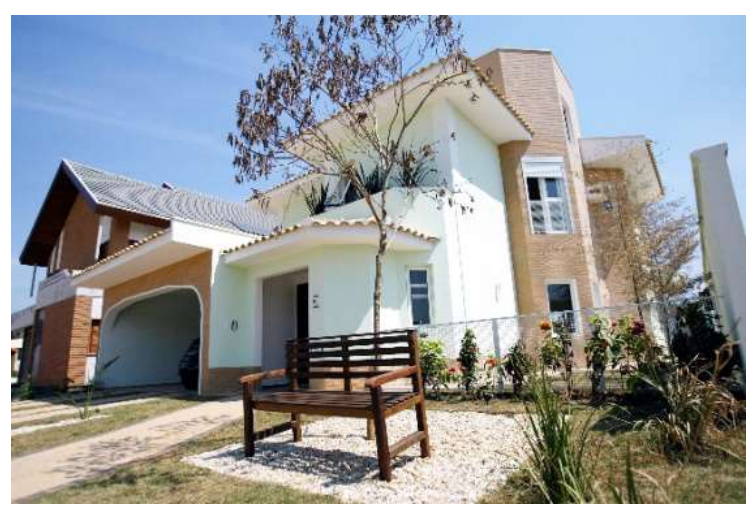

Figure 3.7 Front door

The Taubate House is a two-storey building. The pathway to the house (figure 3.7) has a minimal gradient and the entrance has extra wide doors. The age-friendly factors provided include wide circulation paths between rooms and lift access to the top floor.

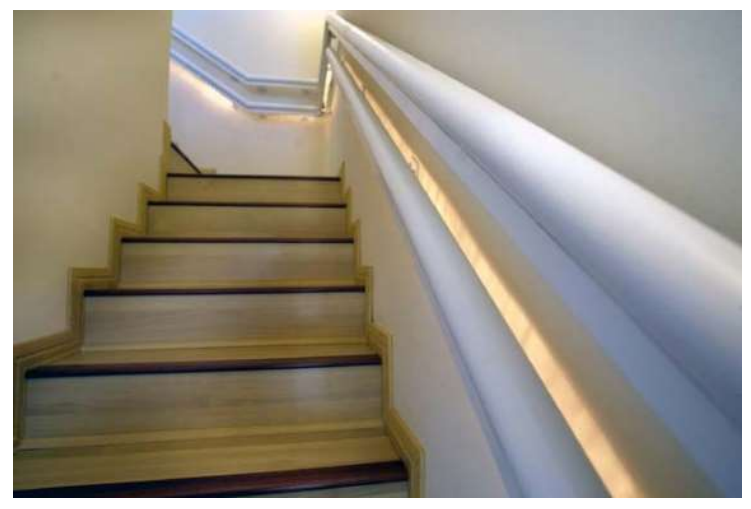

Figure 3.8 Double rails

The front balcony has generous space for packages and is brightly coloured to help people who have visual impairments, and has a motion sensor lighting system. The designer used contrasting colours throughout the

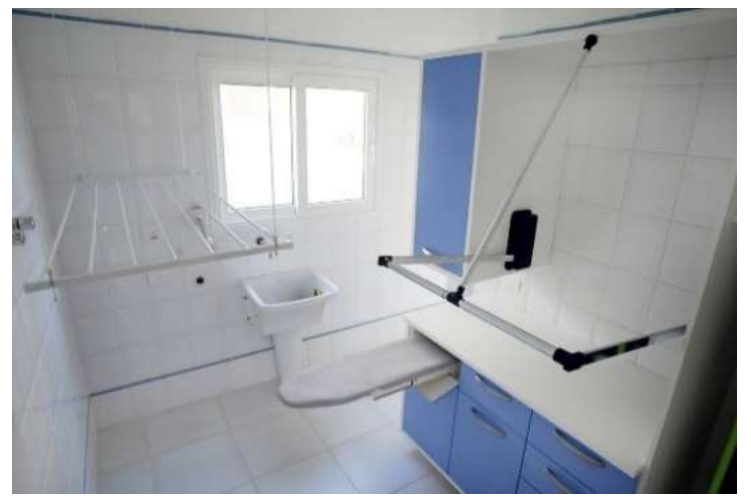

Figure 3.9 Laundry house to support the users' ability to distinguish different surfaces. The amount of natural light and white walls also creates a visual contrast to the dark wooden stairs and other functional areas to help older users who are often visually impaired and thus unable to distinguish their surroundings clearly. The stair also has double height rails (Figure 3.8) with two 
different heights to provide for a range of heights (e.g., older people and children). The handles (Figure 3.9) in the laundry are placed at an easy reach. The ironing board and the drying rack can be pulled out into a horizontal position. This spatially-efficient design is suitable for smaller spaces.

The bathroom (Figure 3.10) is small but it has plenty of natural and artificial light. The space under the sink is open to accommodate users using a stool or a wheelchair. For emergencies, the bathrooms have a telephone system, and the kitchen is installed with gas detractor sensors for safety. There are also lights inside cupboards and closets to provide better visibility.

Double sliding doors open onto the backyard from the living room, which is more extensive than typical doors and all the windows have a lower height

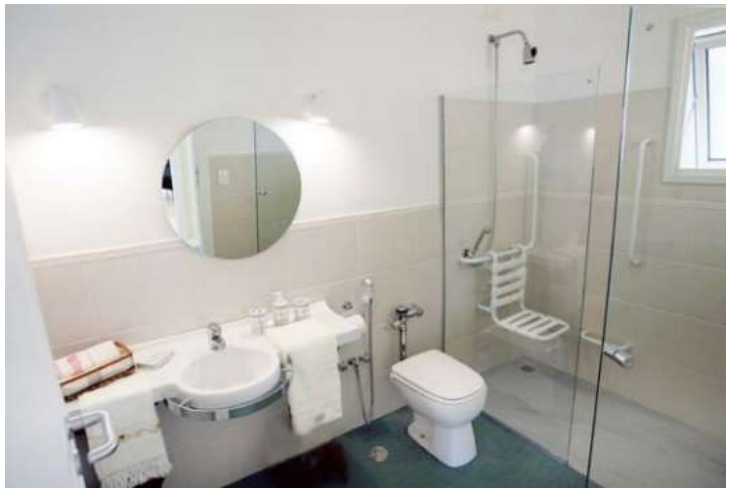

Figure 3.10 Bathroom

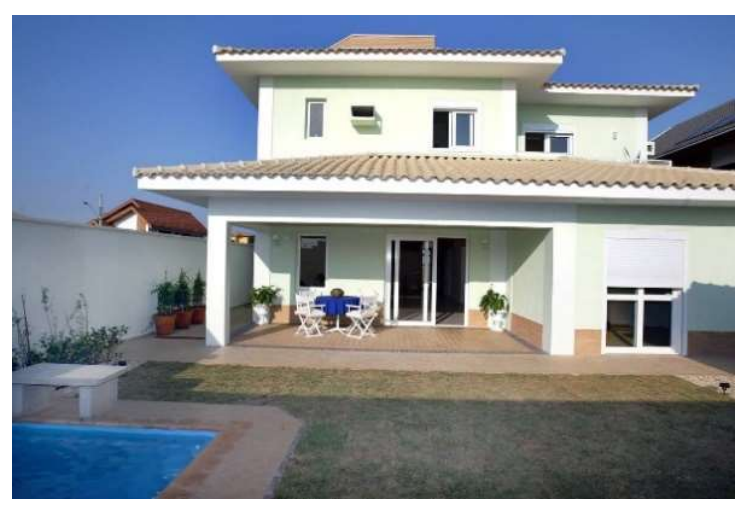

Figure 3.11 Backyard (700 $\mathrm{mm}$ ) than general standard. This is important because the wheelchair user has a lower angle of view than a standing person. At the rear of the house is a large backyard with a terrace, a barbecue area, and a leisure annex (Figure 3.11). To support physical activity, the outdoor space is provided with a pool and a walking area. 


\section{Siple House}

Type: Renovation

Location: North Vancouver, British Columbia, Canada

Year Completed: 2004

Designer: Ostry Architects of Vancouver

The Siple House is a one storey house that was

renovated to provide better universal design to support its single occupant (Murray Siple). The renovation resulted in the full opening of exterior routes for great accessibility with other rooms and outdoor space for free circulation (Figures 3.12 and 3.13). Because the user (Siple) relies on a wheelchair most of the time for movement, an accessible internal transportation route is

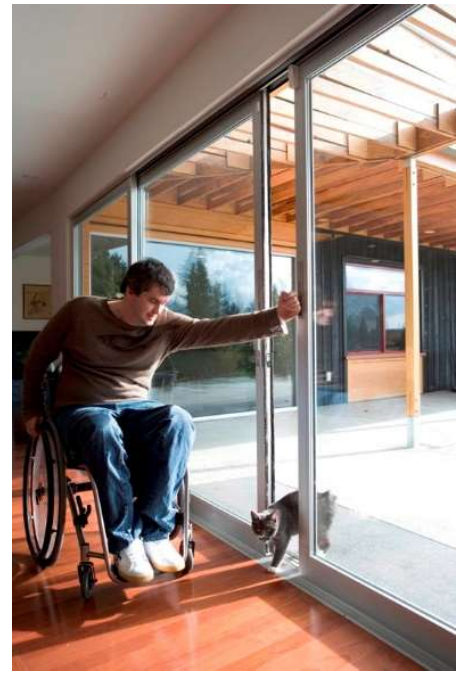

Figure 3.12 Sliding door to the terrace essential.

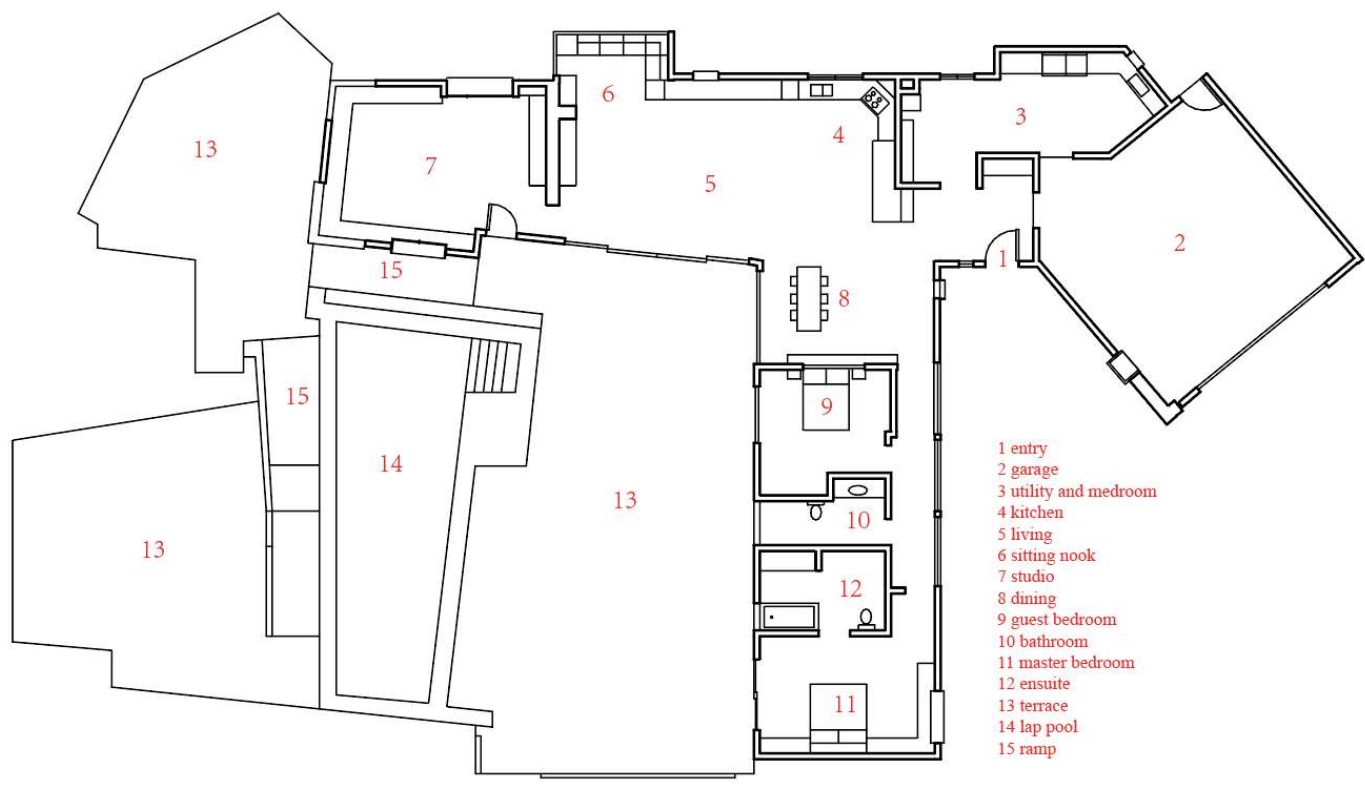

Figure 3.13 The terrace (13) connects the surrounding rooms 
Everything is on the one floor. All of the standard utilities, like cupboards and cabinets (Figures 3.14), are lower than usual $(1000 \mathrm{~mm})$ so they are appropriate for a person in a wheelchair. and lessen the risk of falling for the user. Because of the disability of the user, the bedroom has a low closet with sliding doors. For wheelchair users, hung doors are easier to use than swing doors. Wheelchair users do not need to move too much to open and close the door.

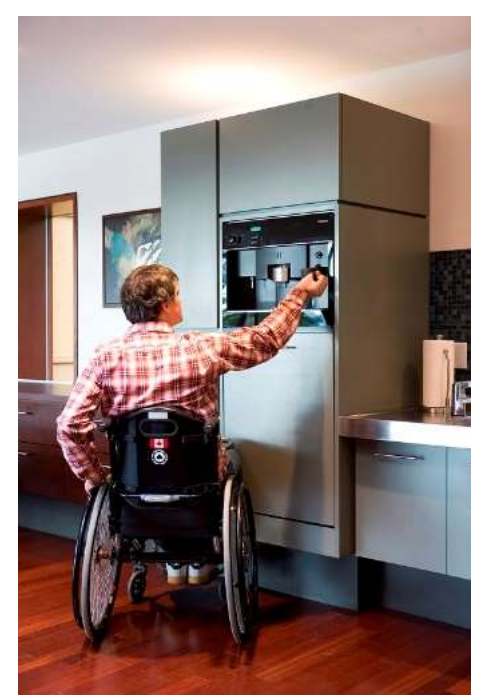

Figure 3.14 Built-in coffee dispenser in cabinet Other elements, like kitchen utilities, the non-slip tile shower, and built-in coffee dispenser (Figures 3.15, 3.16), are all designed to meet the needs of the user. In particular, the height of the device is at a level that Siple can easily reach.

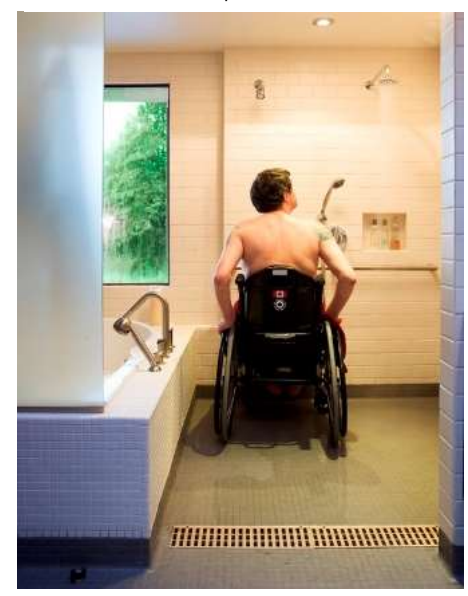

Figure 3.15 Tile shower

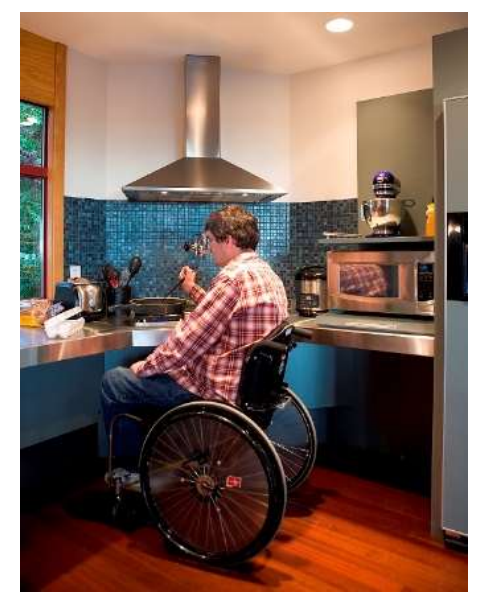

Figure 3.16 Kitchen unities 
Figure 3.17 shows the minimum passage widths of the four types of doors. Among them, the hung door is the most suitable for wheelchair users, because the bottom of the hanging door does not require a rail and does not obstruct the passage of the wheelchair.

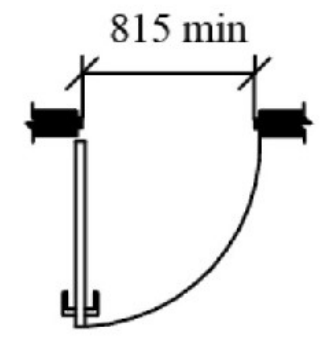

Single door

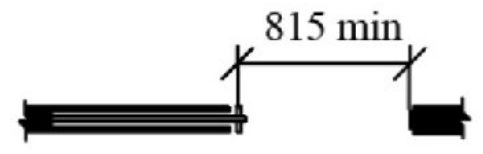

hung door

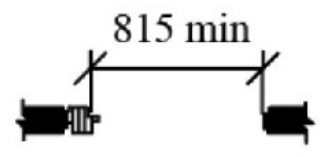

Floding door

Figure 3.17 Standard of door size for wheelchair 


\section{D.Egebakken Community Housing}

Type: New Construction

Location: Nødebo, Denmark

Year Completed: 2005

Designer: Michael Steen Johnsen

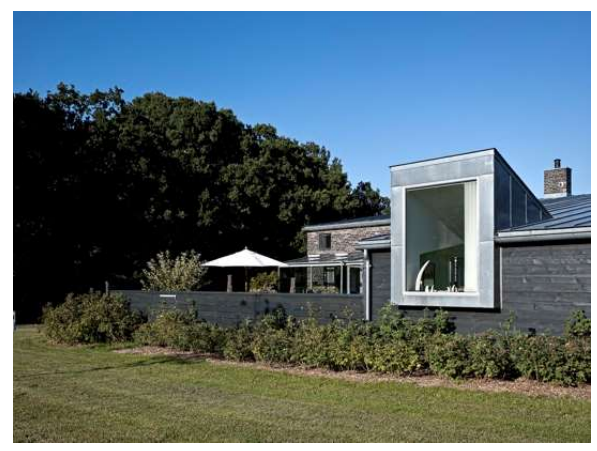

Figure 3.18 Outside of house

The community housing (figure 3.18 ) located at Egebakken was planned for a group of retirees from Nødebo, Denmark.

The building designs were approved according to

Denmark building code requirement (BR95), giving higher importance to the needs of older people.

The UD features at Egebakken include that the entrance faces east to ensure that the room

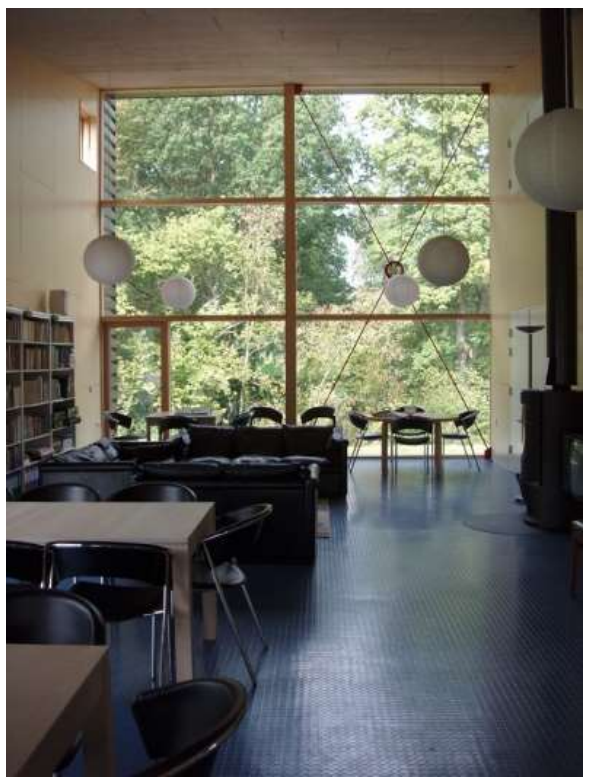

Figure 3.19 Sidewalks in house receives plenty of natural sunlight in the morning; wide and bright footpaths to assist people in wheelchairs (Figure 3.19). The paths to the front doors for each house also have a gradual slope (Figure 3.20) for wheelchair access and drainage.

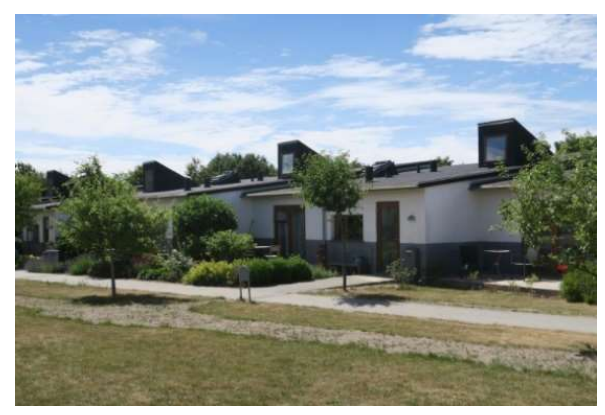

Figure 3.20 Slope 
The kitchen work surface is $865 \mathrm{~mm}$ above the finish floor or ground which is required by the ADA standard for both sitting and standing poses (Figure 3.21).

According to the ADA compliance

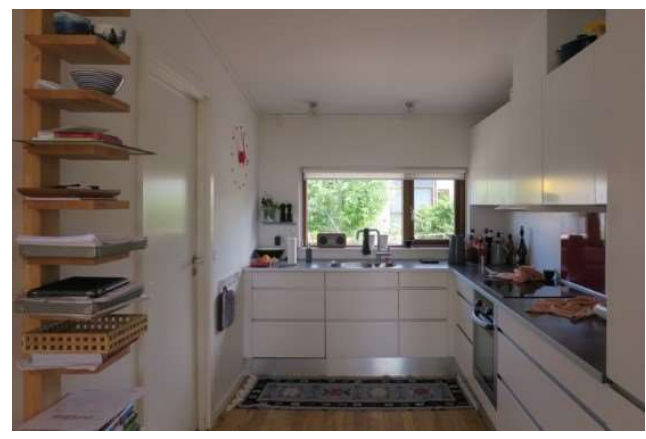

Directory, the work area of the U-shaped

Figure 3.21 Kitchen unit kitchen (Figure 3.22) shall be 60 inches $(1525 \mathrm{~mm})$ minimum. This width fully allows wheelchair users to swivel, move, etc. in the U-shaped kitchen.

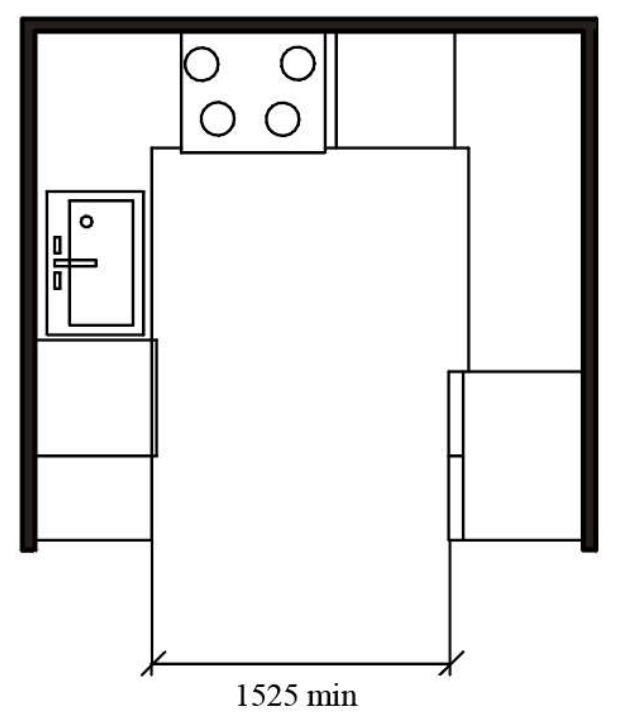

$1525 \mathrm{~min}$

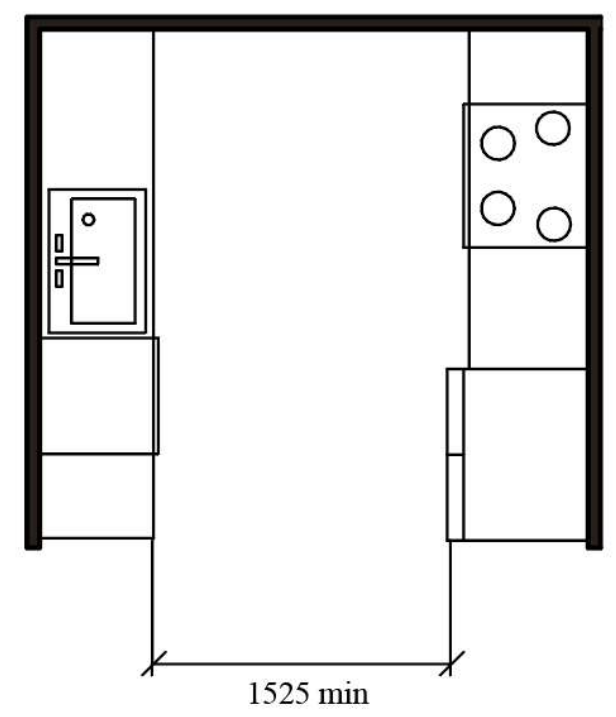

Figure $3.22 \mathrm{U}$-shaped kitchen

At the outset, the designers sought feedback from the clients of 29 houses to inform the designs. This included designing for easy-to-maintain doors, windows, roof, and outer walls. The flexibility was given in the houses with all kinds of kitchen and other equipment and no thresholds. Ergonomically designed kitchen for both sitting and standing poses, easy access, and use of hardware in the house are provided. 


\section{E. Parents' Flat}

This residence is a project that the designer renovated for her parents. The flat is located in a six-family apartment building. The type of building was two bedrooms flat and the area is about $74 \mathrm{~m}^{2}$. The designer knows the users' living conditions very well and is aware of the effect of ageing on the occupants' mobility and speed of movement. Therefore, in order to better meet the needs of users' lives, Yanmin redesigned the rooms from the perspective of visual, sound, storage, space, and furniture selection.

Yanmin made five changes to the interior space of the house as Figure 3.23 below:

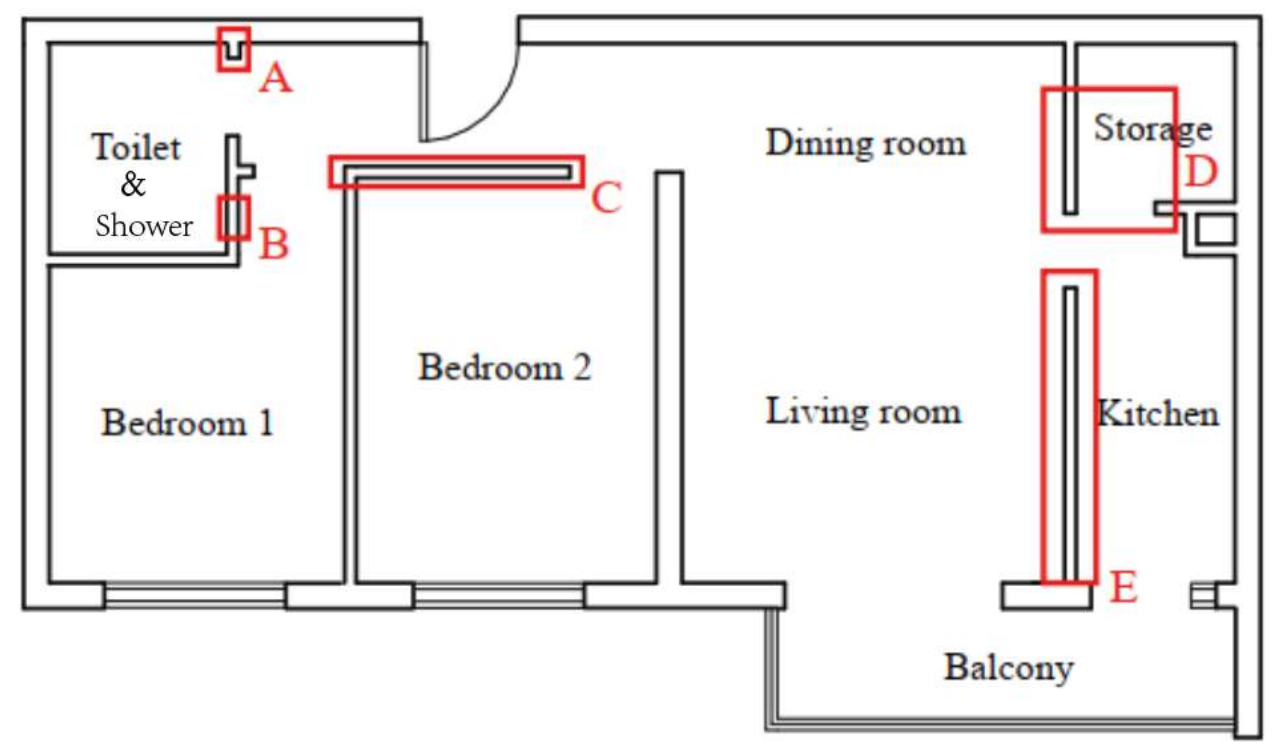

Figure 3.23 Original plan 
A. The toilet door was moved 300mm (Figure 3.25) away to the south. Therefore, the space of cabinet behind the door has increased more.

B. The wall between the toilet and the drain pipes is opened with an opening with $300 \mathrm{~mm}$ long and embedded with frosted glass. Since the toilet space is dark and cannot be opened to the outside, therefore, the designer added an opening in the partition wall to bring some of the natural light from the bedroom into the toilet.

C. The non-load-bearing wall of the bedroom was changed to a glass partition wall. Therefore, the designer added an opening in the partition wall, bringing the natural light from outside into the bedroom.

D. The original door into the storage room, which faced the kitchen was re-oriented to face the dining area. The designer cut off the route between the storage room and the kitchen, strengthening the connection between the dining area and the kitchen. The kitchen, dining area, and kitchen do not interfere with each other when used.

E. The non-load-bearing wall between the kitchen and the living room was changed to a glass partition wall with sliding door. The glass partition with sliding doors allows the sunlight from the balcony to enter the living room and kitchen from morning to afternoon. 


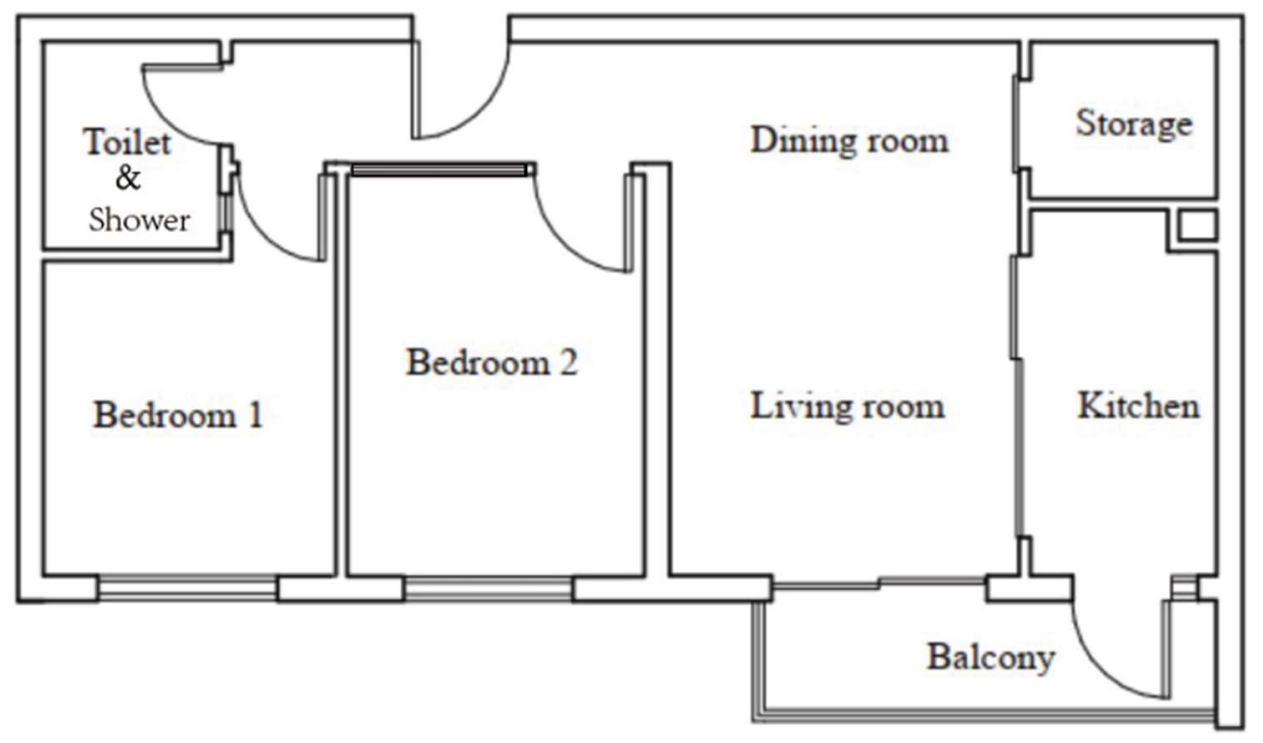

Figure 3.24 The Plan after redesign

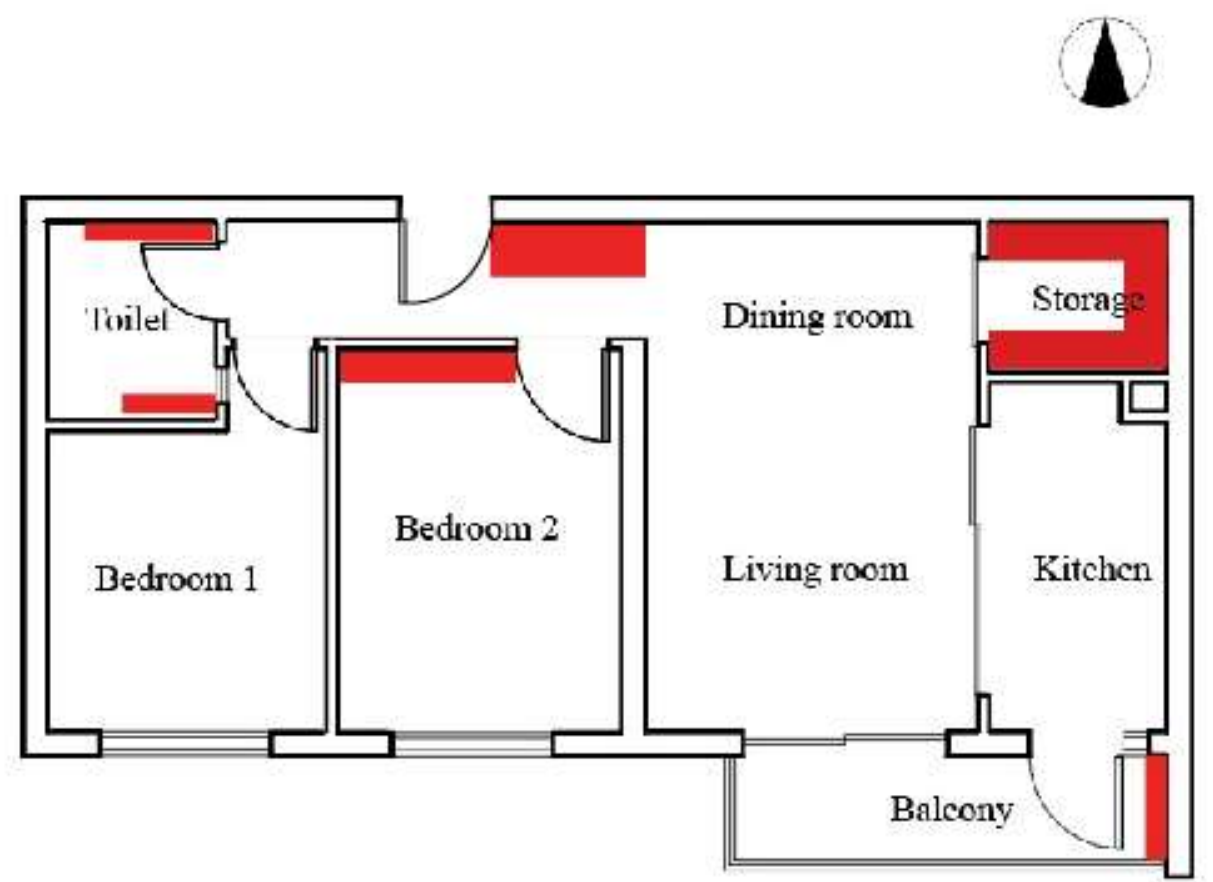

Figure 3.25 Redesign of storage area 
The design addresses these aspects as Figures 3.26 and 3.27 show next page:

It is convenient for older people to observe the indoor situation, such as installing a mirror in the living room, using the principle of reflection so that older people can observe the situation at the entrance at any time

And also, the living room and dining room are connected together to form a natural line of sight communication between family members, and strengthen communication. 

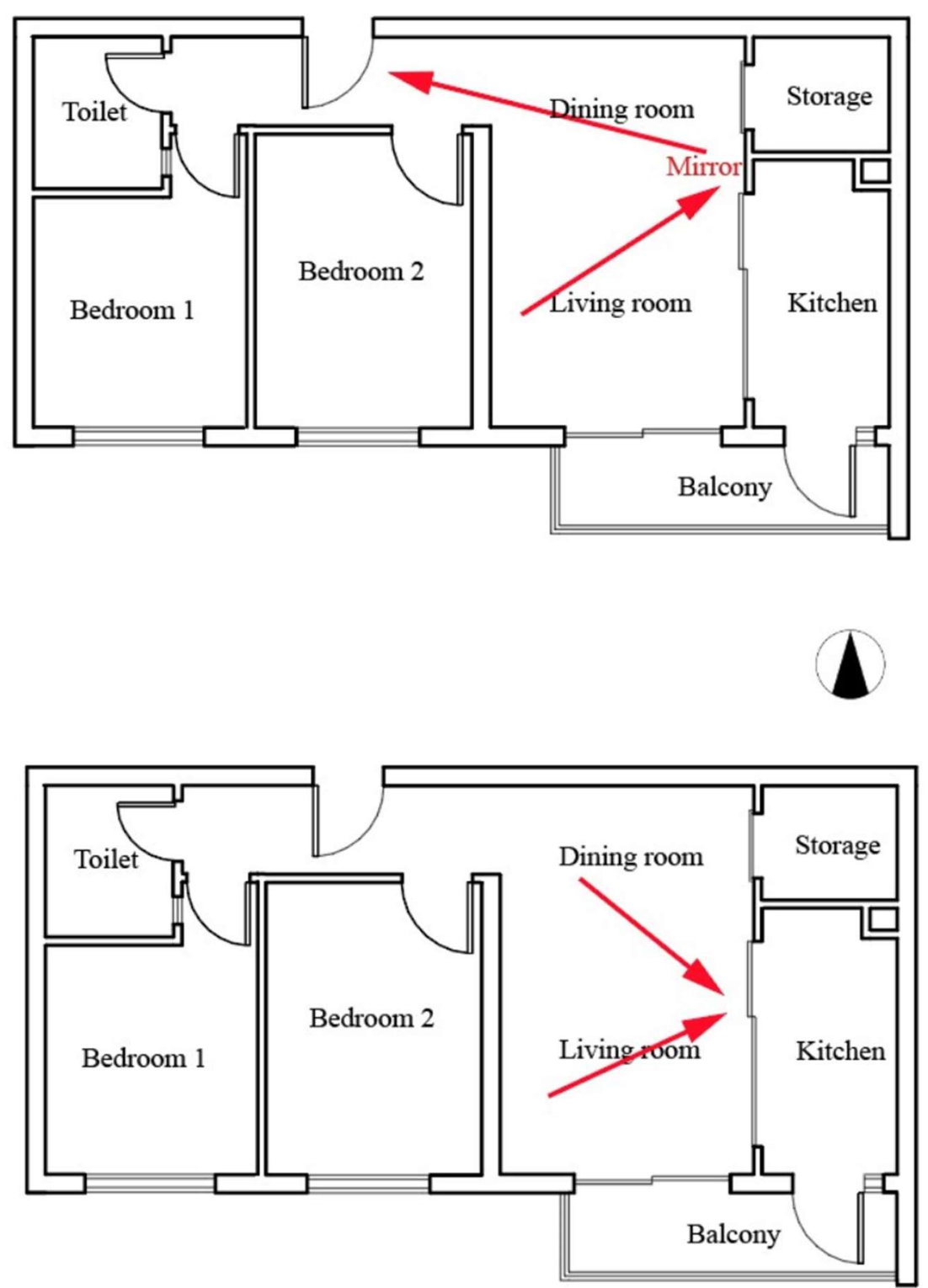

Figure 3.26 and 3.27 Visual design 
In order to increase indoor light, Yanmin used translucent materials to introduce light into the room.

The frosted glass (Figure 3.28) of the toilet introduces light into the internal space to brighten the space.

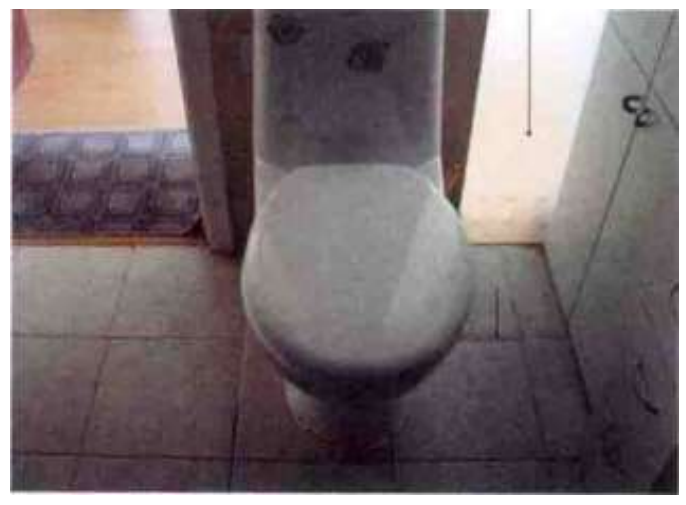

Figure 3.28 Toilet

The glass partition wall (Figure 3.29) of the kitchen and the living room and the sliding door allows the southeast light to enter the living room from the kitchen to provide natural day lighting. In the afternoon, light from the southwest enters the kitchen through the living room. The

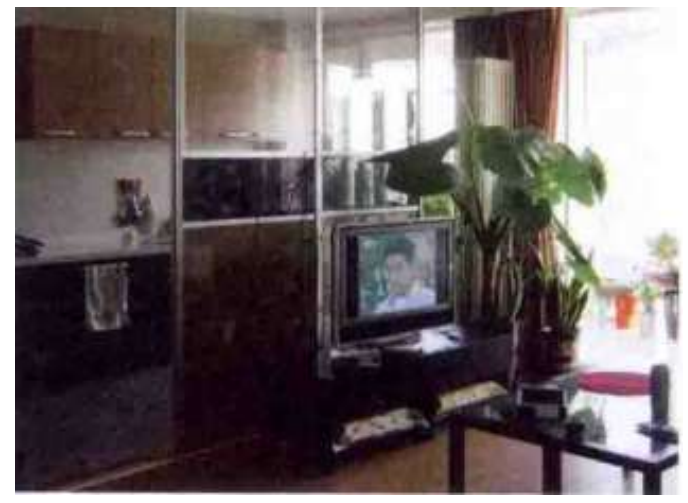

Figure 3.29 Glass partition wall of kitchen designer considered parents' declining eyesight and supplemented the light in the area of kitchen bench by enhancing natural lighting.

The glass partition wall (Figure 3.30) in the bedroom has the effect of widening the view and transmitting light

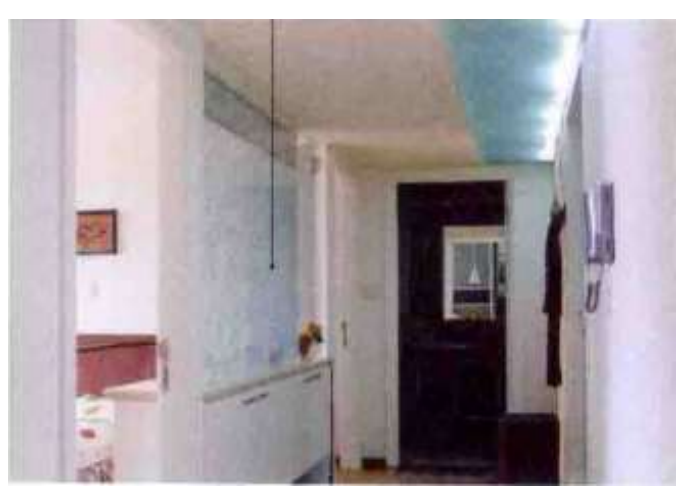

Figure 3.30 Glass partition wall of bedroom

In addition, Yanmin decentralized storage space into small spaces with different sizes. As can be seen from the figure 3.28, 3.29 and 3.30, the designer set up a variety of different sizes of standing cabinets located in the room. 
For the decoration, Yanmin chose small and lightweight furniture. The older people can freely change the position of the furniture depend on their own needs.

Among them, the sofa, coffee table and TV cabinet are composed of independent small units that can be combined freely.

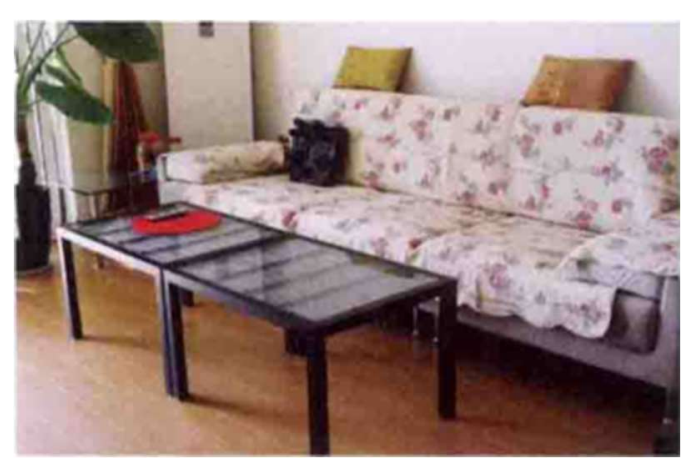

Figure 3.31 Coffee table placed together length-wise

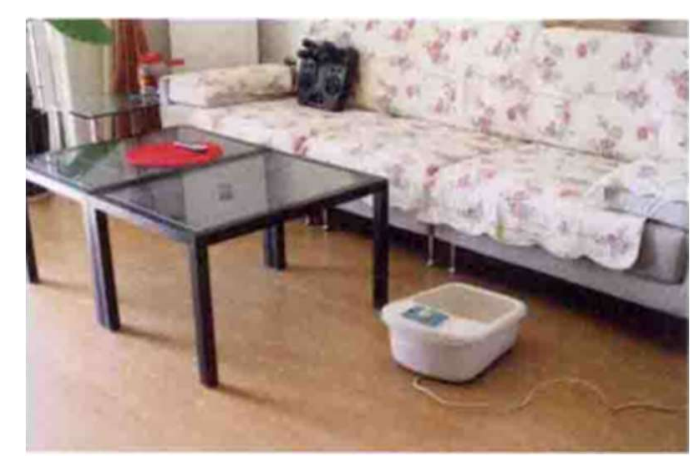

Figure 3.32 Coffee table placed together width-wise 


\section{F. UD observations to support accommodation to older people}

The case studies provide the following design concepts and details to support UD.

1. Internal doors and entrances to the house are the primary design factor to focus on. For example, in the Egebakken Community Housing design, there is a ramp at the entrance to allow access for older people or wheelchair users, and there is no height difference in the interior floor.

2. Have the same standard of size across the house. For example, for wheelchair users, the whole house needs to be designed with their needs in consideration.

3. The design of floor should be followed in the needs of rooms and users. For example, the design of Siple house used non-slip tiles in bathroom for wheelchair users.

4. Bathing facilities should be placed at a reasonable height. The design of all utilities is highly sensitive to the needs of older people.

5. Older people should be accommodated in separate rooms, fitted out with shelves and personalized equipment.

6. Provide pleasant landscaping and gardening feature to enhance mental and physical health.

7. Support interaction with the wider neighbourhood and community.

8. Use smart systems installations (e.g., telephone, alarms) at specific locations for health emergencies. 
9. In bathrooms and kitchens use a light-sensing light fixture, which lights up automatically when the light is dim; the foyer and hallway can use a sensorcontrolled floor lamp that automatically operates when it detects someone passing through.

10. To ensure the safety of older people, handrails should be installed in bathrooms, stairs, and other areas to help them maintain their balance.

11. The design of cabinets must consider older people's dimensions and the height and depth of cabinets. Base cabinets and operating tables should be determined according to older people's arm length and sitting height.

12. The advantage of hung doors is that there are no tracks on the floor, making it easier than sliding door for wheelchair users to use. According to the analysis of Siple house, it is recommended that use hung doors instead of sliding doors.

13. For users with injured hands, the doors with a level handle are easier to operate. The users can press down on the lever handle with their elbow to open the door.

14. When purchasing home appliances for older people, the needs of older people should be fully considered, and their actual conditions should be taken into account. For older people with strong learning and hands-on ability, they can choose smart home appliances. In contrast, older people with obvious physiological deterioration should try to buy appliances that are easy to operate.

15. The color of flooring, furniture and walls should be contrasting to ensure that older people can distinguish between them, as seen in the Taubate House.

16. Use the characteristics of the material to achieve the final effect. The materials can be used that insulate, conduct, or absorb sound to meet the needs of different 
functional areas. For example, using sound-absorbing or sound-insulating materials in a bedroom or study to create a quiet resting environment

17. Use natural light sources. For example, the design of Parent's house uses glass partition to increase the natural light in the kitchen.

18. The main circulation route should go through the foyer and living room, connecting to other functional areas. For example, the design of Parent's house ensures that each functional area does not interfere with the other while also visually strengthening the areas' connection. 


\section{Site Analysis}

\section{A. The main type of 1980 s residences in China}

Since 1980, the Chinese government has implemented a new housing reform policy in response to the original housing allocation policy.

According to the description of modern urban housing in China 1840-2000 (Lue, Peter \& Zhang, 2001), the rapid modernization of China's cities after the 1980s led to an expansion of the urban population and a dramatic increase in residents' demand for housing. During the construction process, many real estate developers did not maintain a human-centered design philosophy and their understanding of the needs of human habitation was extremely simple. They generally design houses according to the size of the minimum dwelling area required by regulations and the number of living rooms, halls and bathrooms. Generally, there are different types of dwellings, such as one-bedroom and one-bathroom, two-bedroom, two-bathroom and onebathroom, and three-bedroom, two-bathroom and two-bathroom.

Although design according to a set type can effectively increase the number of dwellings and land use. This can limit the user's living experience. This is because the initial suite design only met the basic needs of the user and ignored the needs of specific users, such as the older people, the disabled people, and large families. From a perspective of universal design, the suite design suffers from poor functional quality, single space structure, poor kitchen and bathroom facilities, and lack of attention to spatial details (Lue, Peter \& Zhang, 2001).

By the mid-1980s, most residents lived in brick-concrete dwellings. Residents did not need to share space with others except for access units such as entrance and common usage space. The integral parts of the house are generally composed of kitchens, bathrooms and other rooms. The number of bathrooms and kitchens is not limited, but 
all rooms must be in the same whole.

The 1980s dwellings in China were mainly apartments, most of which had the following characteristics:

1. The height of floor to ceiling is generally not less than $2500 \mathrm{~mm}$, and the area of each household is about 60 sqm (Lue, Peter \& Zhang, 2001).

2. The unit type of each household is repetitive and single. Generally, the households are mainly divided in to one-bedroom, two-bedroom or threebedroom. Each of them has its own kitchen, bathroom and balcony (Yanmin Z, 2012).

3. The structure of the unit building mostly adopts a multi-layer brick-concrete structure. The wall is generally made of clay bricks and mortar. Floor slabs are pre-stressed hollow slabs. Due to the limitation of plan layout, the loadbearing mode of the wall is mixed load bearing of vertical and horizontal walls (Yanmin Z, 2012). 


\section{B. Existing problems with 1980s residences}

In the past three decades, China's urban construction has experienced a period of rapid development, and the urban environment has undergone great changes. But there are still large areas of old houses that have not been improved. Most of these old residences were built in the 1980s.

According to Yanmin's investigation (2012, p.6), the 1980s old residences generally have the following six problems:

1. There are many load-bearing walls in the residential structure. Limited by the walls, the indoor space is small (usually about 3 to 3.3 meters wide), and the small window size leads to poor indoor light.

2. The kitchen and bathroom are small and the equipment is poor. The kitchen area is usually less than 4 square meters, and the width is less than 1.5 meters. It is difficult to accommodate two or more people in the same space.

3. The equipment placement is chaotic. In the last century, the level of residential construction stayed at a relatively backward stage, and many equipment and pipeline arrangements conflicted, making the limited space itself more difficult to be fully utilized.

4. The space cannot accommodate large appliances. Due to the small size of the kitchen and bathroom, there is not enough space to accommodate large appliances such as refrigerators and washing machines.

5. The division of spatial functional areas is not obvious. In many residences, there is no obvious division between the bedroom and the living room, which makes the use of each space very confusing. A living room often serves 
multiple functions such as resting, chatting, meeting and eating.

6. The demand for storages is relatively large. Many residences are equipped with large storage room or large cabinet to solve the problem of storing items.

The author searched information about the old residential buildings from the 1980s to the 1990s in southern China, and targeted the household groups to older people. 


\section{Description of the building}

Year: 1989-1990

Dwelling type: 1 bedroom and 1 living room

Area: $76 \mathrm{~m}^{2}$

User: An older couple

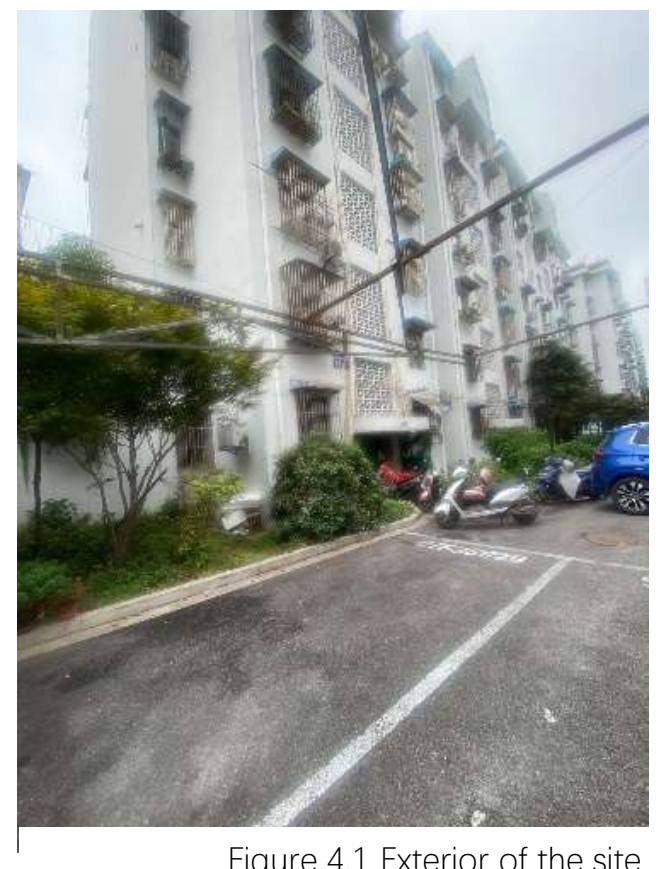

Figure 4.1 Exterior of the site

As figure 4.1 shown, the apartment building has six floors, and each floor has two flats. The apartment is planned to provide necessary facilities to the occupants. The entrance of the flat leads to the living room. The location of the apartment means that there is a lack of privacy because it is collective housing. 
The flat 201 is a one-bedroom flat, equipped with basic amenities appropriate for the needs of a retired couple. The size of the rooms is sufficient, but the functionality of the study is compromised because of its proximity to constant noise from outside (figure 4.2).

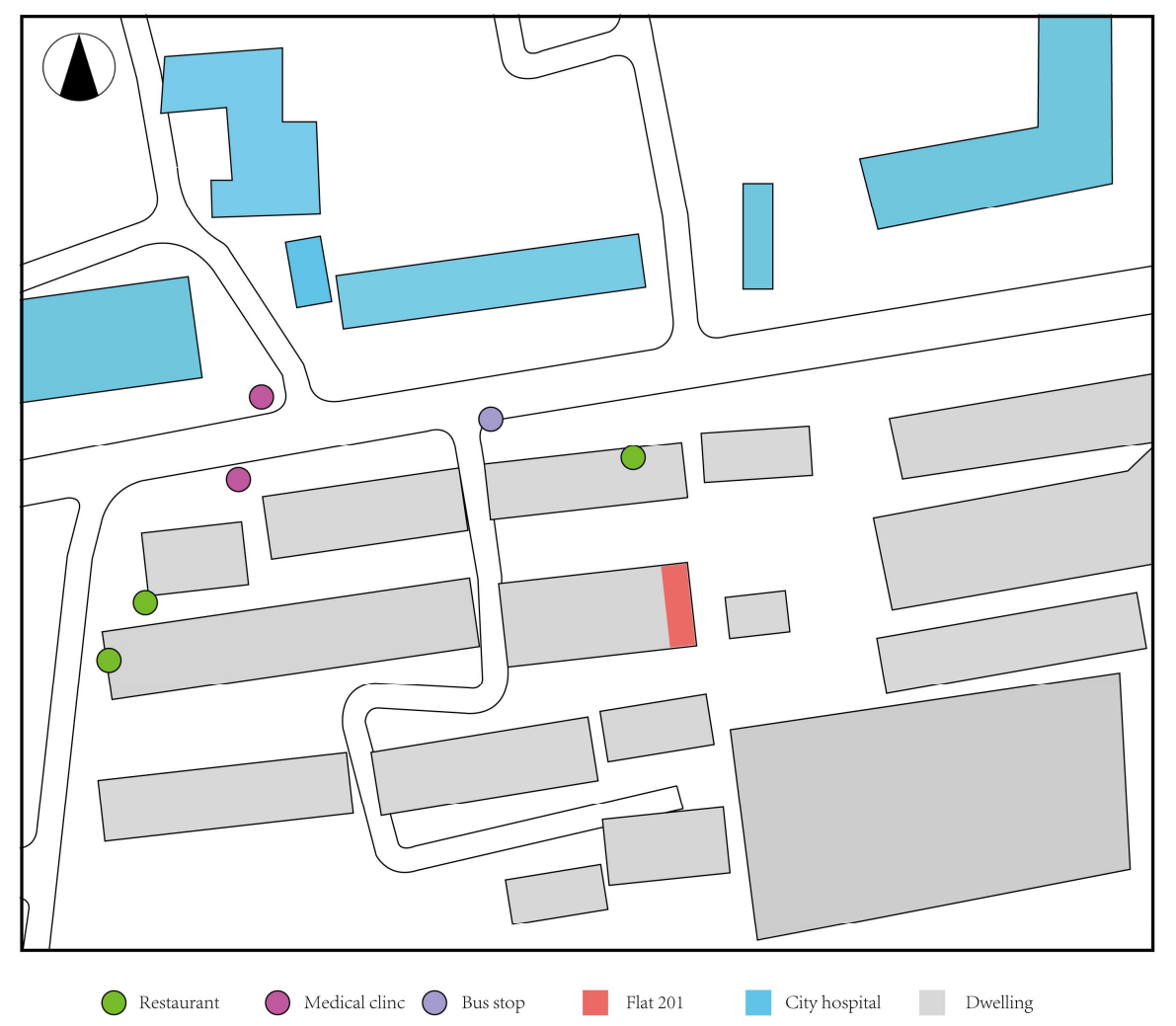

Figure 4.2 Site Plan

Due to the construction technology and budget when built, the apartment building used brick-concrete structures with prefabricated concrete slab. Therefore, the floor slab, external brick wall and internal load-bearing wall cannot be changed because they are load-bearing. As figure 4.3 shows, the walls of the kitchen, toilet, and storage room are non-load-bearing interior walls, and the other load-bearing walls of brick-concrete. In addition, Apartment 201 is located in a temperate monsoon climate zone, therefore, it is not going to cause the rooms to be too cold or too hot. 


\section{$(1$}

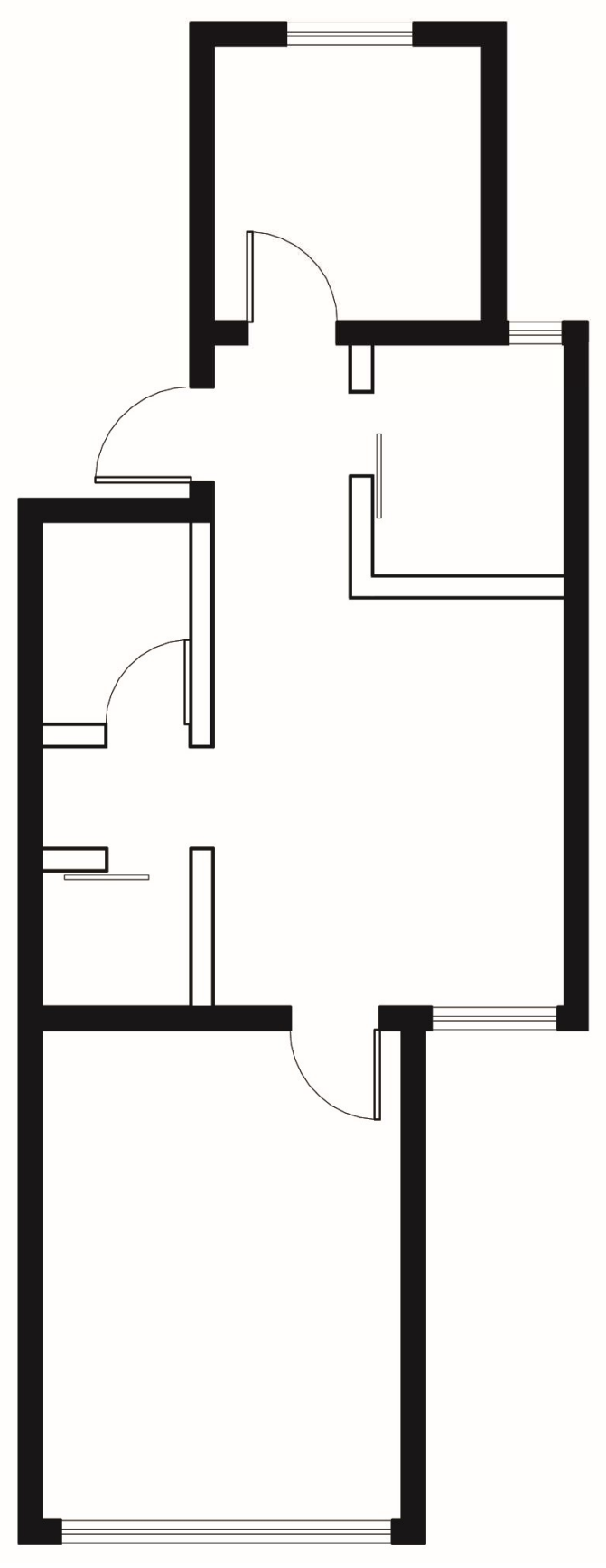

$\square$ Non-bearing wall

Bearing wall

Figure 4.3 Non-bearing wall and bearing wall of flat 201 


\section{Analysis of basic layout}

The flat 201 contains one bedroom, one study, one kitchen, one storage, one bathroom and one living room. All walls are white stucco with timber skirting on the underside. The bedroom and the study have laminate wood floors. Other rooms have plain tiles with no anti-slip surface. The apartment's lighting is a combination of artificial light (incandescent bulb) and natural sunlight.

The entrance lobby is located to the west and faces the kitchen door. There is a height difference between the floor tiles of the lobby and the kitchen's floor tiles. User B said that she had fallen down because of the height difference. The kitchen is a small space. Usually, there is only one person who can move around in the kitchen. Therefore, the two users would stagger their kitchen use separately so that the kitchen use frequency was quite heavy. There are storage cabinets above and below the kitchen bench, and no appliances such as dishwashers, ovens, etc.

The lobby turns right to connect the living room. The living room's main furniture are a dining table, sofa, coffee table, and TV stand. Acoording to User A's recollection, the original dining table was located on the wall near the kitchen, the coffee table and sofa were near the south-facing window, and the TV stand was opposite the sofa. The natural light in the living room came mainly from near the window, so other areas were darker than those near the window. The living room generally receives sunlight only in the morning.

The lobby turns left to connect to the study. The study is located at the northern end of the house, close to the street. The glass in the study windows is single-pane. Users described the noise outside as being noticeable in the study during the day. The study's main furniture are a desk, closet, and chairs. The study is where users usually read or surf the Internet. 
The living room is connected to the bathroom and storage room. The bathroom and the storage room are opposite to each other, and there is a washing machine in the center aisle. The bathroom is narrow because the width of the space is only $1500 \mathrm{~mm}$. The toilet and shower areas are next to each other, and there is no clear division between wet and dry areas. The tile floor was not covered with non-slip materials such as non-slip blankets. Users described the toilet and shower as being too close together so that two people could not works in the bathroom at the same time.

The storage does not have any windows, so it had to be lit by artificial light. There were no amenities in the stall. All of the stuff is piled on the floor and rarely used.

The southernmost room is the bedroom. The bedroom's main furniture are a bed, a TV stand, locker, closets, and two bedside tables. The bed is positioned near the window and the window aisle is narrow. The other side of the bed is opposite the closet. 


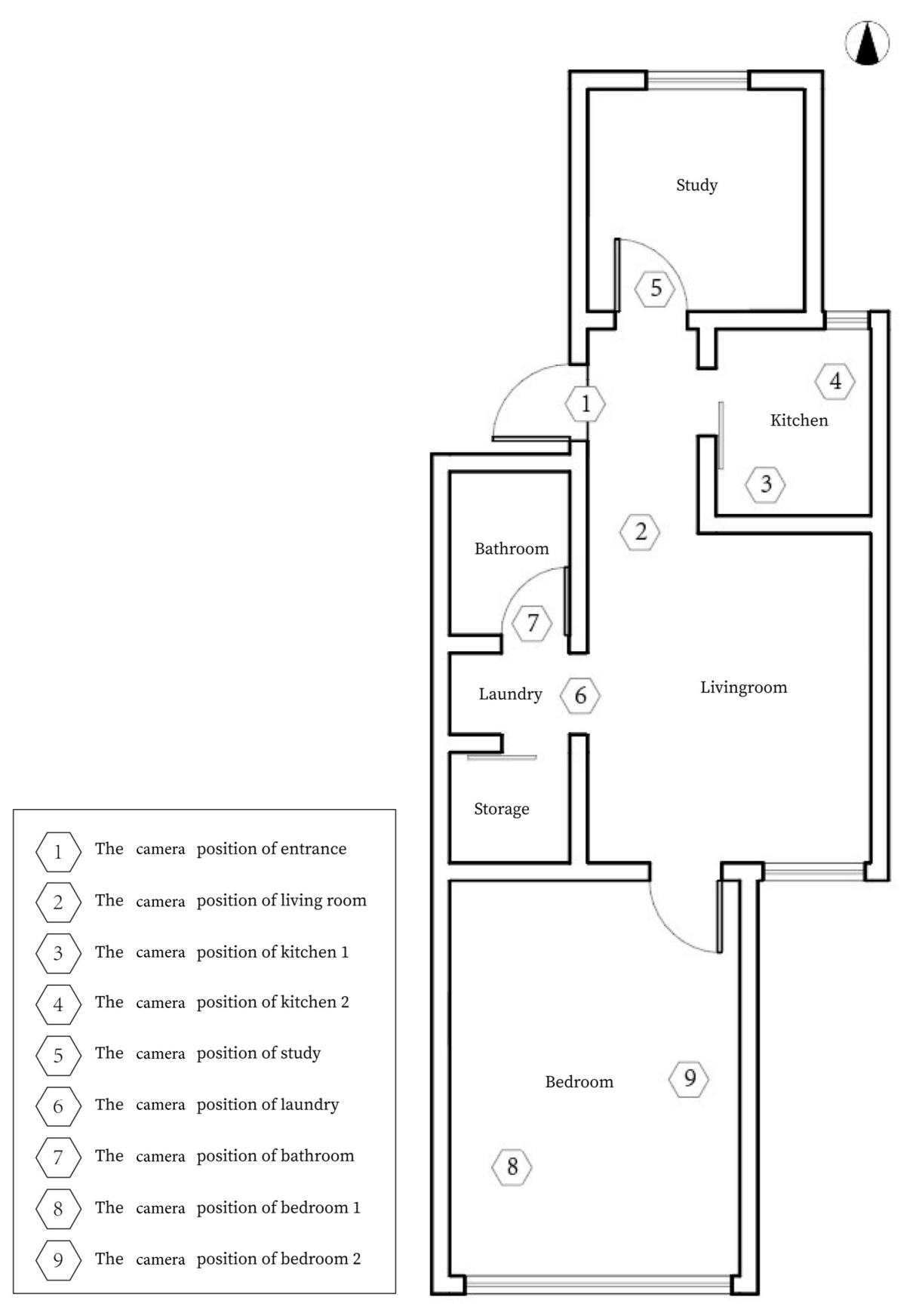




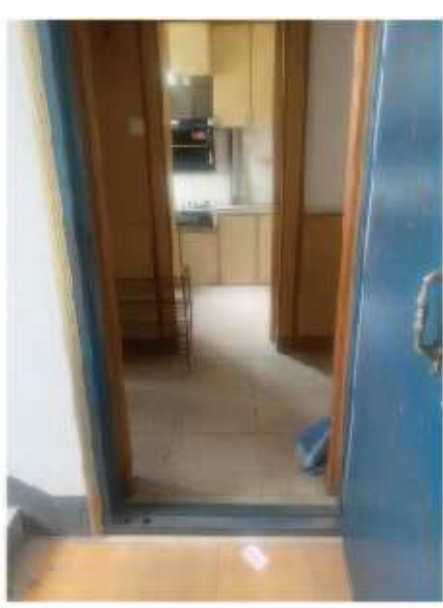

1

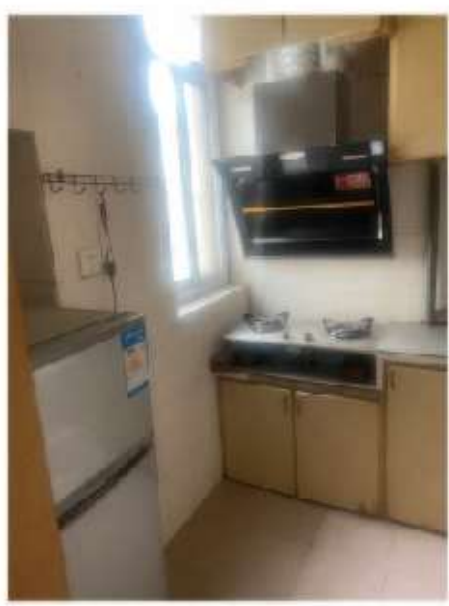

4

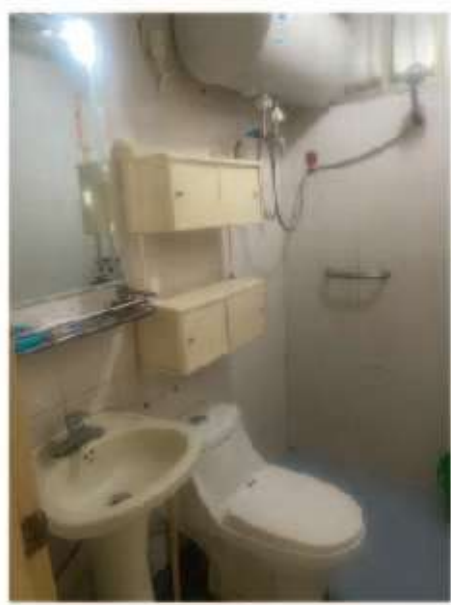

7

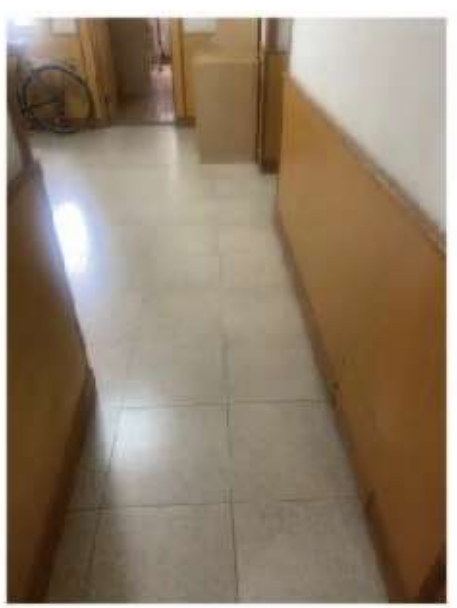

2

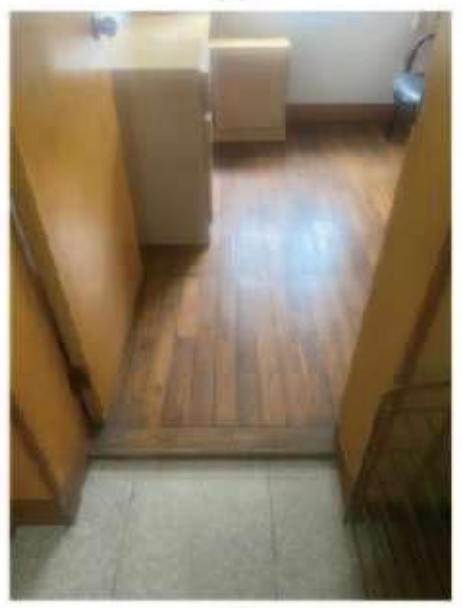

5

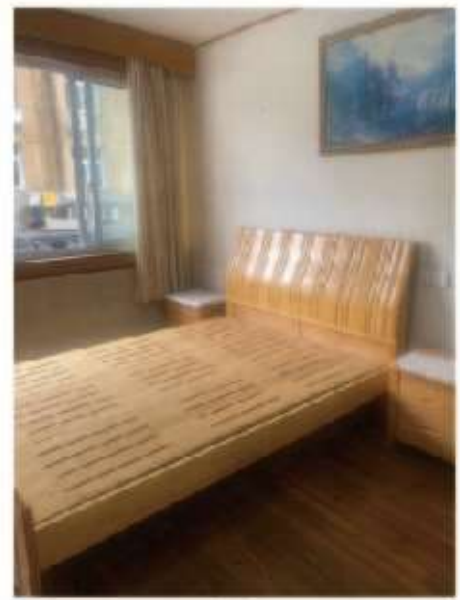

8

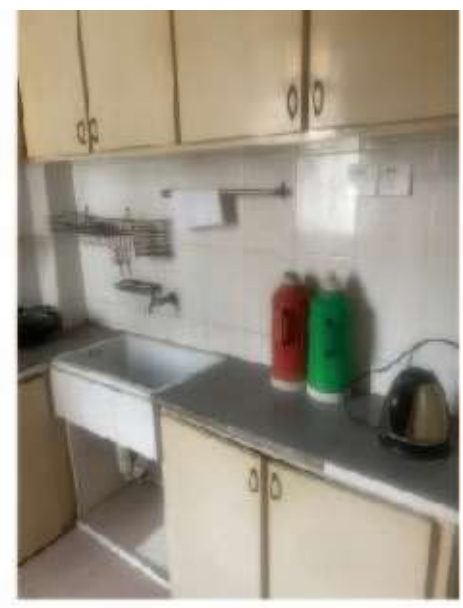

3

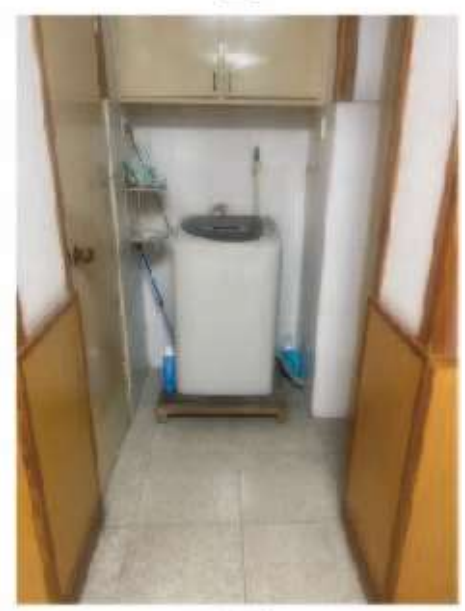

6

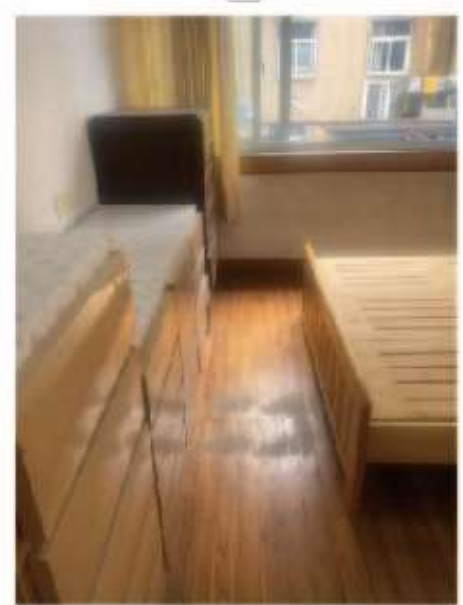

9

Figure 4.4 and 4.5 Photos of flat 201 


\section{E. Analysis of lighting and activity tracks}

\section{Natural light}

Due to windows facing south, the bedroom and living room which have large windows usually have plenty of sunlight during the day. This is especially so in the morning when the southern end of the bedroom and living room is bright and warm.

Although the study has a large window, it has almost no direct sunlight because it faces north.

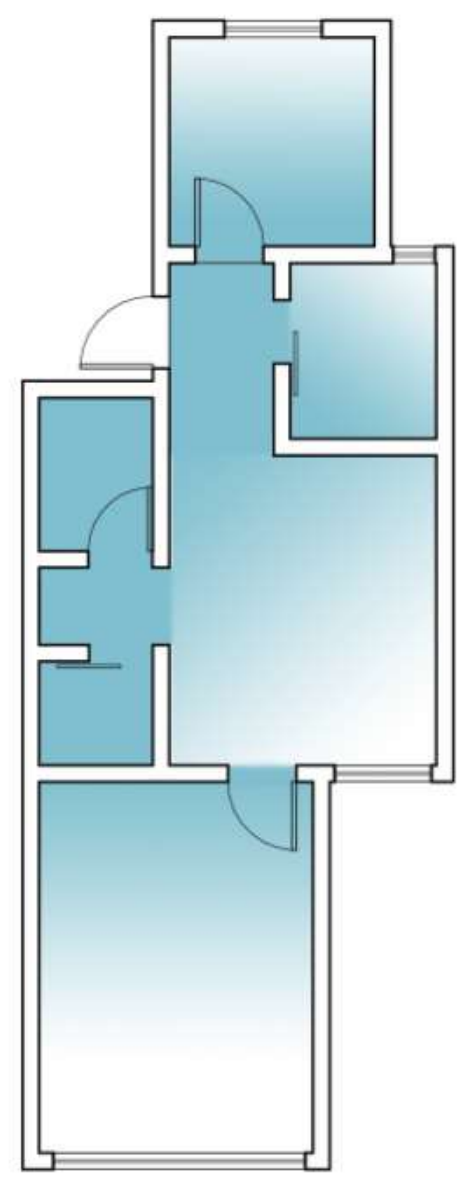

Natural light

Figure 4.6 Natural light in flat 201 


\section{Artificial light}

The main source of artificial lighting in the rooms comes from ceiling light. The ceiling lights in the study room, living room and bedroom are only used at night. The ceiling lights in the toilet and storage are used for almost all periods of use within 24 hours. The ceiling light in the kitchen is used from noon to night.

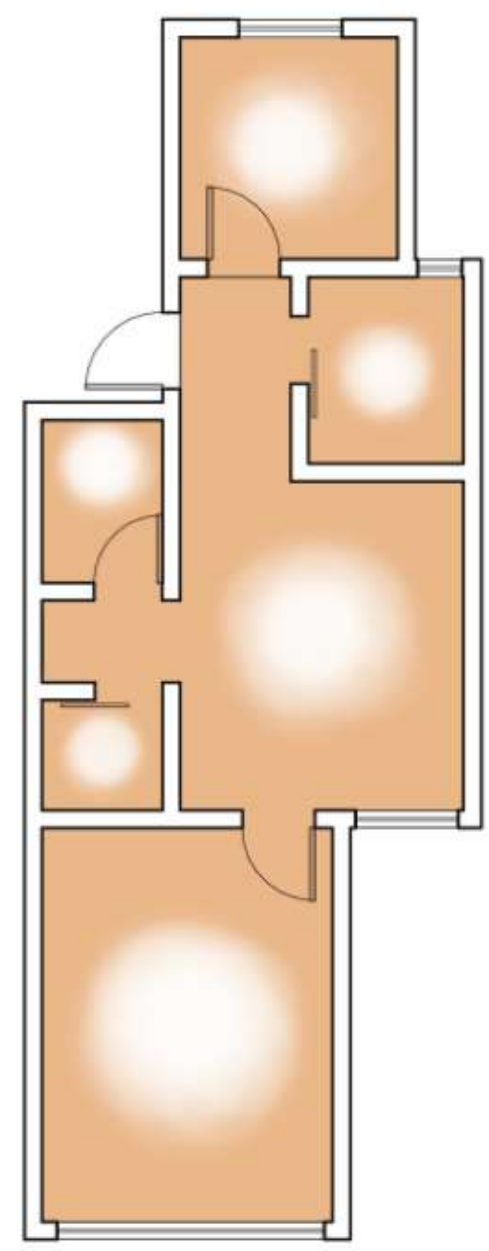

Aritifical light (top)

Figure 4.7 Artificial light in flat 201 


\section{Noise source}

All the windows are single-glazed. Therefore, the noise from outside can be easily heard inside. This is especially the case in the study, because it is close to other residential apartments. Occupants can often hear the sound of cars and conversation from people outside during the day.

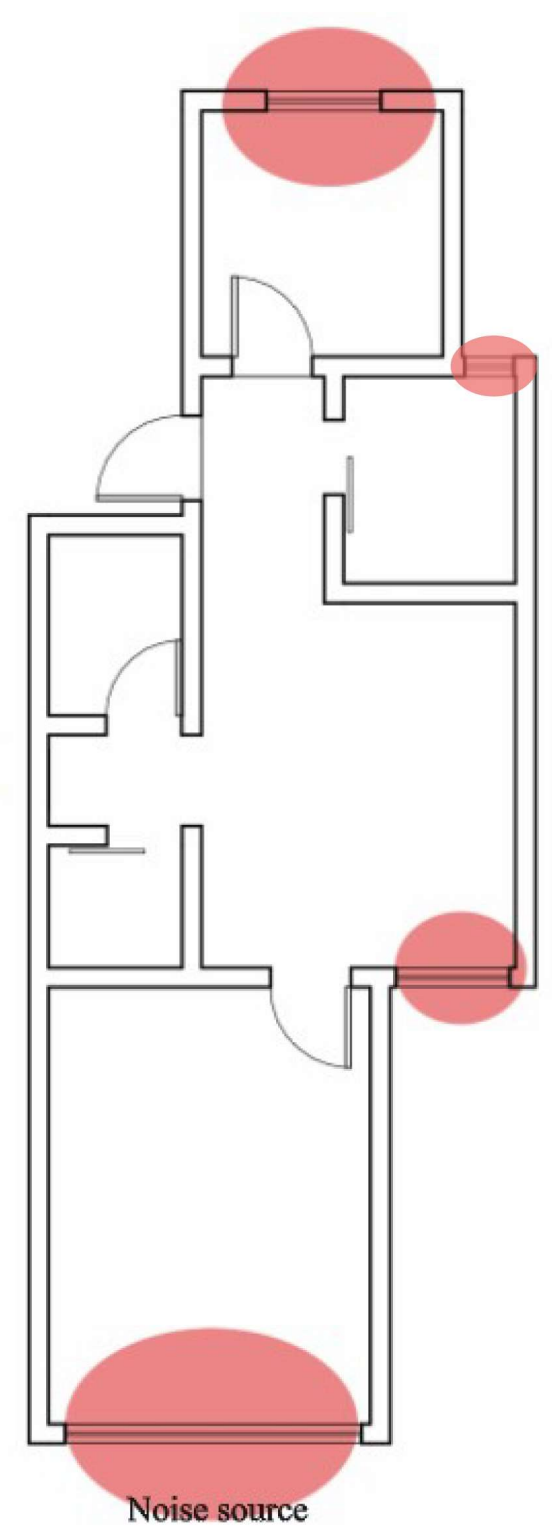

Figure 4.8 Noise source in flat 201 


\section{Activities}

The blue dots represent the users' main activity location in the rooms, and the dotted lines indicate their tracks as they move between the activity location (Fig 5.5). It can be seen that the living room and foyer is the main access to other rooms. When users want to reach other rooms, they must pass through the living room and lobby.

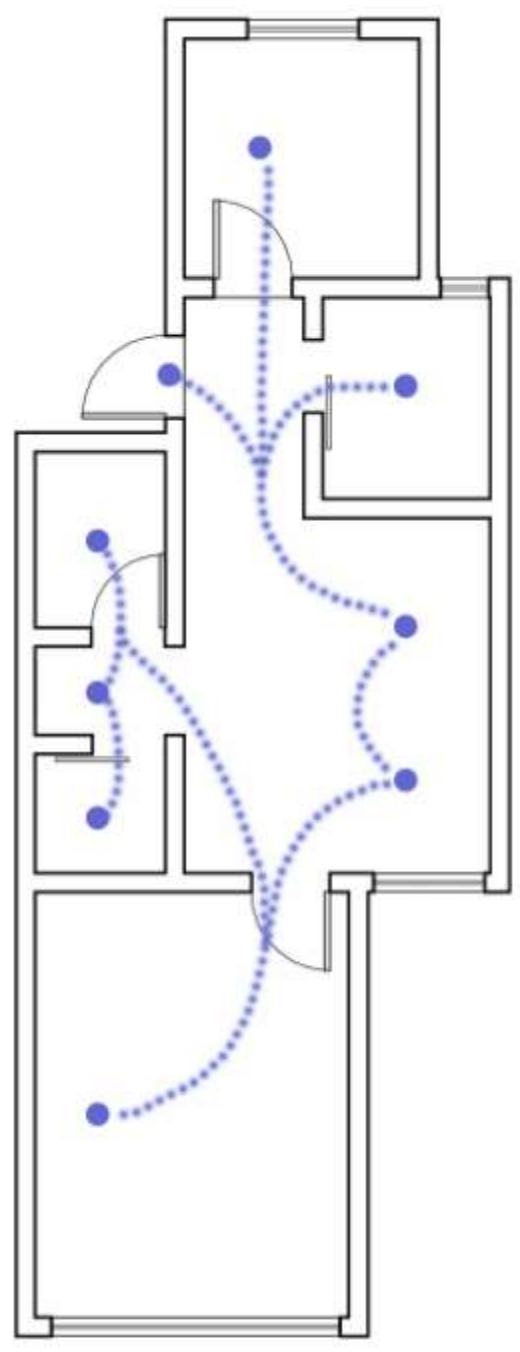

primary movement track

Figure 4.9 Movement track in flat 201 


\section{F. User questionnaire}

During the site investigation, the author contacted the owner of one of the apartments to better understand the housing situation. The owners of one apartment are User A and User B. With their consent, the author conducted an interview with them. Approval to conduct the interview was given by the university's Human Ethics Committee.

The questionnaire (refer to Appendix) is designed to analyze the design and living standards provided within the apartment. Part A of the questionnaire explored the problems faced by the couple in terms of ventilation, space, environment, hobbies, and personal care towards an emergency. Part B identified specific design considerations for older people, such as specific rooms, emergency devices, automated devices, visual impact, and availability of medical supplies. Because this research needs to combine theoretical research with actual conditions, user investigation and analysis is also essential. 


\section{G. Summary of findings}

The interview helped the participants share their overall living experience and the absence of certain essential features for their well-being. The questionnaire helped to trace specific problems related to location and design considerations. The questions framed related to modern living identified the problem faced by the couples in relation to the toilet; both agreed that the toilet is very small and congested. Concerning the north study facing, the couple identified a lack of natural light during the day; the couple would prefer to have more sunlight rather than rely on artificial light.

Three years ago, one of the couples were injured by a fall, due to uneven surfaces between wooden and tiled floor areas. A level floor would have prevented this. The bedroom has good ventilation, and both of couple are happy with the window area. In contrast, the couple has identified problems with the vent and lack of space in the toilet which both need addressing. Other factors that create discomfort for the couple is the absence of an elevator to their apartment's floor and outside noise disturbing the use of the study. The couple is not keen on attending social events, but they would like a quiet and pleasant place within their apartment. An advantage of the location of their apartment building is the close distance to a recreational area; where they can both spend their time. However, the female occupant cannot walk for a long period of time due to physical disability.

The couple is interested in adopting new kinds of technologies like smart gadgets. The male occupant is a retired surgeon and is interested in and aware of new technologies. Their increasing age will create some hurdles in their day-to-day activities. Because of their age they are considering installing a bathtub to avoid standing while showering and to install some equipment for emergencies. The proposed re-design will need to consider their ageing as a priority and their needs for 
medication, and emergency care while improving facilities for hobbies, as well as addressing problems with ventilation, sunlight access, outside noise, and circulation within the house. 


\section{Preliminary Design}

The investigation undergone provided in-depth analysis about the existing features. Information gathered from interviewing the occupants, site analysis, and a review of universal design sources have been used to understand the problems with the existing apartment design. This chapter will explore design patterns that support older people, including wheelchair users, and a number of features are reconsidered for the convenience of wheelchair users.

This chapter is based on the basic design principles applicable to the living habits of older people in China, combined with UD principles and international case analysis to proposes new design plan for the apartment. This part's basic design principles are derived from the indoor dimensions and layout principles for older people mentioned by Yanmin Zhou (2018) in the Housing for older people. More details of Yanmin's design principles have been shown in Appendix D. 


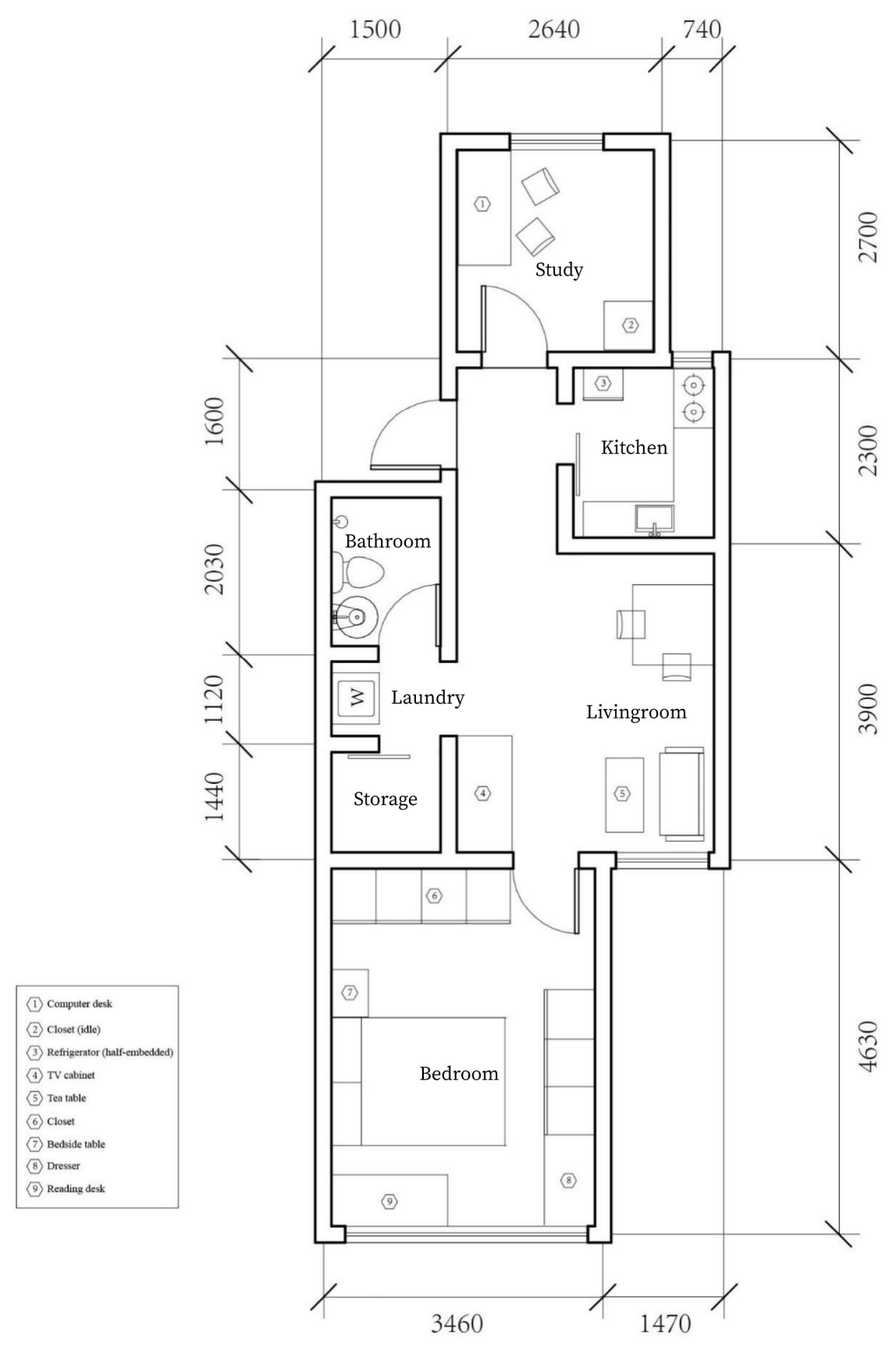

Figure 5.1 Furniture Plan 
According to the site analysis, the design priorities are classified as follows:

1. The division of dry and wet areas around the toilet is not obvious. The toilet and sink are too close to the shower area, making it inconvenient for users to enter and exit.

2. There is not enough space reserved for wheelchair users in the functional areas of the foyer and living room. Storage locations are too concentrated in storage rooms, rather than scattered in various areas of the space.

3. The size and height of the kitchen workbench and cabinets do not take into account the needs of older people.

4. The study needs to reserve enough space for wheelchair users and create an environment suitable for reading.

5. The space around the bed in the bedroom needs to reserve enough space for wheelchair users or medical staff.

6. The floor and walls should be made of non-slip and waterproof materials and eliminate any height differences in the flooring to prevent it becoming an obstacle to walking.

7. The space near windows in the bedroom needs to allow enough space for activity.

8. All windows need to be double-glazed to be soundproofed.

This section examines each room in more detail. While solving the above problems, the space functions and the main large furniture are re-planned. Meeting the basic needs of user, $\mathrm{A}$ and $\mathrm{B}$, and reconsidering for their specific needs. 


\section{A. Kitchen}

\section{Space design strategy}

In order to provide maximum mobility for wheelchair users, the non-load-bearing walls of the kitchen are proposed to be removed to better connect it to the dining room. The functional areas between the kitchen and the other space are separated only by the kitchen counter. The original sliding doors were removed which enabled a wheelchair user to move between the kitchen and the dining area without having to push open the doors. In addition, it is possible to fill in the corners of the kitchen counter to make it easier to control a wheelchair.

The utilities and the required utensils are in a place that enables, without straining, the desired tasks to be achieved easily. Undertaking the diameter of the wheelchair to move circular around within the place, the proposed design needs to be reserved for wheelchair users to move around.

As figure 5.2 shows, L-shaped designs offers the space to rotate within the kitchen area allowing users to swap their position individually while working in different bench areas.

The original cabinets under the workstation can be removed to provide space for wheelchair users, so that they can have a space to tuck in their legs when using the wheelchair. On the other hand, dishwashers and ovens can be reserved for the future. The upper wall cabinets are designed in two parts, including the larger storage cabinet at the top and the smaller cupboard at the bottom (Figure 5.3 and 5.4). The reason for the smaller bottom cabinet is to avoid the user's head hitting the cabinet when standing up. 


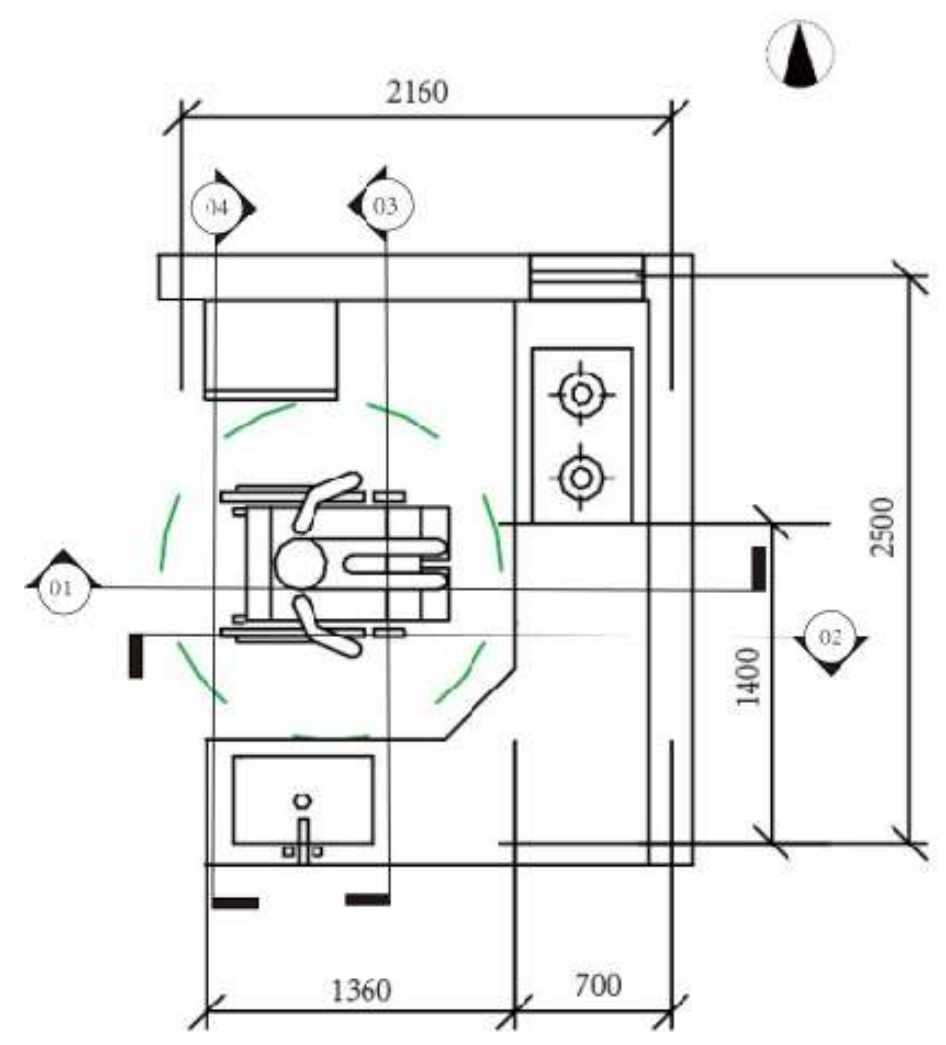

Figure 5.2 Redesign for Kitchen in flat 201 


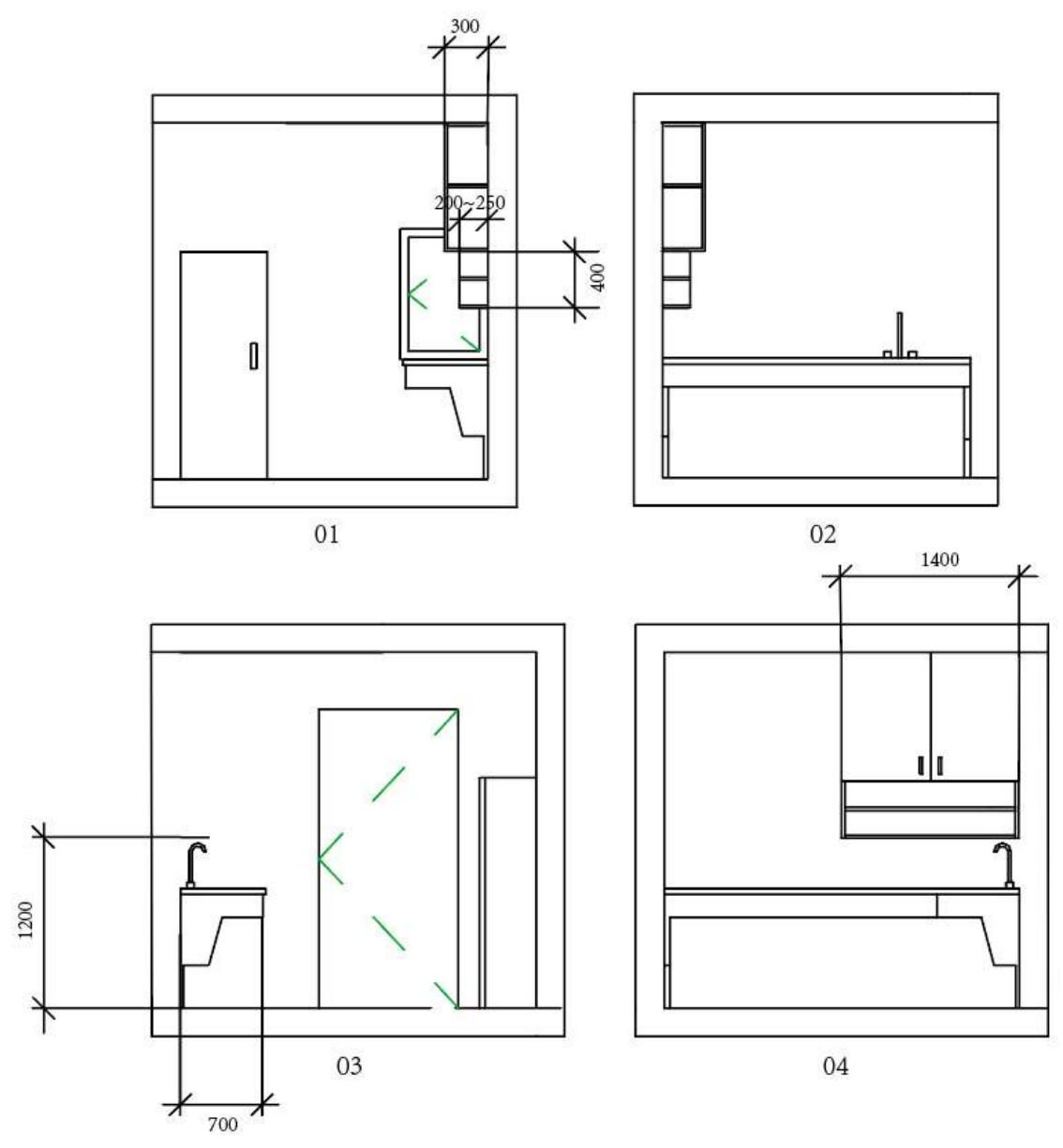

Figure 5.3 and 5.4 Sections of kitchen

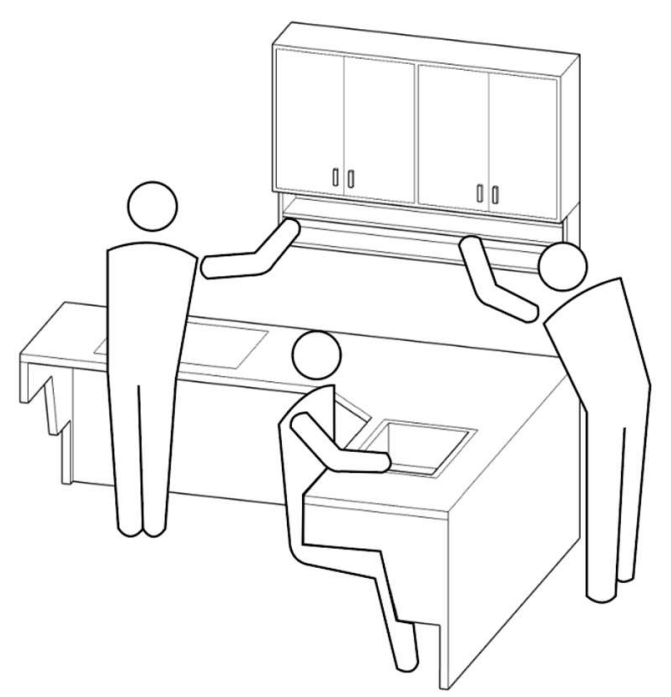

Figure 5.5 Interactive action in kitchen 


\section{Relevant furniture}

\section{a. Ensure the height of cabinets}

Furniture will play a key role in providing storage for food and appliances;

if the furniture design is poor, the users can experience physical stress, because it is awkward to use them. Figure 5.6 below is an example of good design because it is easily accessible for wheelchair users to work unassisted. The shelves are positioned in the user height range to support this. It is important to ensure that people will not get hit by the shelves due to these heights constrain. Shallow shelves can address this.
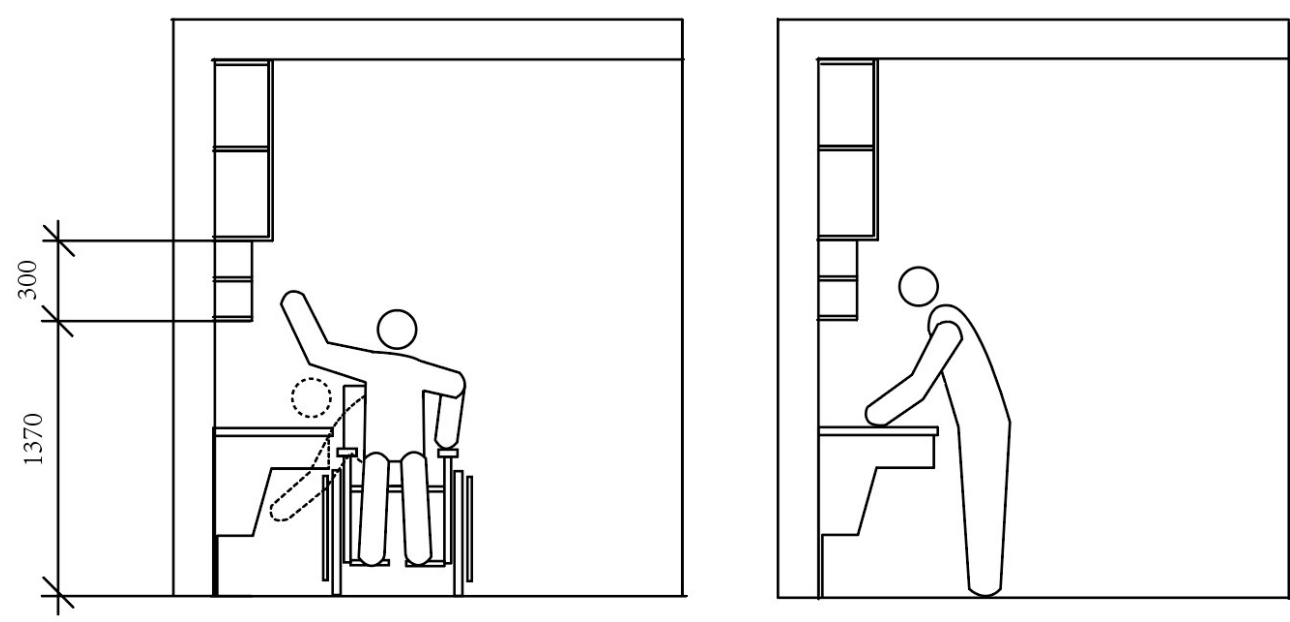

Figure 5..6 Height of cabinets

\section{b. Ensure the size of Benchtop}

Another essential facility that can accommodate wheelchair users is the sink; it is provided at a minimal height, as shown in the figure 5.7, the height of the work bench should be provided at $865 \mathrm{~mm}$ (maximum) that can be easily used by both disabled and able-bodied adults.

In addition, as figure 5.8 shows, the user only needs to rotate 90 degrees to 
operate on all three benchtops.

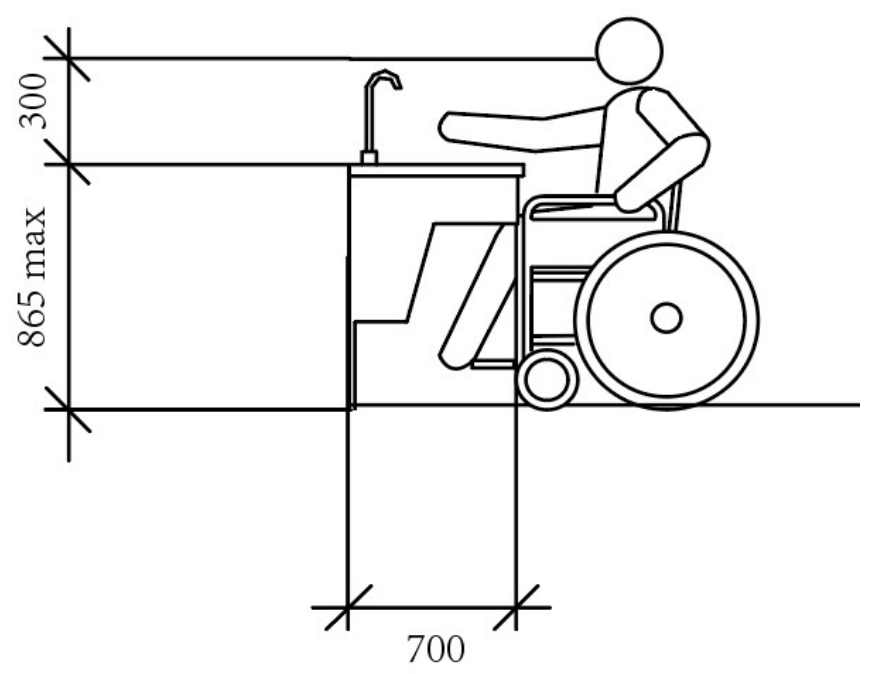

Figure5.7 Height of sink

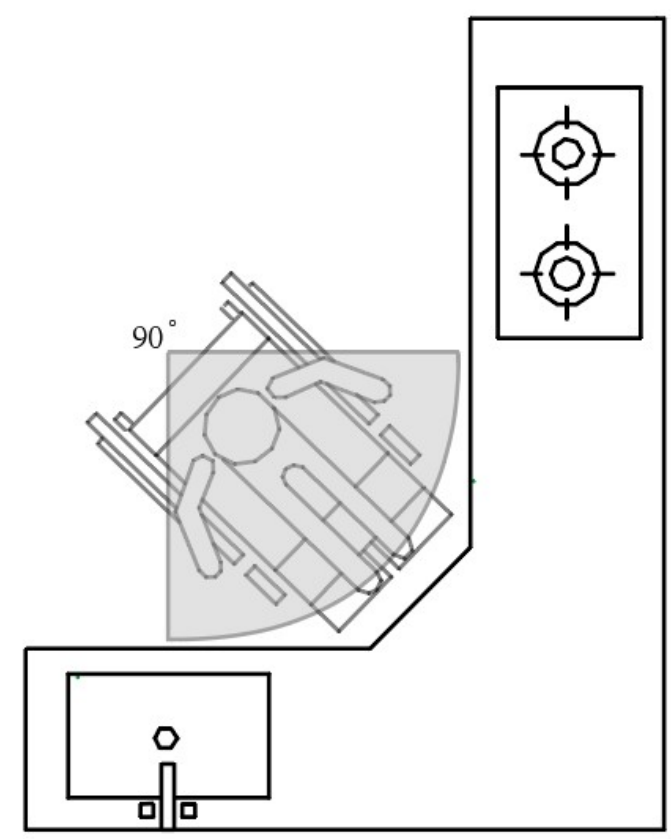

Figure 5.8 Three work platforms 


\section{B. Bedroom}

\section{Space design strategy}

a. Increase the space required by nursing staff and wheelchairs

A circular space with a diameter of $1500 \mathrm{~mm}$ (Figure 5.8) can be designed in the south-facing corner of the bedroom for wheelchair users to easily turn to the activity area.

\section{b. Set the activity area near the large windows}

The activity area needs to be closer to the window so that the occupants can enjoy the sunlight and observe the outdoors. Considering ventilation and lighting, the south-facing space of the bedroom is set as an activity area. Any movable furniture can be placed according to need.

The regular bed width of $2000 \mathrm{~mm}$ is recommended for a couple to provide better comfort. It is also supported to have the cupboards at a reasonable height to enable easy access. The design wants to promote wider space for activities in the room such that by satisfying the essential requirements in the bedroom, it is important to ensure free circulation around the room. The furniture provided in the room, such as cupboards, drawers, are designed according to the body postures of the older adults. For instance, the drawers should have easy operation and be planned according to the sitting posture height. Also, the cupboards are planned to be the recommended height for the occupants. In addition, the height of the wall cupboard can be set at $1000 \mathrm{~mm}$ above the floor for easy access. 


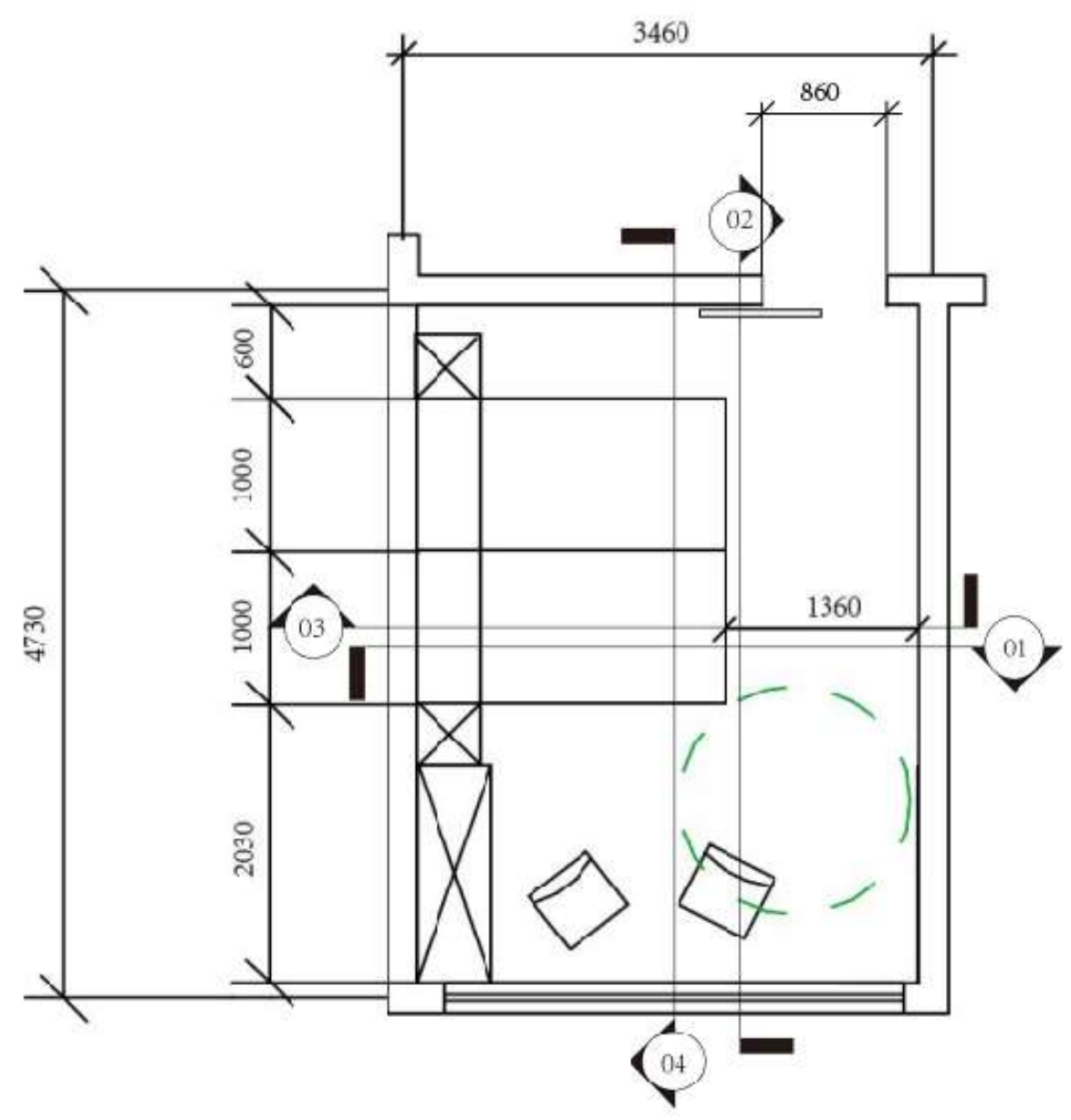

Figure 5.9 Redesign of bedroom in flat 201 


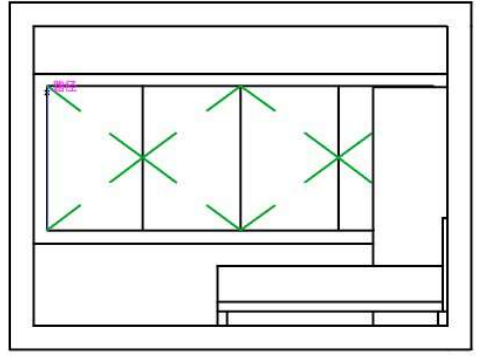

01

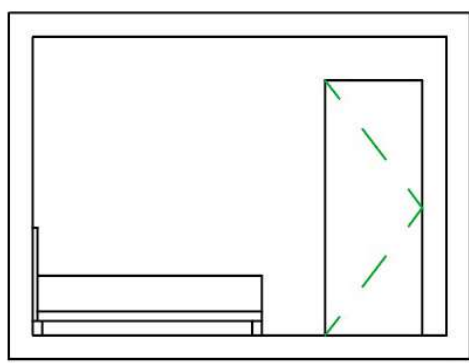

03

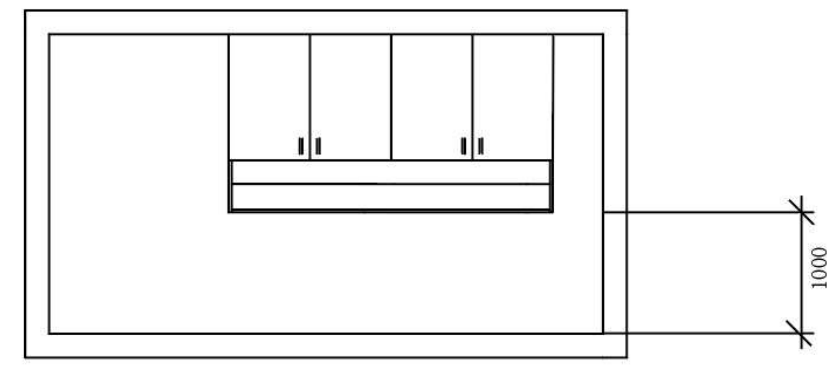

02

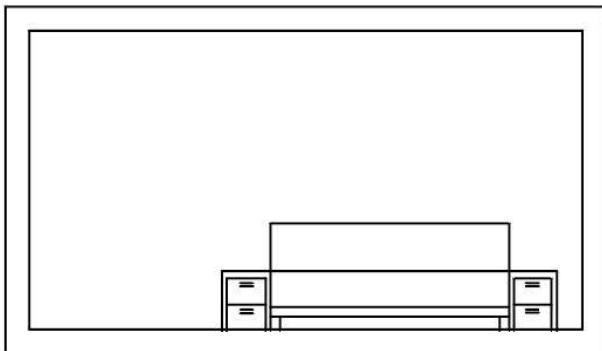

04

Figure 5.10 and 5.11 Sections of bedroom

\section{Relevant furniture}

a. Size and position of the bed

As figure 5.9 shows, the couple's bedroom needs to choose a slightly larger double bed to avoid disturbing each other during sleeping. The size of bed is $2000 \mathrm{mmx} 1800 \mathrm{~mm}$. And it should to leave space on both sides to make it easier for older people to move around. 
b. Use of bedside space

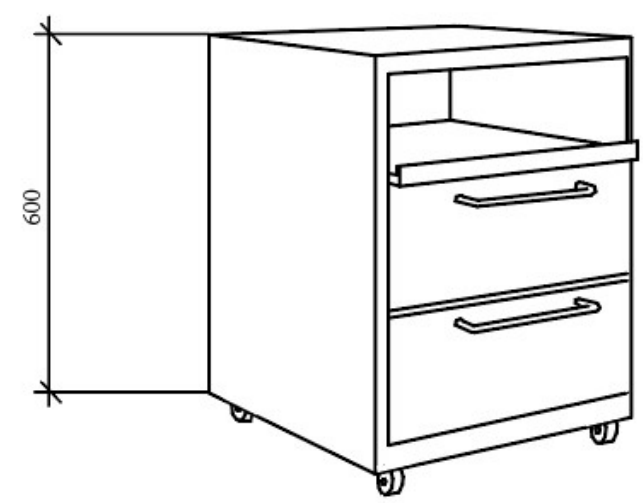

Figure 5.12 Bedside table with pulleys

The bedside table is an essential piece of indoor furniture. The height of the bedside table should be about $600 \mathrm{~mm}$, and the bottom should be set with pulleys to facilitate older people to change the position of the bedside table.

c. Position of closet
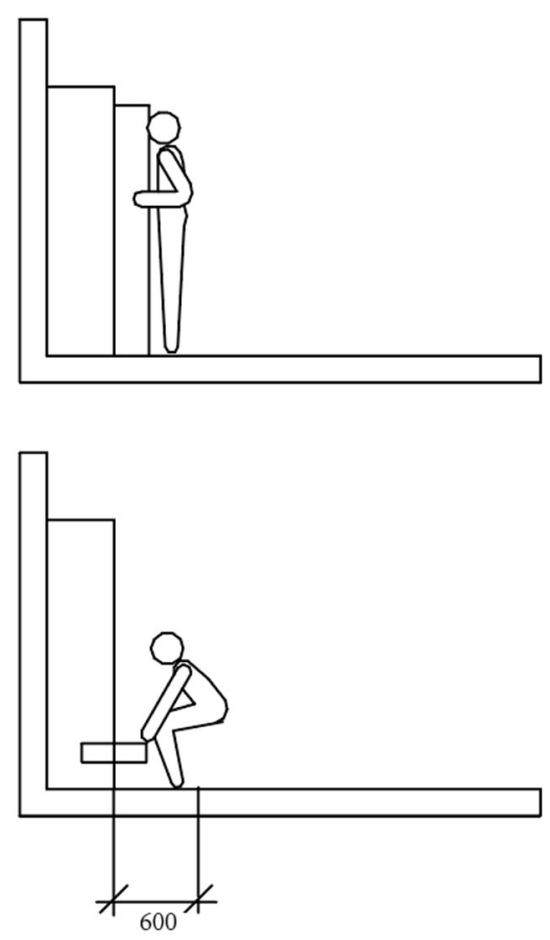

Figure 5.13 Position of closet 
As figure 5.13 shows, there should be a space for opening the cabinet door and taking items in front of the closet, and it should usually be kept at $600 \mathrm{~mm}$ or more. If a sliding door is used on closet, the width can be smaller than $600 \mathrm{~mm}$. 


\section{Study}

\section{Space design strategy}

In order to leave enough space for the wheelchair user, the furniture needs to be placed as close to the wall as possible. As figure 5.13 shows, the furniture should be staggered to maximize space for wheelchair users to change direction. The obstacles cannot be placed in the center of the room. On the one hand, the obstacles will impede the circulation route of older people. On the other hand, enough space is easier for them to move their furniture at any time.

Since the windows are located close to the street outside, noise from outside tends to disturb people in this room. Therefore, in order to maintain a quiet indoor reading environment, the double vacuum glass should be used for window glass to isolate outdoor noise.

Since the user's hobby is reading, it is recommended that fixed furniture such as bookcases and wall cabinets be placed in the space. Other movable furniture such as desks, chairs, etc. can be placed according to the user's preference. As shown in the figure 5.16, the height of the bottom bookcase is recommended to be set at $865 \mathrm{~mm}$ maximum, so that the wheelchair user can access material easily.

The desk needs to be placed close to the window for good lighting, so that older people can read and write. The placement of the computer and television should avoid direct sunlight to avoid glare. 

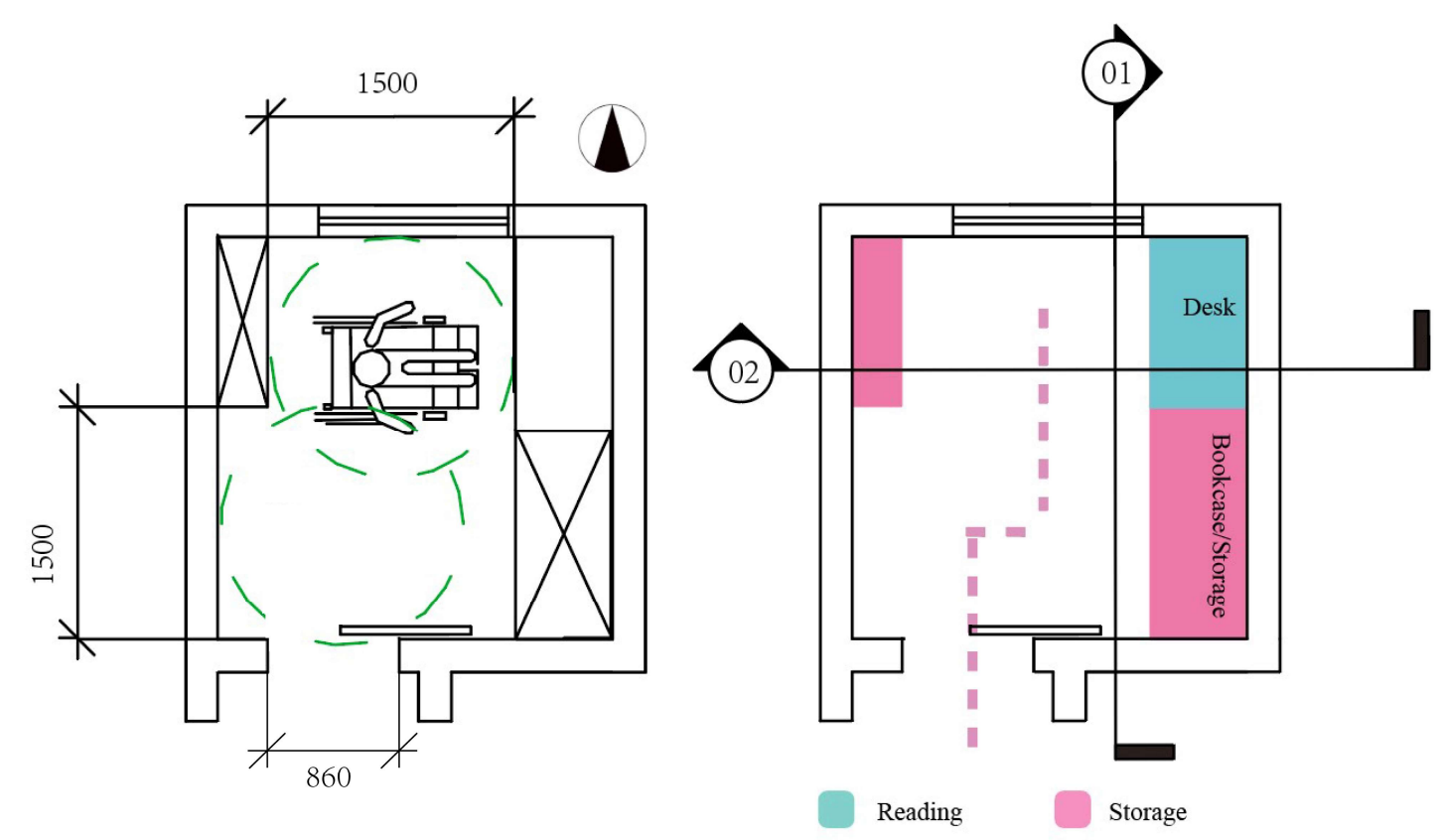

Figure 5.14 Redesign of study

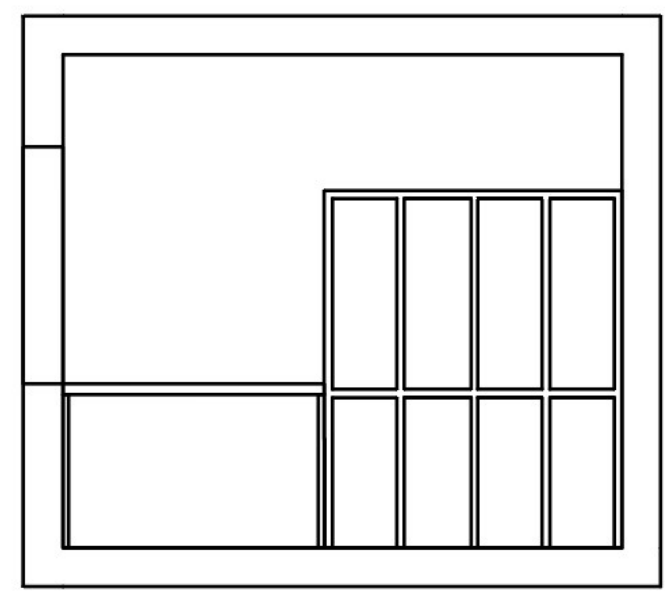

01

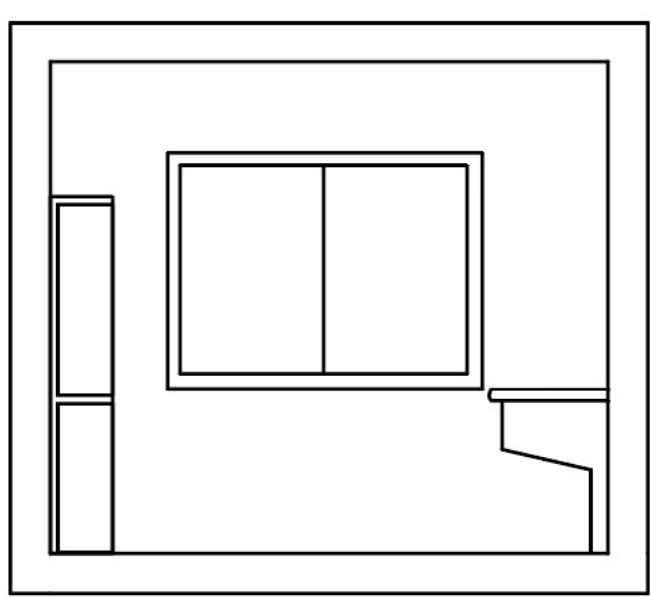

02

Figure 5.15 Sections of study 


\section{Relevant furniture}

\section{a. Size of bookcase}

The desk needs to be placed close to the window to get good lighting, so that older people can read and write. The placement of the computer and television should avoid direct sunlight to avoid glare.

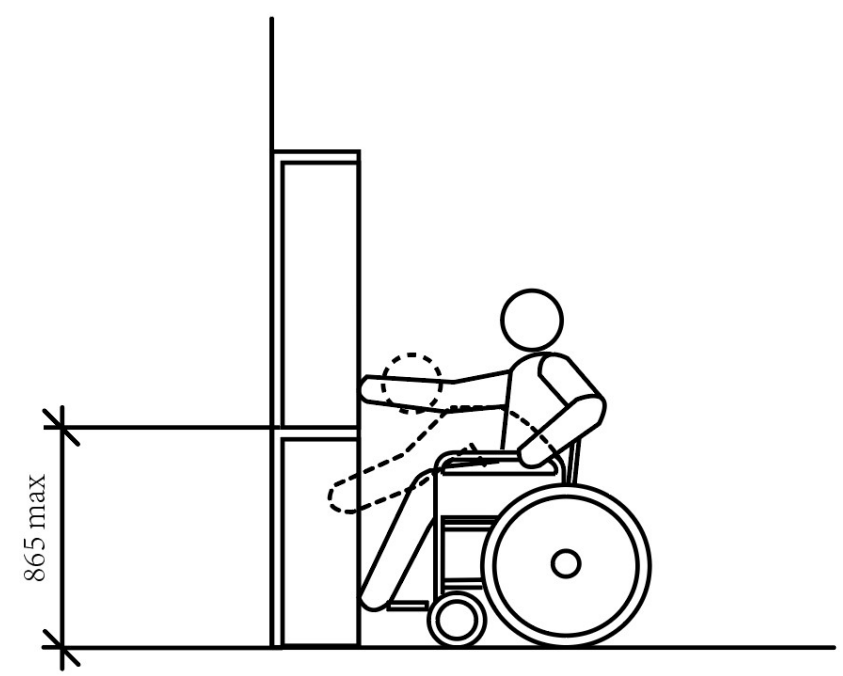

Figure 5.16 Size of bookcase 


\section{D.Livingroom, Dining room and Front lobby}

\section{Space design strategy}

The lobby can be equipped with a standing cabinet and a stool for the older people to change their shoes and clothes after they enter the room. Since the width of lobby is narrow (less than $1500 \mathrm{~mm}$, wall-mounted folding chairs and folding armrests can be considered, as shown in the following figure 5.17. Folding stools allow older people to change shoes while sitting next to the closet.

It is not recommended to install any furniture or other obstructions at the connection between the lobby and the living room, as it is important to ensure sufficient width for the wheelchair user. As shown in figure 5.17 below, the cabinets are set up in the corners of the hall and on the walls of the dining room to store items. Enough space needs to be reserved for wheelchair storage so it does not affect the daily activities of older people. The depth is generally $350 \mathrm{~mm}$ and the width is $1100 \mathrm{~mm}$ at least. Other furniture can be placed next to the wheelchair storage. It is recommended to choose small and light-weight furniture so that users can move them at any time.

Because there are only two long-term users of the apartment, the original larger dining table can be replaced by a folding dining table. During non-dining hours, the dining table can be folded to increase the activity space.

The location of the sofa and tea table can be not changed much, but the original TV stand was eliminated in order to increase the width of the circulation space to ensure that the older people would not bump into the coffee table when walking. A light weight tea table is easy for older people move according to their needs. Generally, the height of the coffee table is about $500 \mathrm{~mm}$. 

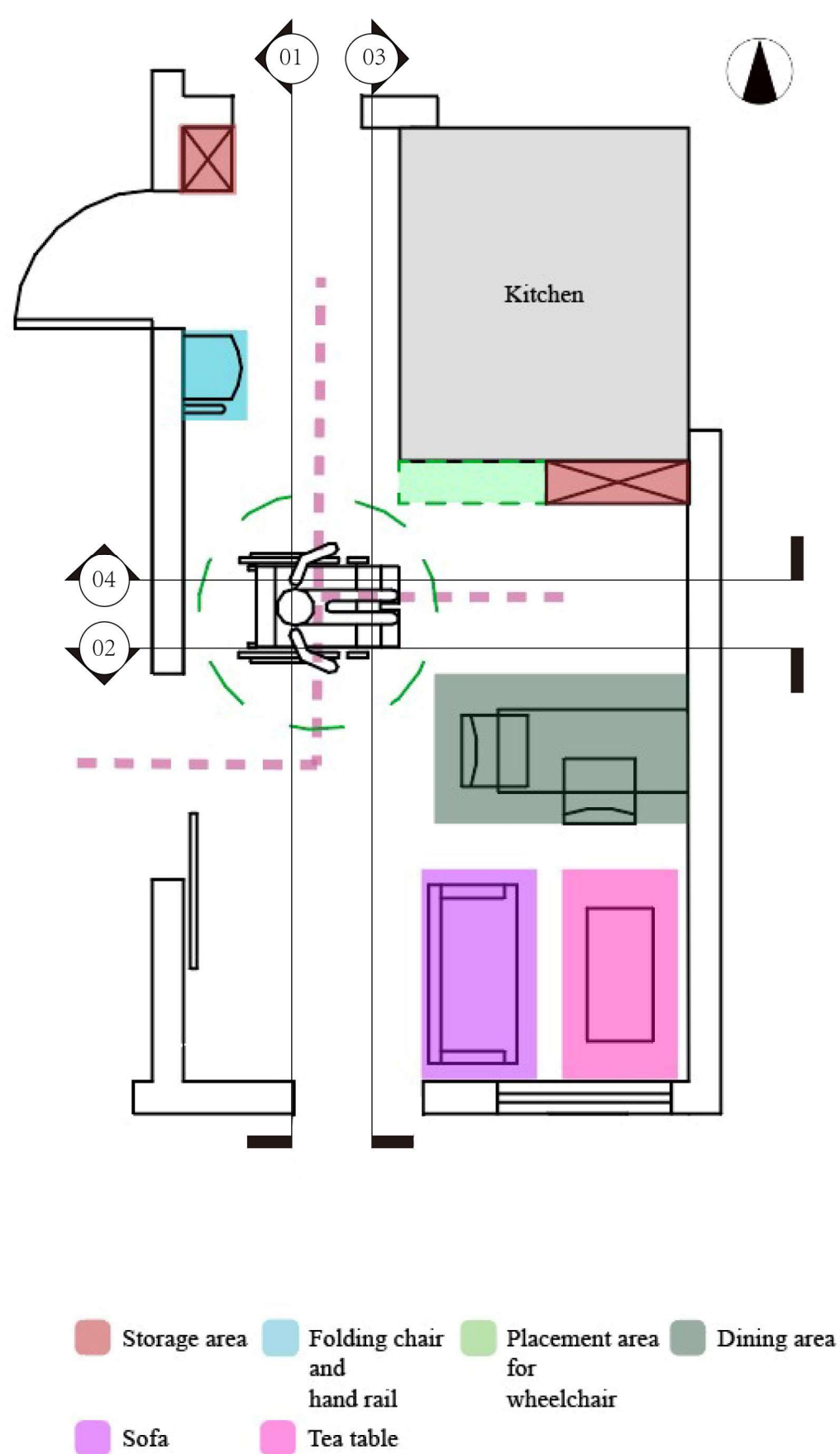

Figure 5.17 Redesign of Livingroom, dining room and front lobby in flat 201 


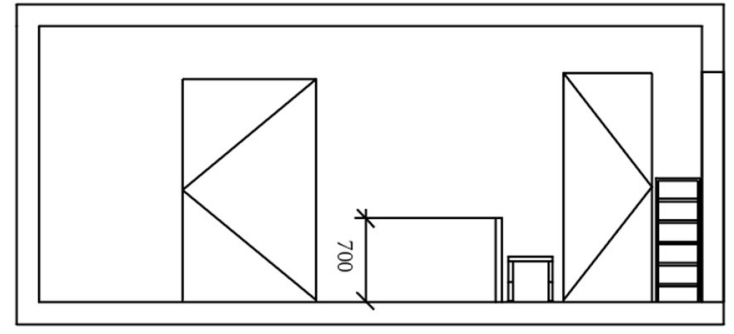

01

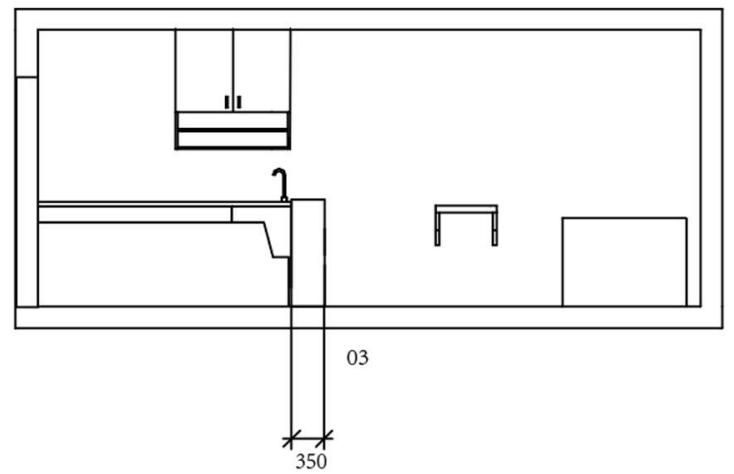

Figure 5.18 Elevation of Livingroom, Dining room and Front lobby

\section{Relevant furniture}

\section{a. Folding dining table}

In order to increase space utilization and expand the range of activities for older people during non-meal times, it is recommended that they use folding tables. The figure 5.19 below shows typical models of folding dining tables that have been investigated. A folding dining table can consist of a storage cabinet and a table top. 

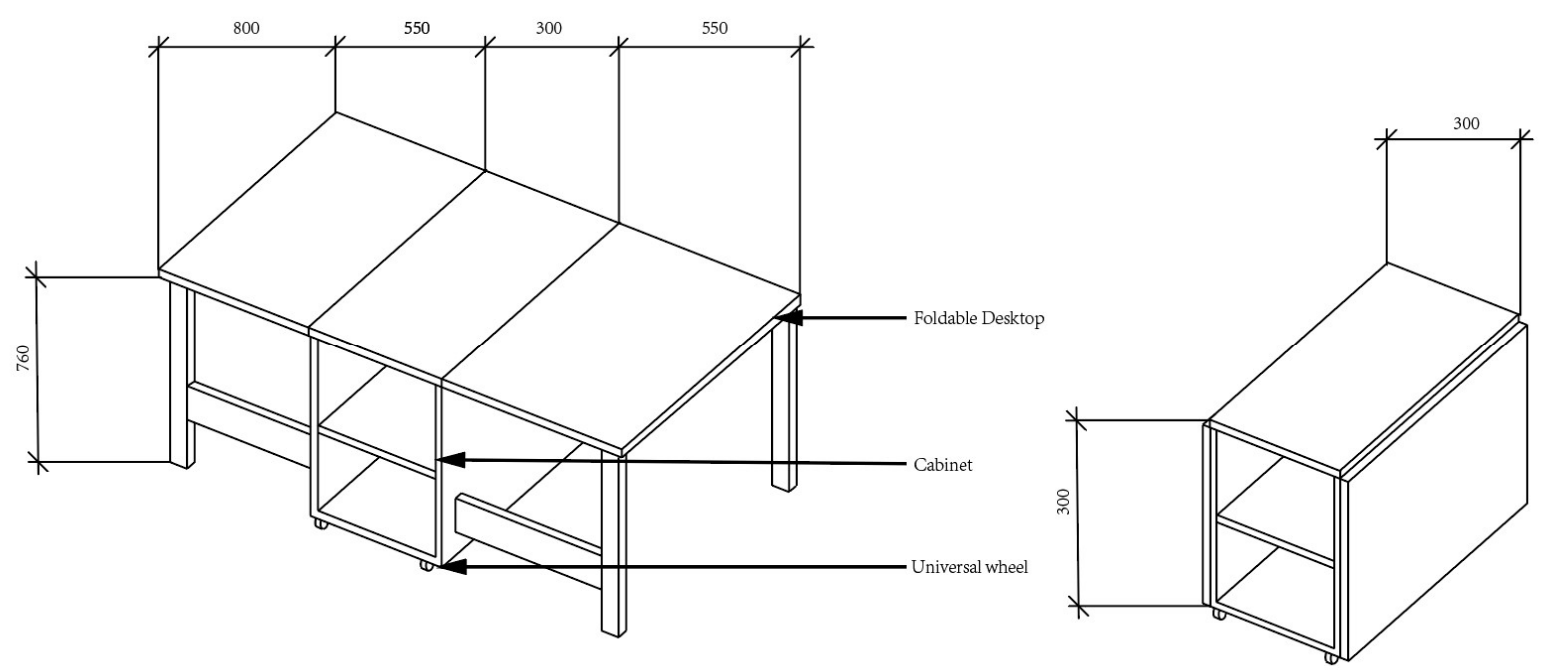

Figure 5.19 Folding dining table

\section{b. Shoes stool}

Due to the limited space in the lobby, the wall-mounted shoe stool was set in the wall side of the living room. A longitudinal handrail is set beside the shoe stool (Figure 5.20) to assist older people to stand up or sit down.

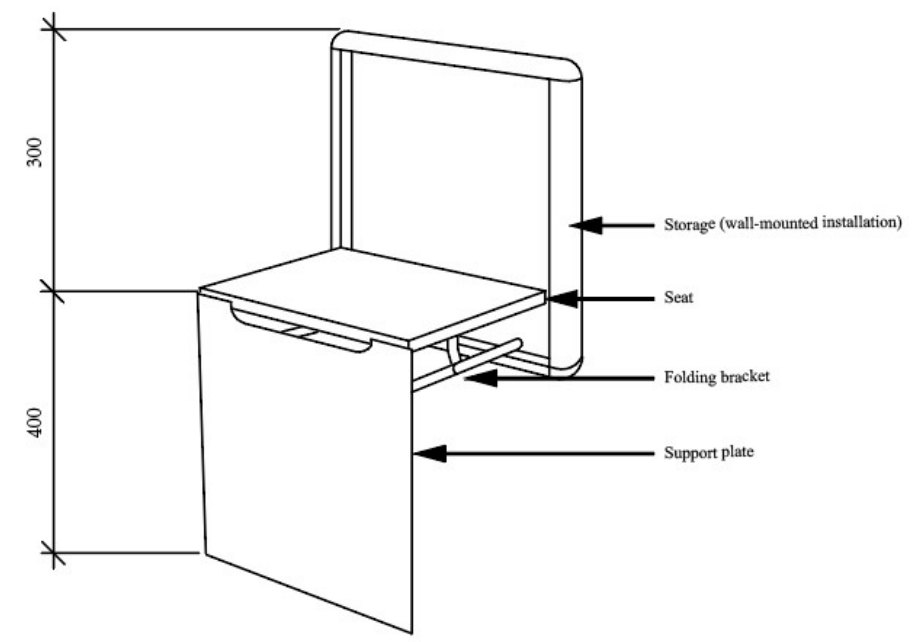

Figure 5.20 Shoes stool for wheelchair user 


\section{E. Bathroom}

\section{Space design strategy}

As the figure 5.21 shows, the wall of the original storage room was removed and rebuilt to expand the scope of the bathroom. The wet area is separated from the dry area to reduce the possibility of the floor in dry areas becoming slippery, thereby preventing older people from slipping. As shown in the figure 5.20, the wet area can be partitioned with a soft material, such as a shower curtain to save space for easier wheelchair access in the bathroom.

The toilet, shower and bathtub are all equipped with handrails to help the older people move, stand and sit down. In addition, from a safety perspective, the door close to the toilet is a sliding door. This is because if the old man falls or faints, his body may block the door leaf that opens inward. The sliding door can be opened from the outside, making it easier for rescuers to enter the bathroom. Therefore, a circular space of $1500 \mathrm{~mm}$ in diameter in the area near the door is reserved as much as possible for wheelchair users. Due to space limitations, the height of the washing machine and sink can be set at $800 \mathrm{~mm}$ or higher and that space be left underneath to ensure that the wheelchair user can rotate the wheelchair during use. In addition, the floor of the bathroom should be made of waterproof and non-slip materials. 


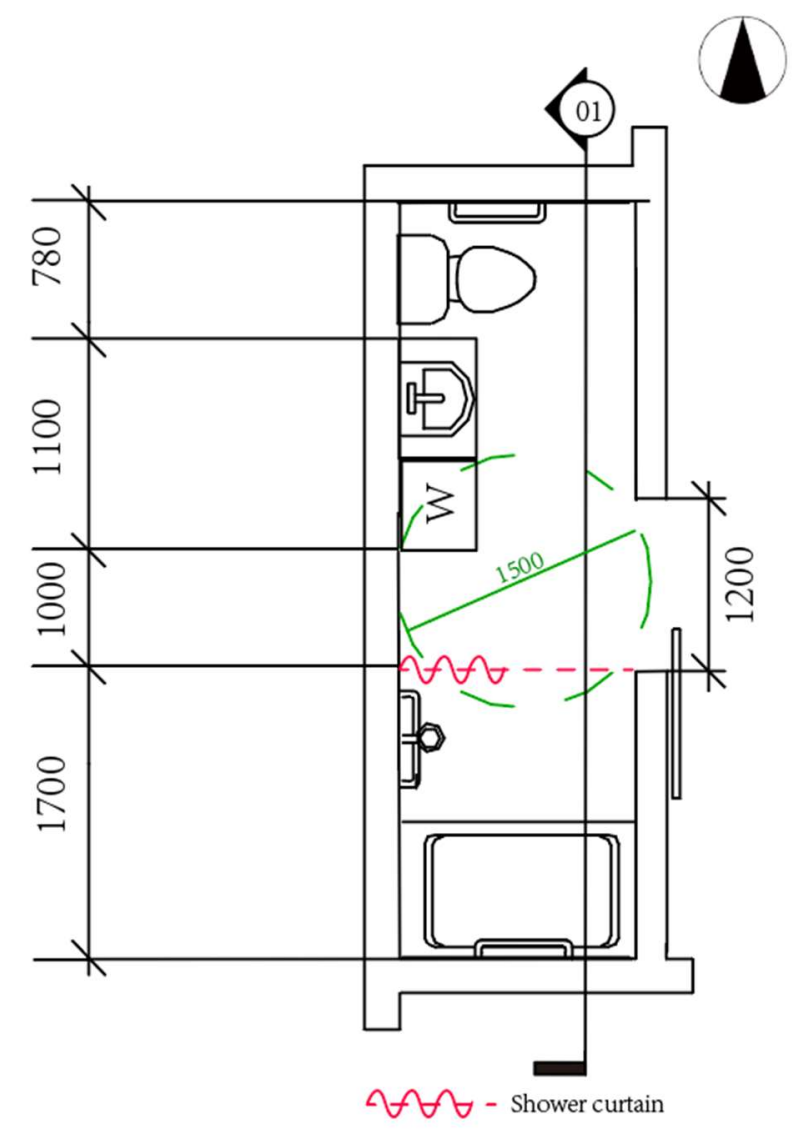

Figure 5.21 Redesign of Bathroom in flat 201

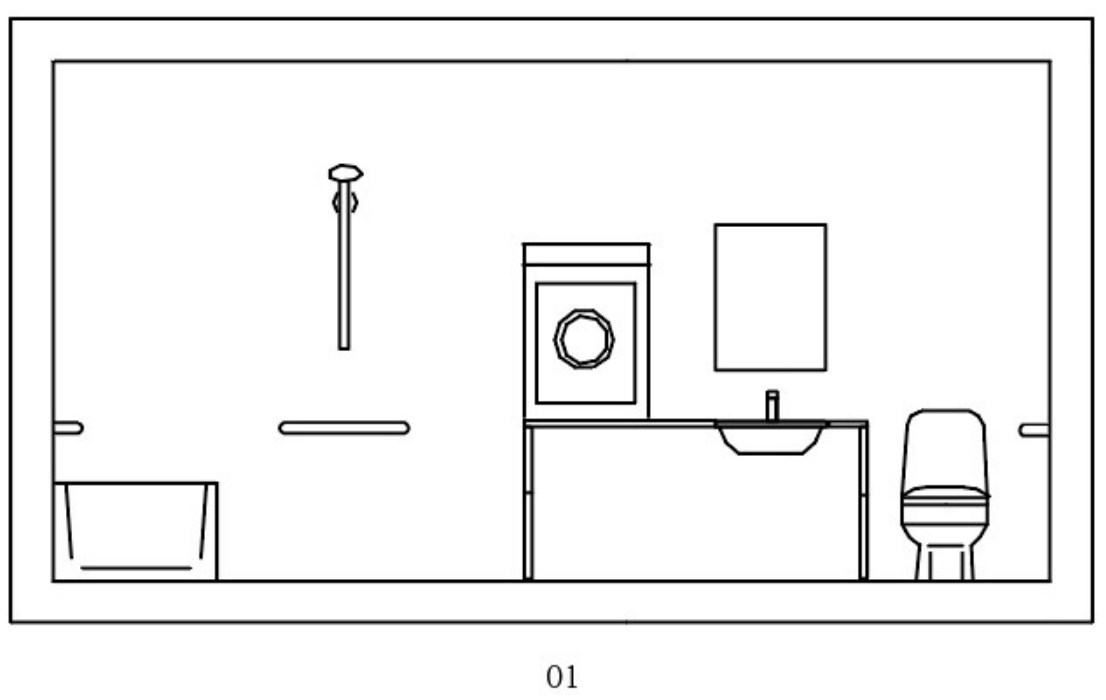

Figure 5.22 Section of bathroom 

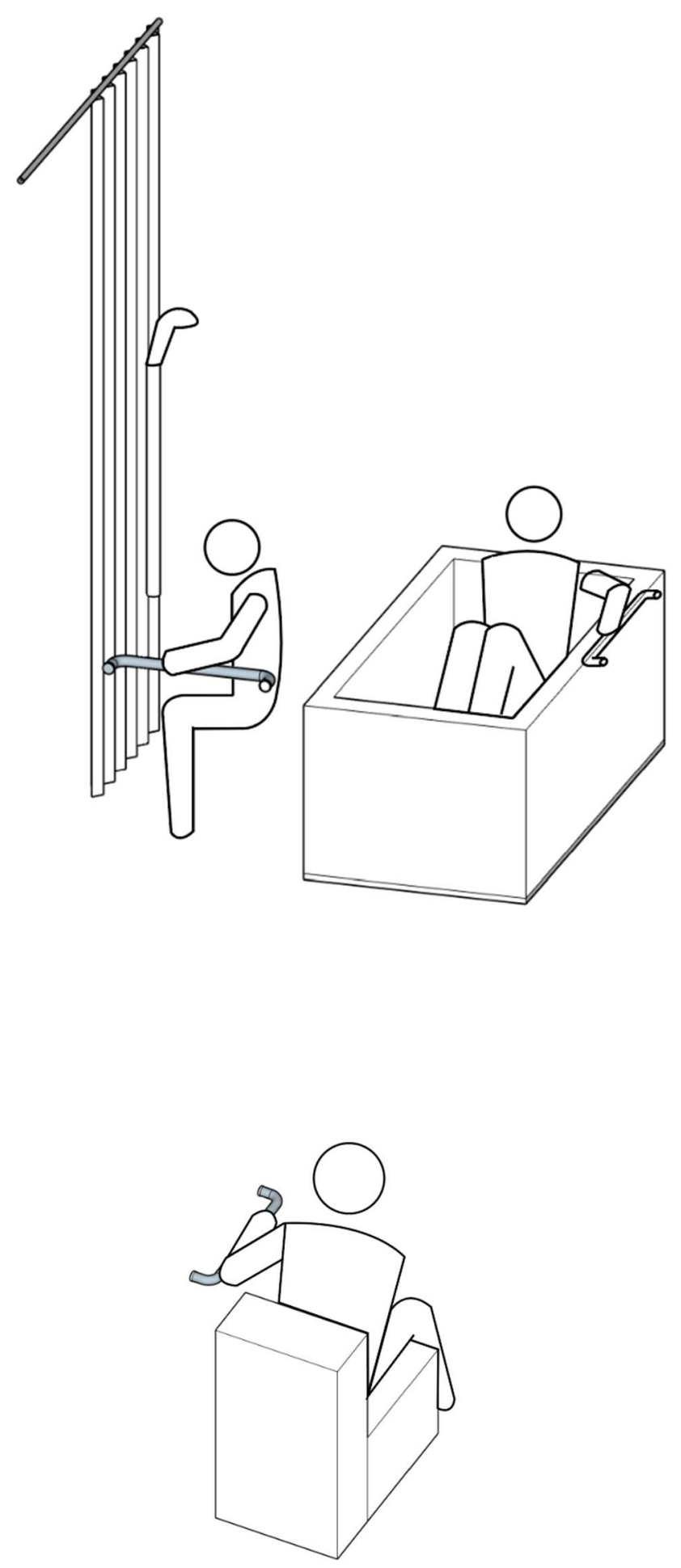

Figure 5.23 and 5.24 Interactive action in bathroom 


\section{Relevant furniture}

\section{a. Bathtub}

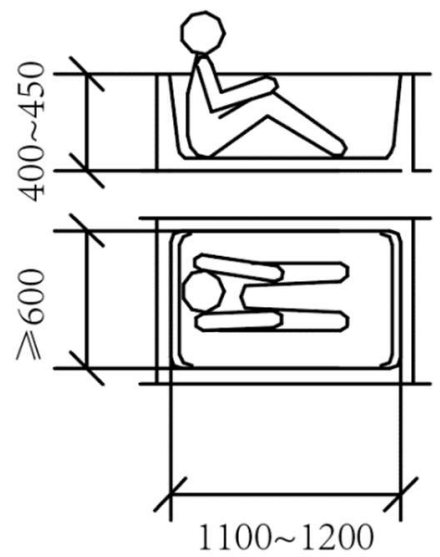

Figure 5.25 Bathtub

The length of the upper edge of the bathtub is preferably $1000 \sim 1200 \mathrm{~mm}$.

For the convenience of older people, the height of the upper edge of the bathtub from the ground should not exceed $450 \mathrm{~mm}$.

\section{b. Hand rail for Shower}
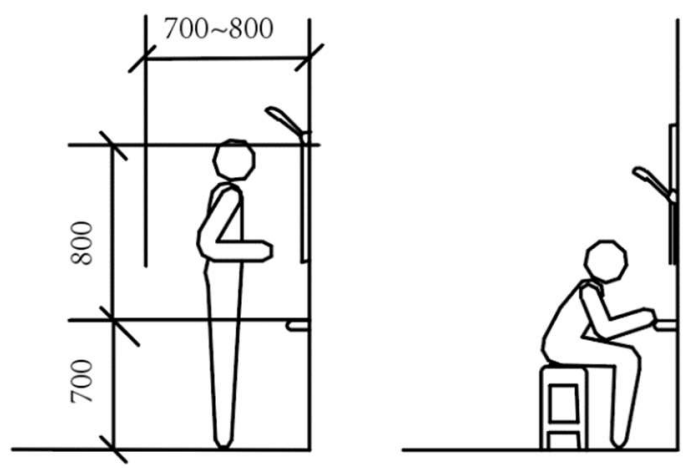

Figure 5.26 Hand rail for shower

Older people are at risk of falling when entering and exiting a shower. The handrail can prevent this hazard. The handrail can be set under the shower to facilitate standing up and sitting down. 
In addition, the physical strength of older people needs to be considered. It is better to set up a stool in the shower room to facilitate sitting in the shower.

\section{c. Space of Basin}

A space can be set up under the basin to allow wheelchair users to use it more conveniently. Alternatively, a cabinet with rollers can be placed below, so that the occupant can change the position of the cabinet at any time according to their needs.

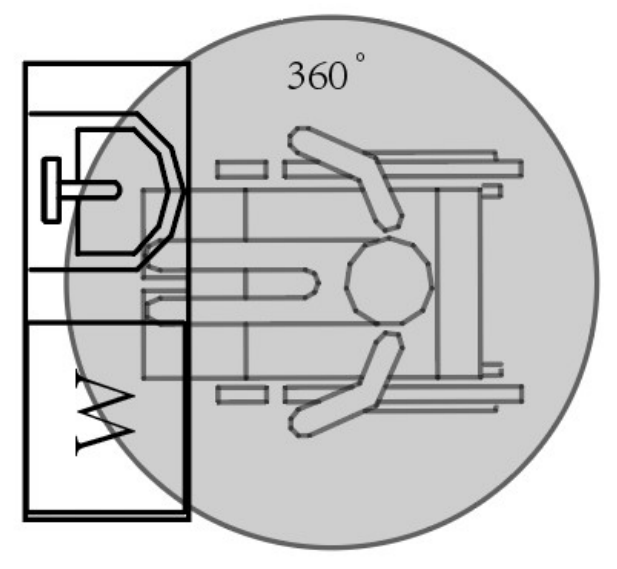

Figure 5.27 Space of basin 


\section{Developed Design}

The sensory design of the interior for older people is an important part of residential decoration. The choice of material and color is directly related to the user's spatial experience. This chapter analyzes and describes design decision related to the wall, ceiling, and floor.

\section{A.Interior finish}

The ceiling needs to be considered from the aspect of soft reflection, which avoids glare and damage to older people's eyesight.

The bedroom ceiling should not be made of highly reflective materials because the older people will see the ceiling when they lie on the bed in the bedroom. Also, for darker rooms without windows, the ceiling color should be a light color with high brightness. The lighter color will diffuse the light from the overhead lights and increase the brightness of the room. Diffuse reflective materials are better for other functional spaces to provide a quiet and soft living atmosphere, such as gypsum board and latex paint.

The ceilings of kitchens and bathrooms need to be water-proof and moisture-proof, and easy to clean. Therefore, stainless steel, aluminum alloy, PVC board, and other water-proof coatings can be used in flat 201.

The floor should not be too smooth, and a glazed finish can cause glare.

For quiet spaces, such as a reading room, bedroom, or other functional room, the carpet is an appropriate choice that can reduce noise. However, soft carpet is not recommended for wheelchair use. 
The living room and bedroom floors should be appropriate soft to reduce injury from falls. Cork flooring, elastic coiled materials, solid wood flooring, or composite solid wood flooring can be used. Because users may use a wheelchair in the future, the living room and bedroom floors should also be made of compressive and wearresistant materials, so floor tiles and laminate flooring can also be selected.

In the toilet, kitchen, and bathroom, water-proof, non-slip, and easy-to-clean materials should be preferred, such as non-slip treated stone and floor tiles. In particular for toilets and bathrooms, it is necessary to avoid using materials with gaps, such as mosaic tiles, to avoid water and drainage requirements.

Walls should be light-colored with mid-to-high brightness because light-colored walls' reflectivity can increase indoor brightness and provide convenience for older people to observe their surroundings. A light-colored background makes it easier to highlight the indoor furniture orientation and prevent older people from colliding with the furniture. Older people usually move slowly. Therefore, warm and soft colors should be used to create a comfortable atmosphere. Also, older people sometimes need to stand up or walk with the wall's support. Therefore, easily cleaned wallpaper or water-proof latex paint that is easy to wipe should be used.

However, wallpaper patterns that can easily cause hallucinations and visual illusions, such as stripes, spirals, or other finely divided three-dimensional patterns, should not be used.

A wall's color and the color of the ground should contrast to visually distinguish the space and distance. However, contrasting colors that are too bright or too dark should not be used because this can cause glare or a lack of light.

For bathroom walls, water-proof wall tiles can be used. Ceramic brocade tiles are commonly used in Chinese interior design wall decoration. The color of ceramic 
brocade tiles is relatively stable, so it can be used for a long time and will not change color due to moisture erosion.

For rooms near the street, such as reading rooms, the walls can be covered with sound-absorbing panels, which are now available in decorative form. Soundabsorbing panels can effectively isolate outside noise and provide a quiet indoor environment for older people. In addition, it is possible to further reduce outside noise by installing soundproof glass windows. 


\title{
B. Furnishing
}

\author{
Furniture
}

Furniture should be light-weight. It is also important to make sure that mobile furniture is stable and will not fall over when user move them.

For low furniture, such as sofas and coffee tables, the height should be set at $400 \mathrm{~mm}$ or above to help older people get up or sit down. For large furniture, such as couches and beds, a low cabinet or table can be a good choice which placed next to it in order to provide a tabletop for placing items. Rollers can be installed underneath the low cabinets and tables so that it is easy for older people to move them.

\section{Drapes}

Older people have weakened eyesight and are therefore less able to adapt to strong light. The use of translucent drapes can regulate the light in the room, making it easier for older people to read, watch TV, chat, etc. in the soft indoor light.

Thicker drapes can help older people to block out excess light. Therefore, it is recommended to use thicker curtains in the bedroom to block out the light. 


\section{Lighting}

Simple, lightweight acrylic ceiling lights should be used for the ceiling while avoiding the use of crystal, glass, and other heavy lamps to prevent the lamps from falling and injuring the older people. For other darker rooms or functional areas that require additional lighting, table lamps can be adopted nearby beds or tables. The wall lamps and other light fixtures gather lighter to improve the illumination of a small area (More details show in Appendix).

In addition, the lights in bathrooms and toilets should be bright, uniform, shadowfree, glare-free, and the exterior of the fixtures should be waterproof. For wheelchair users, the switch needs to be set at the height of $800 \mathrm{~mm}$ from the floor.

For the bedroom, the lighting should not be too complex and harsh. If there is enough space, consider placing a floor lamp near the bed's head to make it easier for older people to get in and out of bed. Also, a switch panel with luminescent light can be used to make it easier for older people to find the switch position in the dark. 


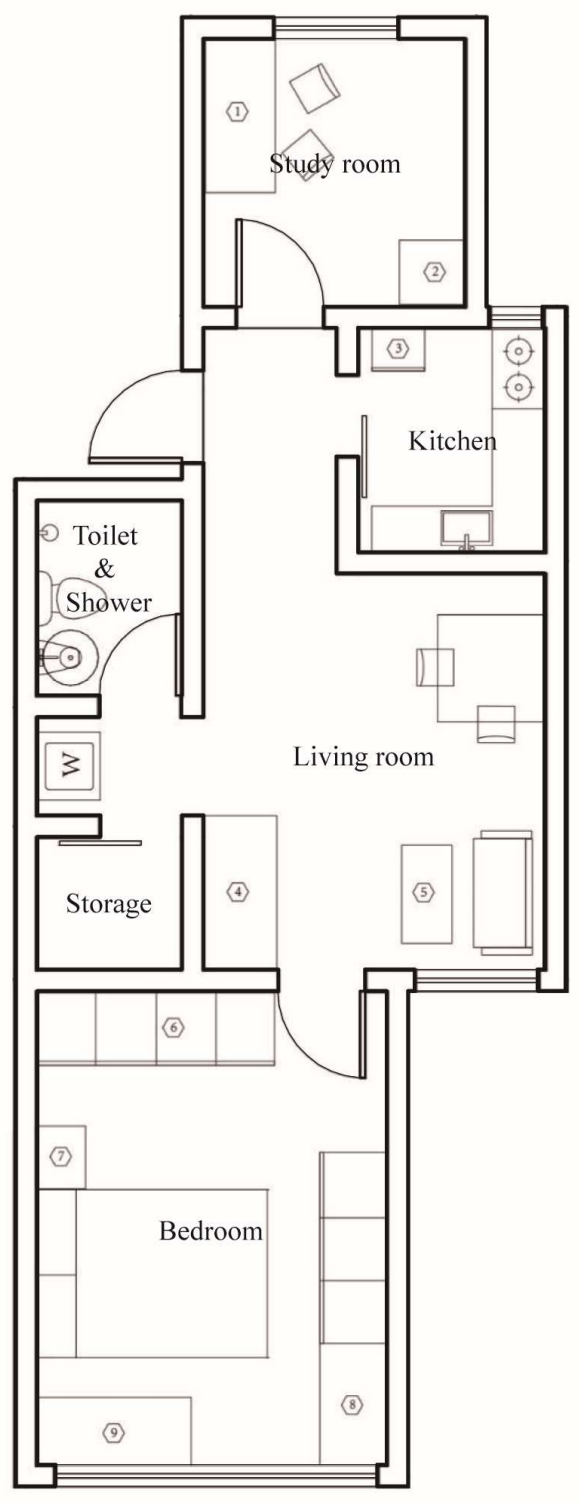

Original plan

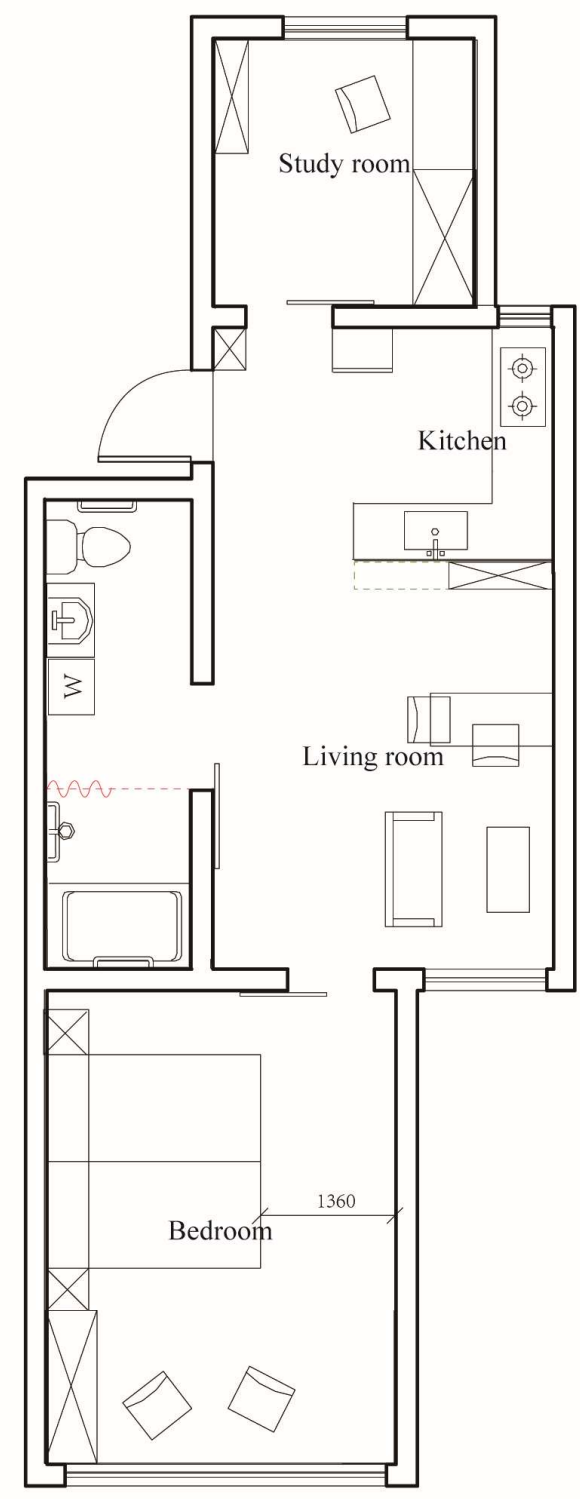

Redesigned plan

Figure 6.1 Original and redesigned plan 


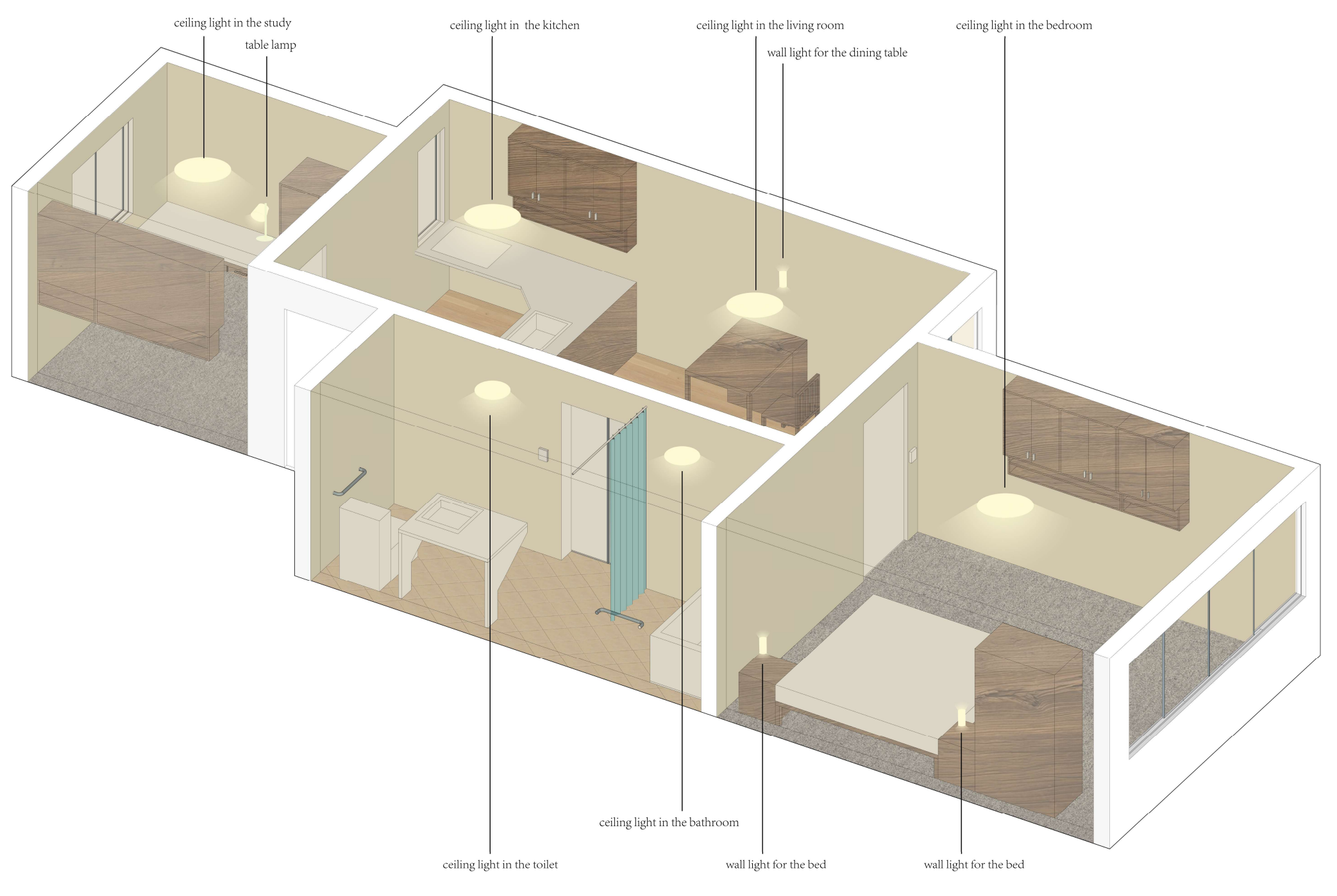

Figure 6.2 Lighting 


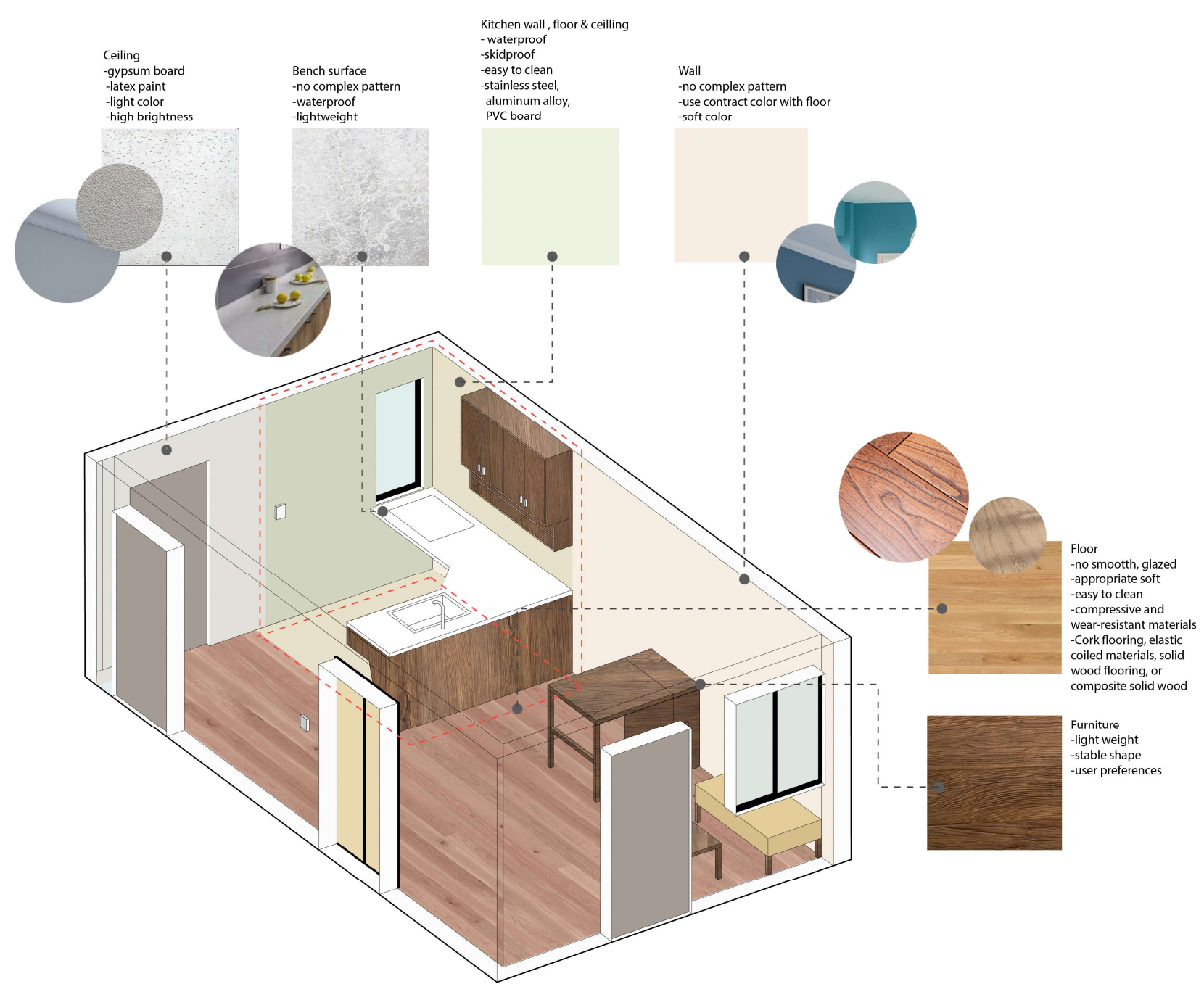

Figure 6.3 Living room and kitchen 1 


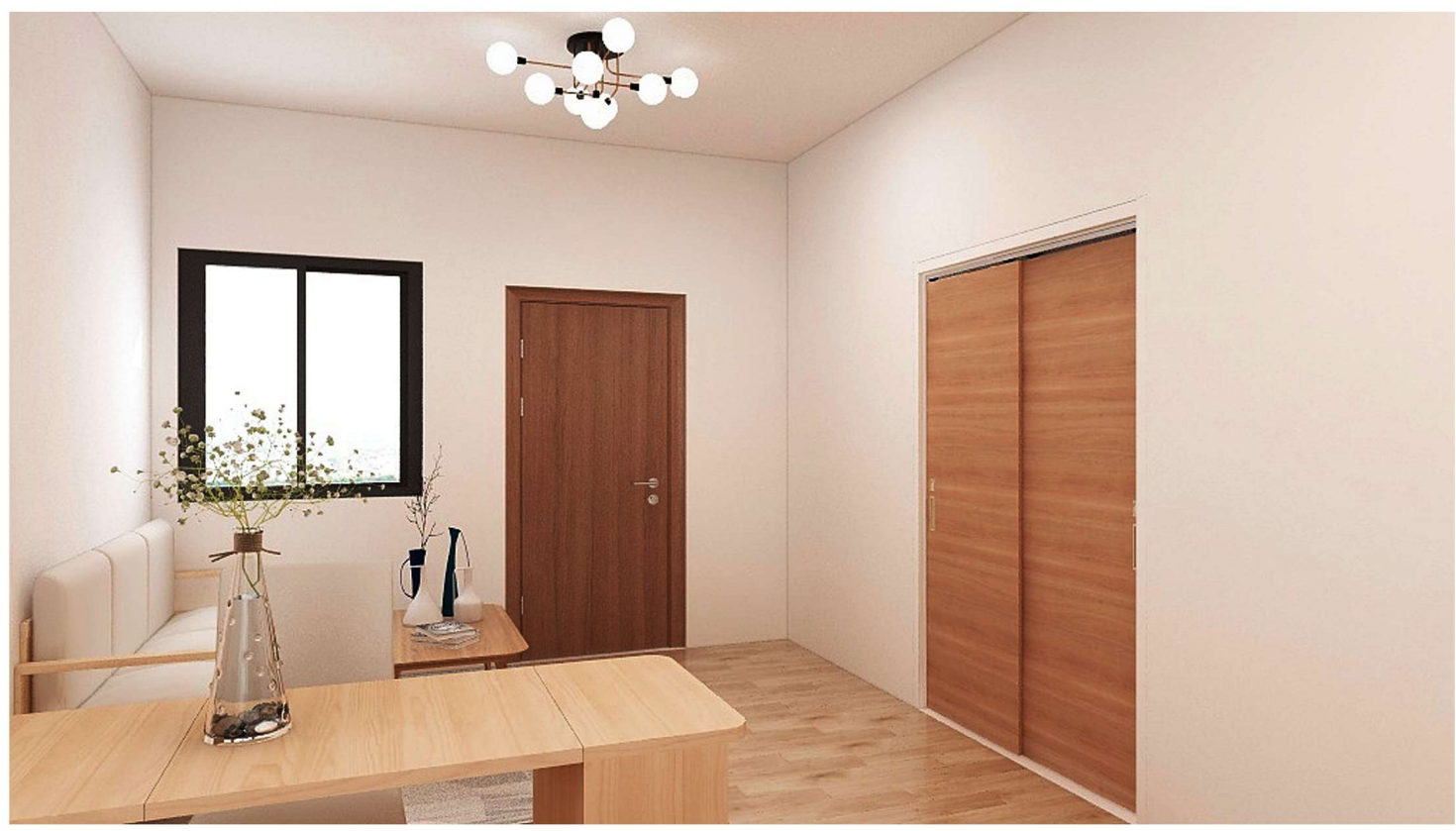

Living room 1

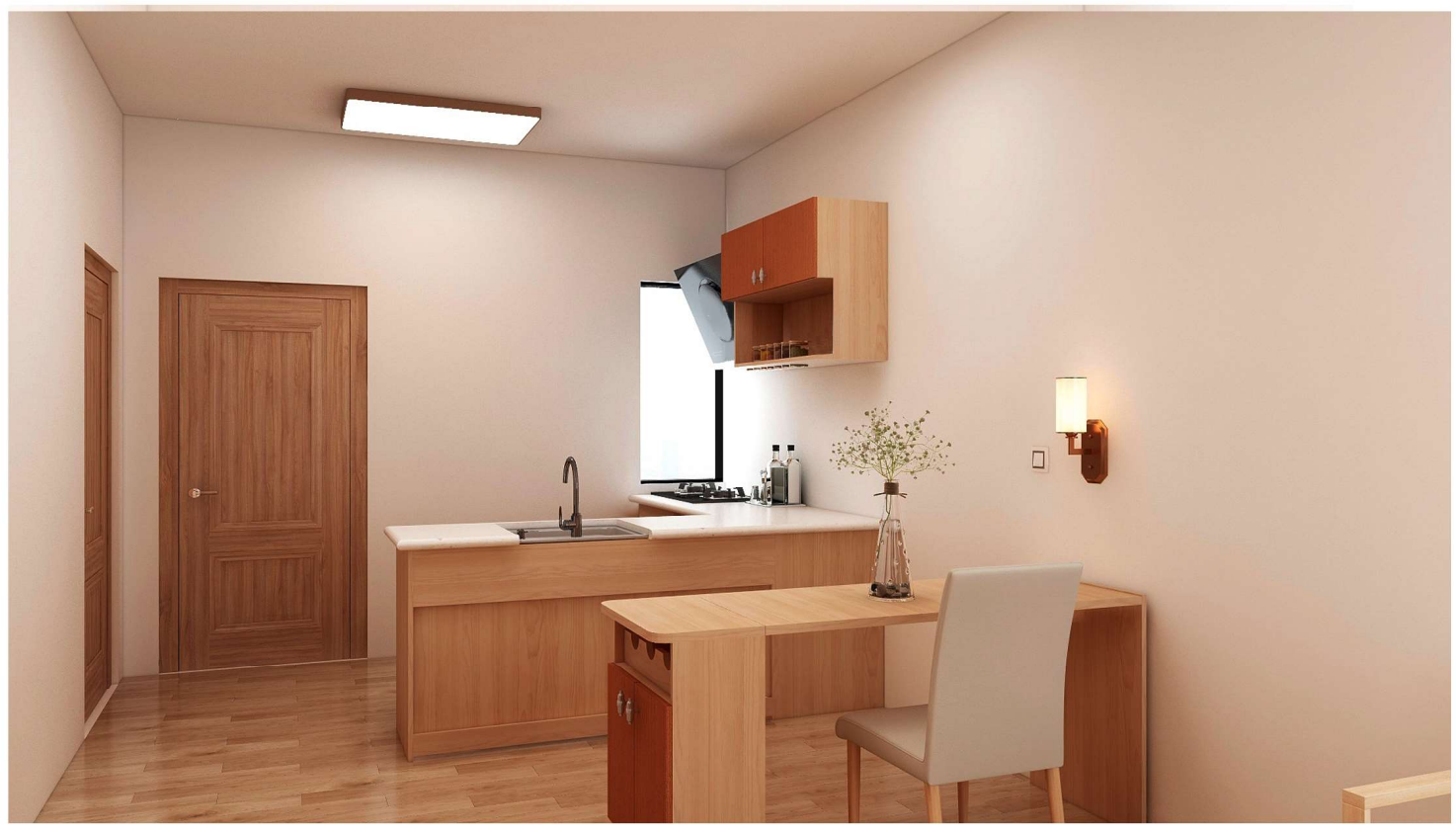

Living room 2

Figure 6.4 Living room and kitchen 2 


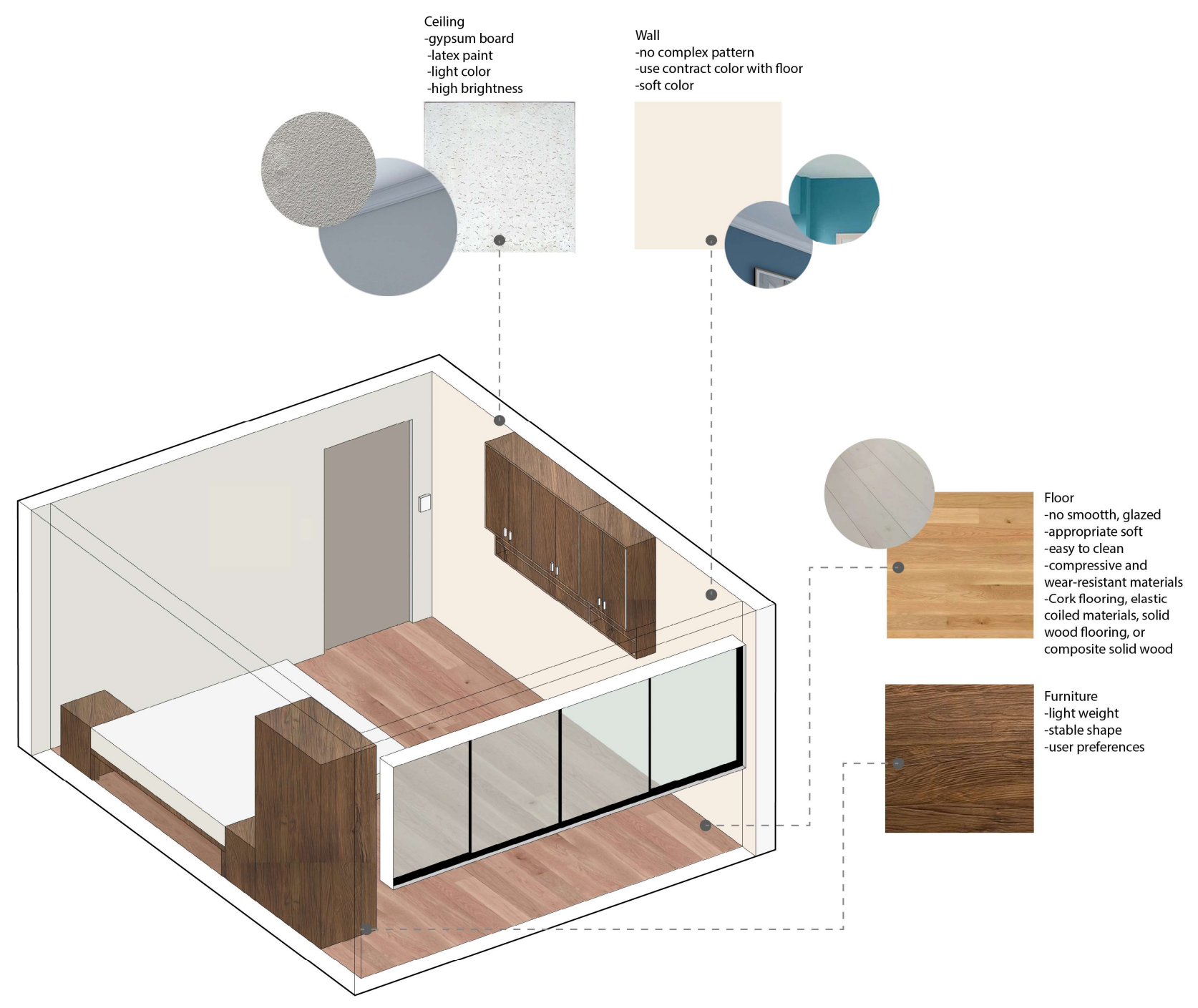

Figure 6.5 Bedroom 1 


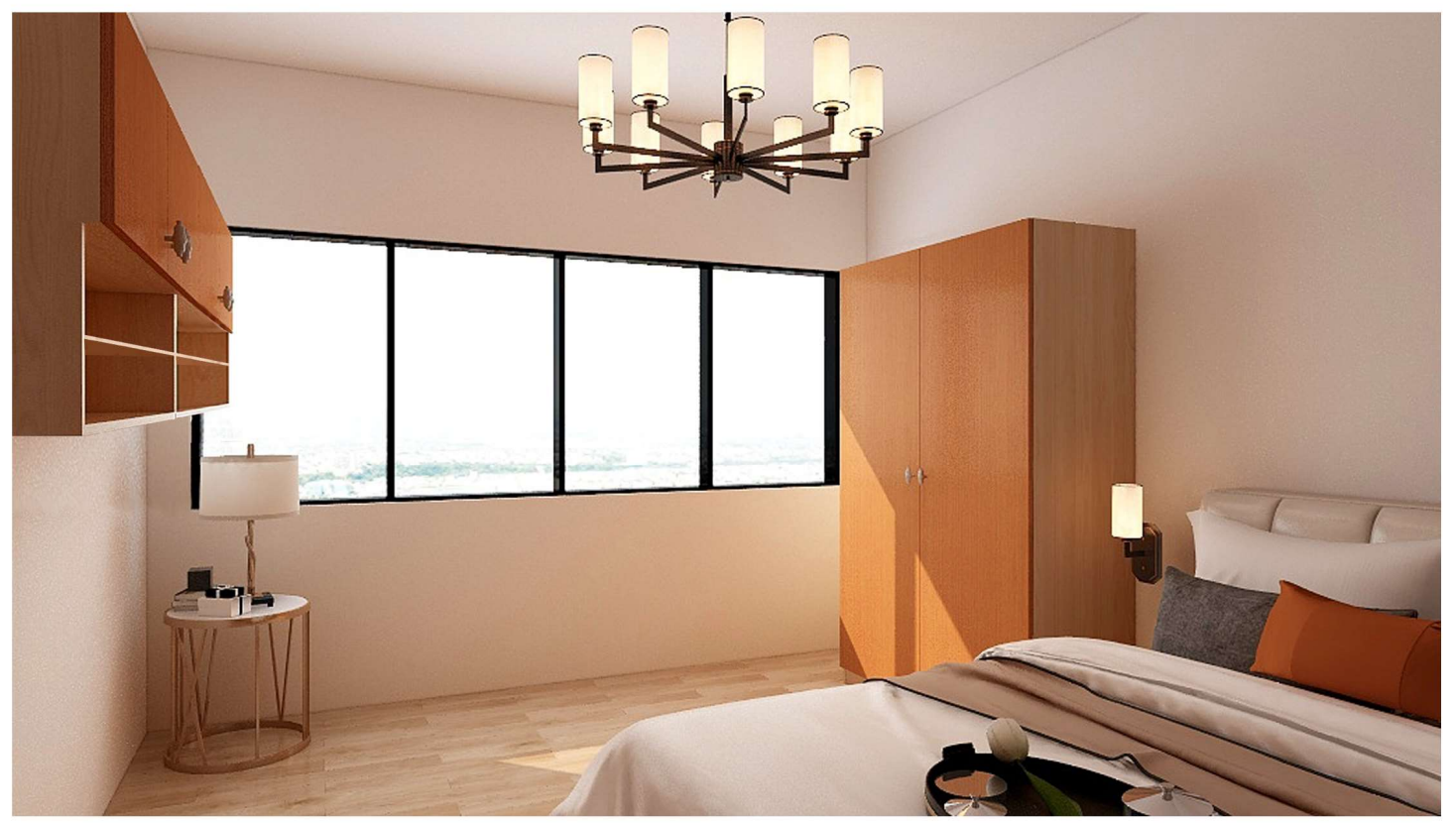

Bedroom 1

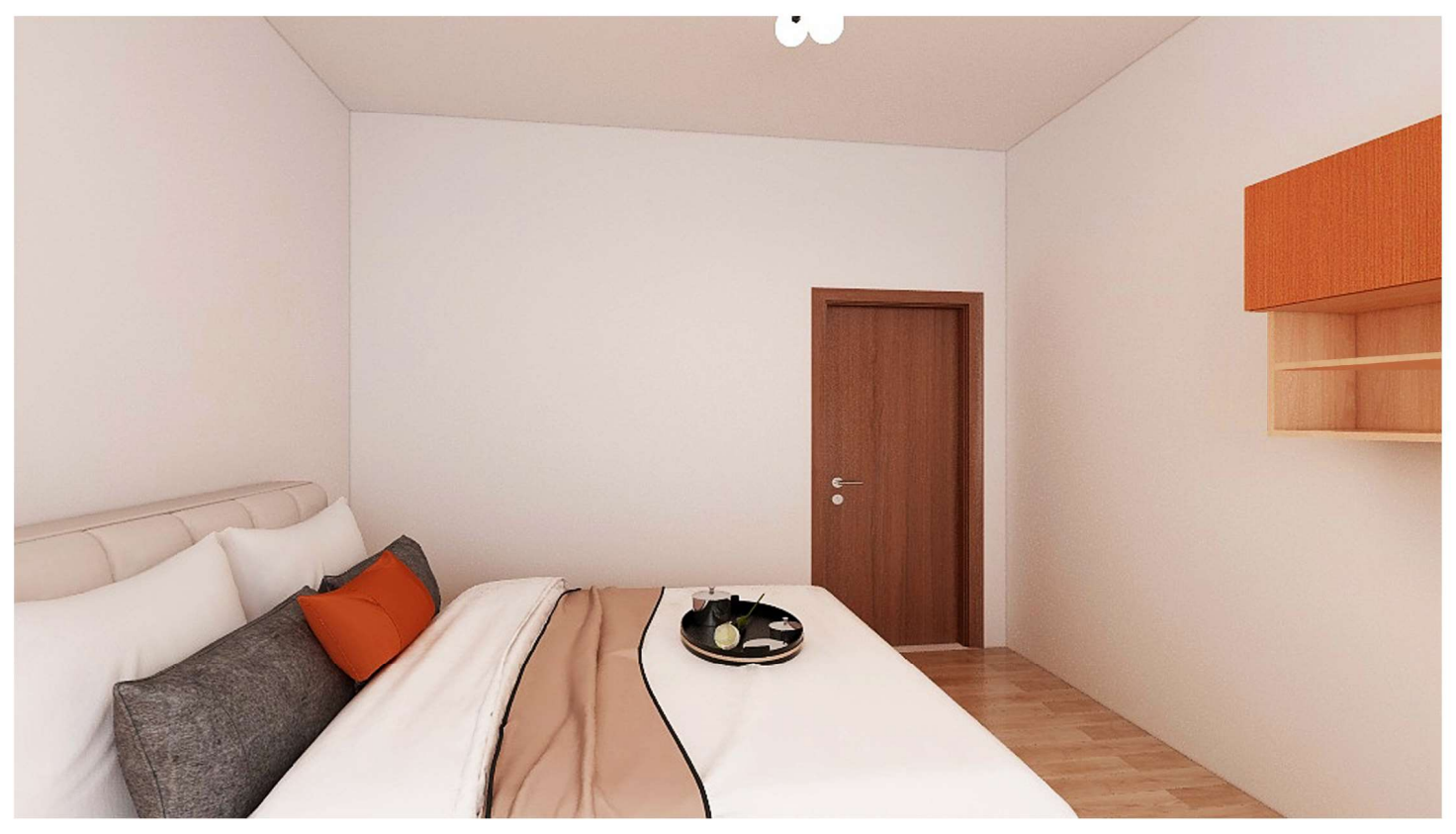

Bedroom 2

Figure 6.6 Bedroom 2 


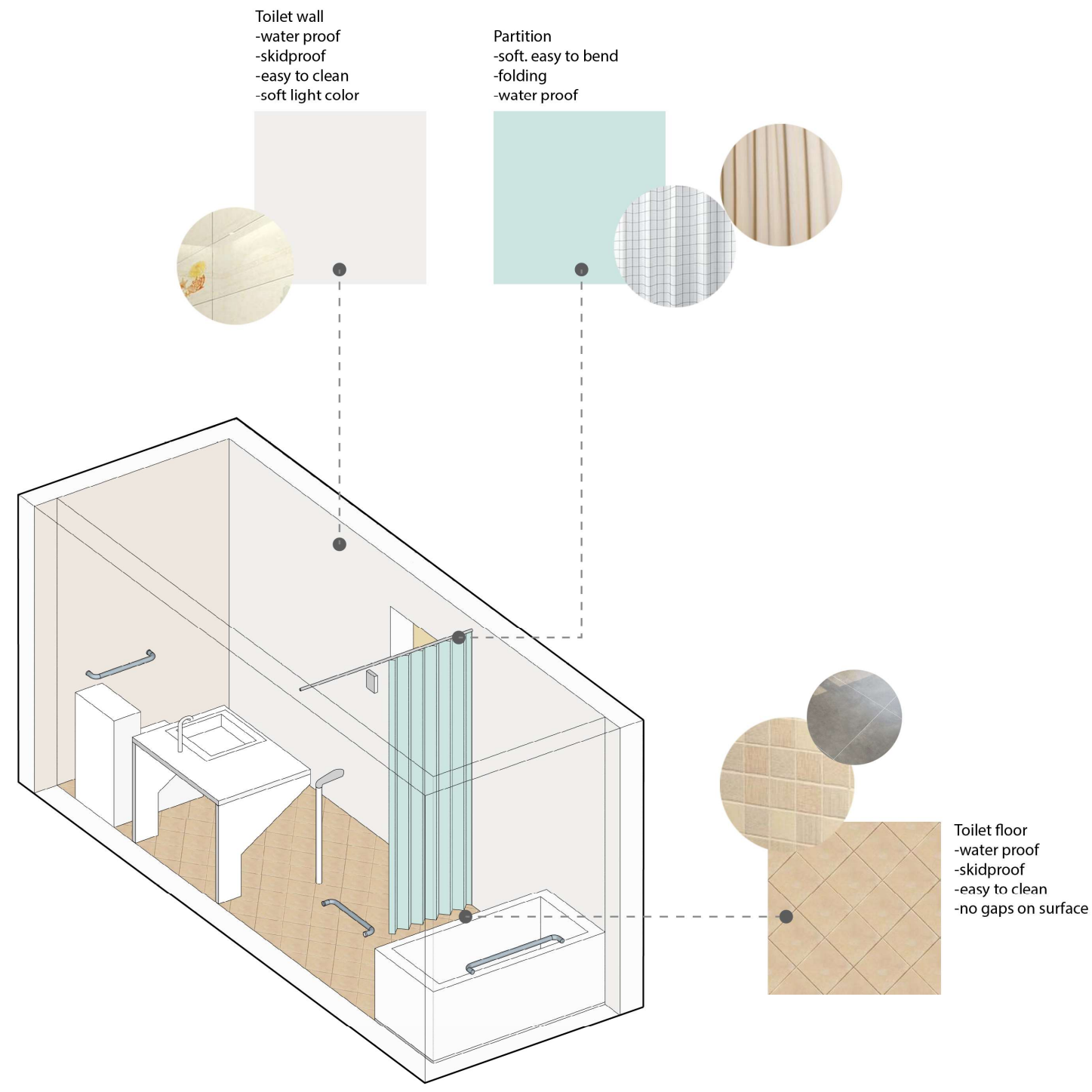

Figure 6.7 Bathroom 


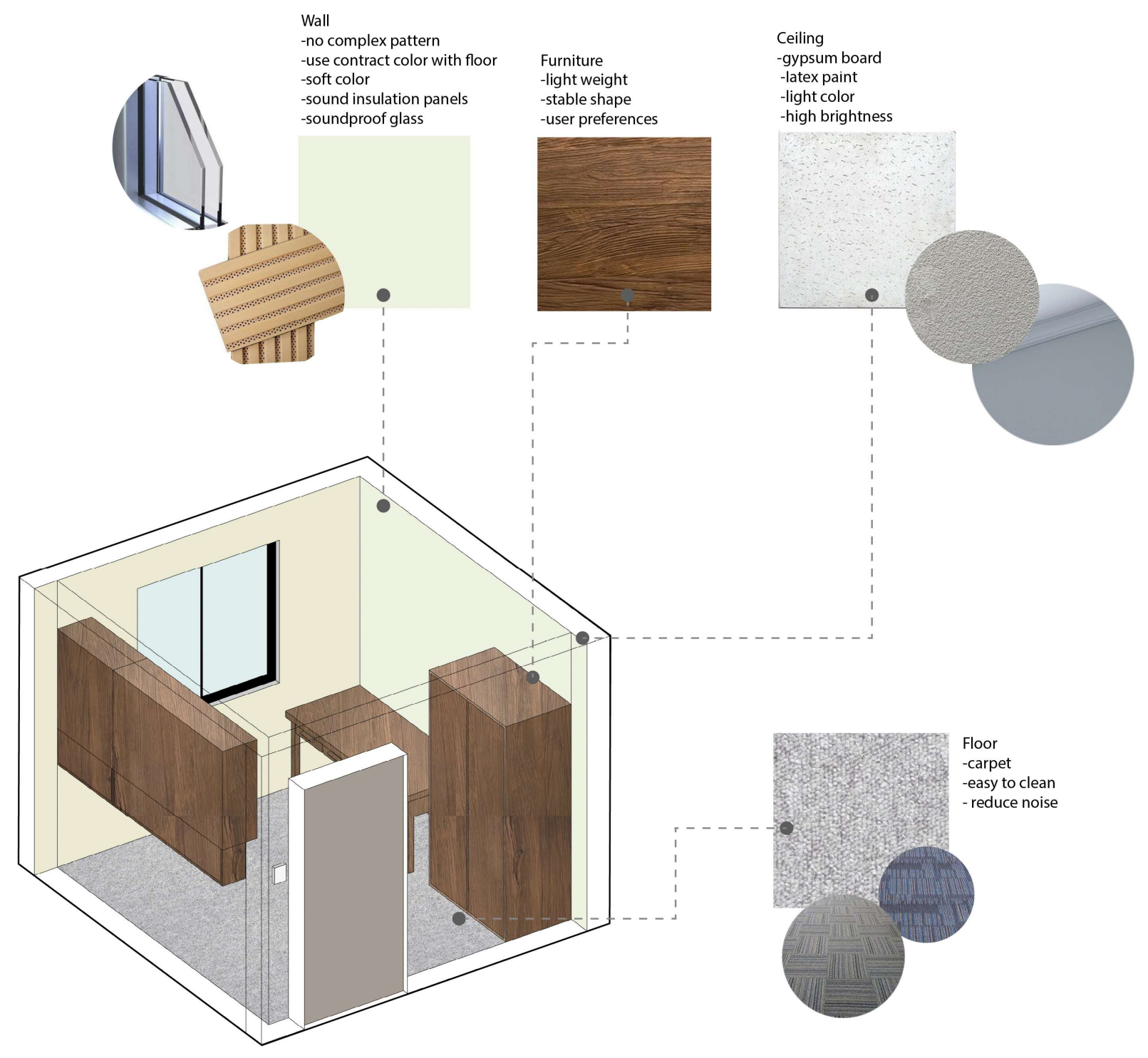

Figure 6.8 Study 


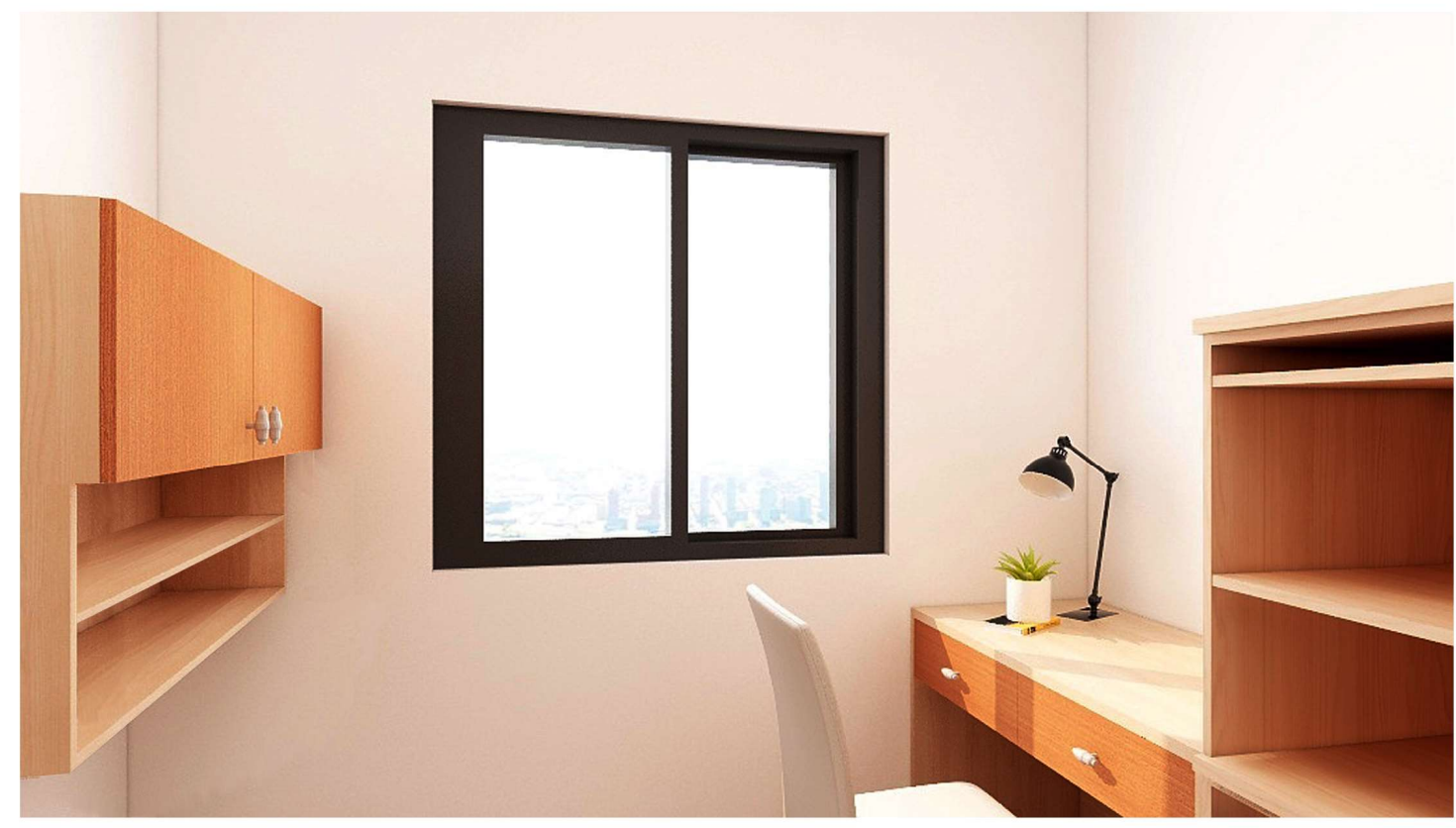

Study

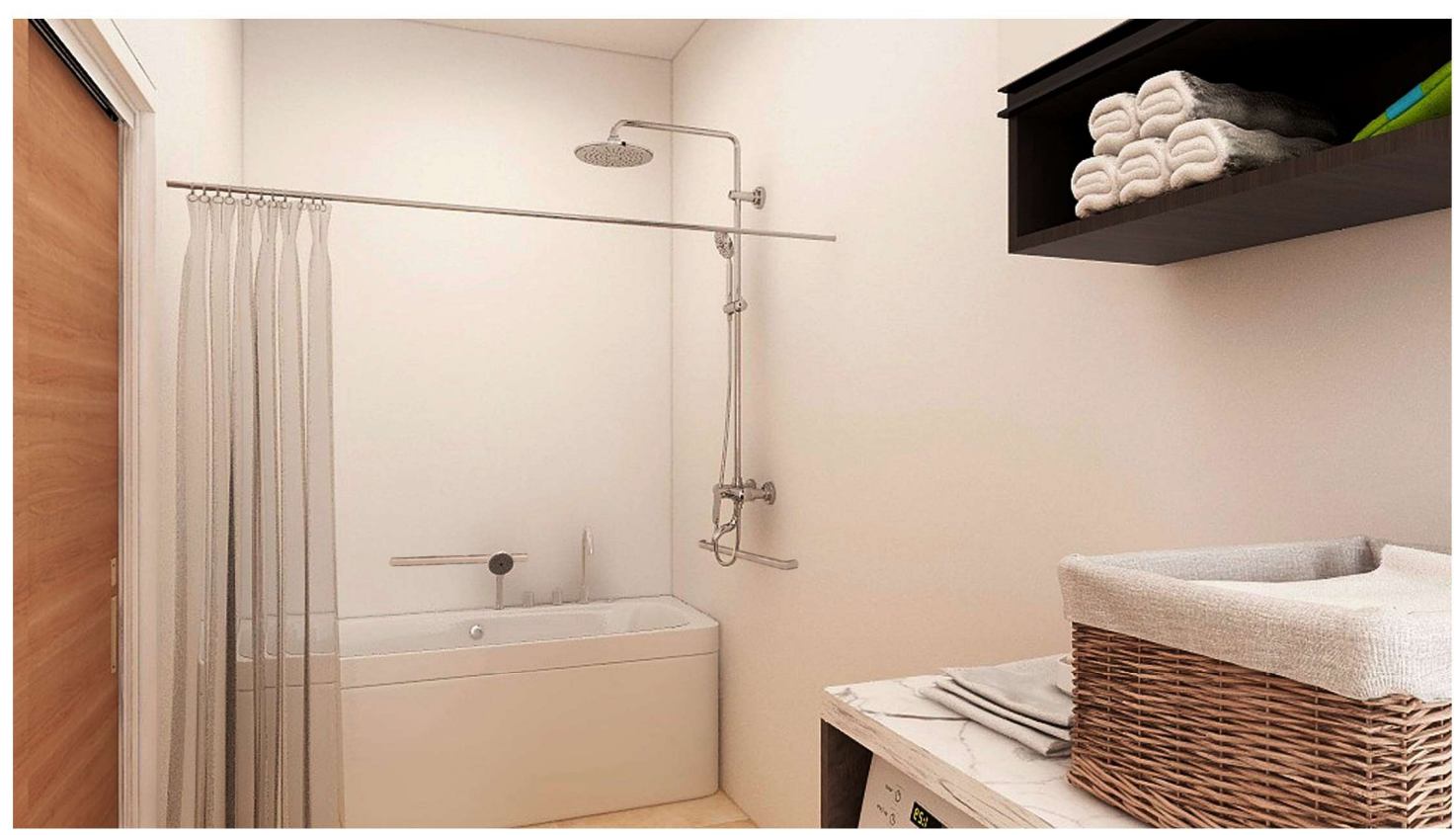

Bathroom

Figure 6.9 Bathroom and study 


\section{Conclusion and Critical Reflection}

\section{Research outcome}

This thesis explores the current problems of home care faced by the older people in China in the context of an aging society. Using the UD principles as a starting point, it analyzes and summarizes the problems of the predominantly 1980s-1990s dwelling and proposes solutions. The specific contents and results of the study are as follows :

1. in the context of the aging population, the relevant social situation and design concepts are studied and discussed from the perspective of older people housing and universal design concepts, which provides the theoretical basis for the thesis

2. The analysis summarizes the special psychological and physiological problems and behavioral characteristics of older people. It provides a factual basis for the renovation of residential buildings for aging.

3. representatives of the homes within the scope of the study were selected for practical investigation to provide the target audience for the design.

4. the survey made the universal design case of the senior housing, which was able to inform the research of this paper only. 


\section{Knowledge and understanding}

Through design practice, the author came across the following points that had been overlooked prior to the design phase.

1. due to the limitation from the layout of flat 201, the researcher considered how to extend the space on the original universal design principles in order to ensure the minimum dimensional requirements of the universal design principles. For example, in order to ensure that the range of movement of the elderly was not restricted, the researcher used a folding table and specially designed wall cabinets, and ensured that each space had a maximum width walkway and a circular space with a radius of $1500 \mathrm{~mm}$ to allow wheelchairs to turn.

2. In practice, the needs of the users also need to be taken into account and this often becomes an interfering factor in the design. For example, user B has mobility problems and is at high risk of becoming immobile in the future. Therefore, in the design, the author has focused on the interaction and movement routes of the wheelchair user with the space. To ensure that the design content meets the needs of the user 30 years into the future.

3. In practice, design solutions often need to be changed according to the facts of the situation. During the design process, the author found that some of the walls could not be removed, so new solutions had to be made to the initial structure of the space. While retaining the basic load-bearing walls, the author removed all non-loadbearing walls to ensure maximum use of the space and to simplify the user's route of movement within the space. 


\section{Limitation}

Geographical limitations

The cases mentioned in the site analysis and retrofit design in this article are commercial residences in East China. Due to regional environmental differences, it may not apply to anyone in all areas.

\section{Group Limitations}

The residential age-appropriate renovation studied in this paper meets that most older people's everyday needs as far as possible, but each older person's specific situation is different. This study is mainly aimed at a group of older people who are over 60 years old and have a certain degree of self-care ability. However, it does not apply to some of the older people with severe physical and mental disabilities. The design process of thesis focuses on how to meet the needs of user A and B. The main points in the design chapters do not cover the entire group of older people. For example, the memory loss of older people mentioned in the UD chapter is not highlighted in the subsequent design. Therefore, the differences of needs of individual users also influence the design in practice.

\section{Professional Limitations}

This thesis only gives retrofit recommendations from a design perspective. Therefore, it does not consider the actual situation and the problems faced in the subsequent implementation process. The promotion of a good design concept requires the government, real estate developers, and other organizations' attention and cooperation. Also, this paper's design mainly gives suggestions for a typical 1 bedroom, 1 bathroom apartment in flat 201, so there may be some limitations for other existing apartments in the 80 s. It is necessary to adapt the design to the local 
conditions and analyze the individual cases. 


\section{References}

A. Bowling and P. Dieppe, "What is successful ageing and who should define it?" British Medical Journal, vol. 331, no. 7531, pp. 1548-1551, 2005.

Boshchetti MA (2002) An observational study of older people's use of standard US kitchens. Housing and Society 29: 1-12

Crews DE (2005) Artificial environments and an aging population: designing for agerelated functional losses. Physiol Anthropol Appl Hum Sci 24: 103-109

Croll EJ. Social welfare reform: trends and tensions. China Q. 1999;159:684-99

C. J. Deardorff and C. Birdsong, "Universal design: clarifying a common vocabulary," Housing and Society, vol. 30, no. 2, pp.119-138, 2003.

D. E. Crews and S. Zavotka, "Aging, disability, and frailty: implications for universal design," Journal of Physiological Anthropology, vol. 25, no. 1, pp. 113-118, 2006.

D. L. Charbonneau-Lyons, P. M. Mosher-Ashley, and M. Stanford-Pollock, "Opinions of college students and independent-living adults regarding successful aging," Educational Gerontology, vol. 28, no. 10, pp. 823-833, 2002

Gu D, Dupre ME, Liu G. Characteristics of the institutionalized and community-residing oldest-old in China. Soc Sci Med. 2007;64(4): 871-83.

J.W. Rowe and R. L. Kahn, "Human aging: usual and successful," Science, vol. 237, no. 4811, pp. 143-149, 1987.

J. M. Guralnik, L. P. Fried, and M. E. Salive, "Disability as a public health outcome in the aging population," Annual Review of Public Health, vol. 17, pp. 25-46, 1996. 
J. E. Hertz and C. A. Anschutz, "Relationships among perceived enactment of autonomy, self-care, and holistic health in community-dwelling older adults," Journal of Holistic Nursing, vol. 20, no. 2, pp. 166-186, 2002.

K. E. Thorpe and M. Philyaw, "The medicalization of chronic disease and costs," Annual Review of Public Health, vol. 33, pp.409-423, 2012Lawton MP (1980) Environment and aging. Brooks-Cole,Monterey

Lue Junhua, Peter G. Rowe and Zhang Jie. Modern Urban housing in China 1840-2000, pp.231, 2001.

Lawton MP, Simon B (1968) The ecology of social relationships in housing for the elderly. Gerontologist 8: ,pp 109-115

L. W. Guse and M. A. Masesar, "Quality of life and successfulaging in long-term care: perceptions of residents," Issues in Mental Health Nursing, vol. 20, no. 6, pp. 527-539, 1999.

Mullick, A., "Bathroom Lifts," Buffalo, N.Y.: Center for Inclusive Design and Environmental Design, University at Buffalo, 1993

M. Levasseur, L. Richard, L. Gauvin, and E. Raymond, "Inventory and analysis of definitions of social participation found in the aging literature: proposed taxonomy of social activities," Social Science and Medicine, vol. 71, no. 12, pp. 2141-2149, 2010

Null R, Cherry K (1996) Universal design: creative solutions for ADA compliance. Professional Publications, Belmont. pp. 23-48

Null R, Cherry K (1996) Universal design: creative solutions for ADA compliance. Professional Publications, Belmont, pp. 35-65 
Ontario Ministry of Community and Social Services, "About the Accessibility for Ontarians with Disabilities Act (AODA), 2005," Catalogue 7710-AODA-B01, Queen's Printer for Ontario, Toronto, Canada, pp. 34-58, 2008.

R. B. Tate, L. Lah, and T. E. Cuddy, "Definition of successful aging by elderly canadian males: the Manitoba Follow-Up Study," The Gerontologist, vol. 43, no. 5, pp. 735-744, 2003

S. Iwarsson and A. Stahl, “Accessibility, usability and universal design_- positioning and definition of concepts describing person-environment relationships," Disability and Rehabilitation, vol. 25, no. 2, pp. 57-66, 2003.

Shang X. Moving toward a multilevel and multi-pillar system: changes in institutional care in two Chinese cities. J Soc Policy. 2001; 30(2):259-81.

T. Lang, T. Streeper, P. Cawthon, K. Baldwin, D. R. Taaffe, and T. B. Harris, “Sarcopenia: etiology, clinical consequences,intervention, and assessment," Osteoporosis International, vol. 21, no. 4, pp. 543-559, 2010.

T. Hedden and J. D. E. Gabrieli, "Insights into the ageing mind: a view from cognitive neuroscience," Nature Reviews Neuroscience, vol. 5, no. 2, pp. 87-96, 2004.

U. Lindenberger and P. Ghisletta, "Cognitive and sensory declines in old age: gauging the evidence for a common cause," Psychology and Aging, vol. 24, no. 1, pp. 1-16, 2009.

United Nations. World population prospects: the 2010 revision, pp. 1, 2010.

WANG Zhuang, The Functional Design of Senile Apartment : Journal of Jilin Teachers, Institute of Engineering and Technology, 26, pp. 21-22, 2010.

Wong L, Tang J. Non-state care homes for older people as third sector organizations in 
China's transitional welfare economy. J Soc Policy. 2006; 35(2):229-46.

Yanmin Z. Lao Ren jia Collection of housing renovation design. pp. 8,128-136, 2012.

Yanmin Z. Housing for the Elderly. pp. 21-36, 2018.

Zavotka S, Teaford M (1997) The design of shared social spaces in assisted living for older adults. J Interior Design 23: 2-16

Zhao LX. On community construction and community \& home-based care of the elders. Popul J 2004;3:35e9. 


\section{Appendix:}

\section{A. Based on the location:}

\section{Are you facing any problems related to the current living home? Brief out.}

\section{Answer:}

The bathroom is small and the toilet is too close to the shower area.

The north-facing study room has poor lighting for reading, and they need to turn on the lamp to read during the day.

There was a height difference ( $30 \mathrm{~mm}$ approximately) between the wooden floor and the tiled floor. User B took a fall for it 3 years ago.

The distance of the top cabinet is too high, they need to step on the ladder every time when they want to take stuff from the top cabinet.

2. Based on the location, do you feel you are having fresh air in the surrounding environment?

\section{Answer:}

The bedroom and living room are well ventilated.

But there is only one window in the toilet leads to the outside, and the window is 
pretty small. User B expresses that the water vapor always accumulates in the room after taking a shower.

3. Do you feel the discomfort of hearing high noise levels from the traffic from nearby the vicinity?

Answer:

The study room is closer to the road outside, and it is easy to hear noise during the day.

4. Are you satisfied with the total carpet or floor area provided by the authority?

Answer:

Basically satisfied. Due to brick-concretestructure, it cannot be expanded anymore, and the utilization rate can only be expanded from the perspective of space height.

5. Tell us in brief, if you are missing with a specific amenity?

Answer:

Elevator. 
6. For a personal comfort prospective, are you aware of the present toilet pattern?

Answer:

Poor ventilation in the toilet, small space, and accumulation of water vapor.

7. a. Do you go for social gathering with same age group in nearby park or any recreational area?

Answer:

Fewer social interactions. Both parties prefer a quiet environment

b. Does the nearby park or recreational area was located in the same locality

\section{Answer:}

The park is close to the home. Due to inconvenience of slow movement of older people, they seldom go to the park. However, the traffic is very convenient, and there is a bus stop in front of the community.

8. What are your hobbies and habits? Can you talk about a 


\title{
general description of your daily life?
}

\begin{abstract}
Answer:
User A

He worked as a surgeon before retiring. Although he is old, he has a clear mind and he likes to accept new things. His daily hobbies are playing games online and reading medical journals and newspapers. He suffers from diabetes, in addition to being in good health and being able to take care of himself. He is used to getting up early and going to bed every day, and also stays in bed for a short time during the day. On sunny days, he like to stand by the window to smoke, to bask in the sun, and to look out over the crowd at the window.
\end{abstract}

User B

After she retired, she spent most of her time on doing housework. She likes a neat and orderly lifestyle, so she organizes the kitchen and bedrooms every day. In addition, she will ask the hourly worker to do house cleaning once a week. She suffered from heart disease, high blood pressure. And due to her age, she suffered from hearing loss and vision loss, slow walking and other characteristics of physical aging. But she still insists on doing basic life self-care, and only needs to help her family if she can't handle things such as carrying heavy objects or walking for a long time. Sometimes her legs will be sore and swollen because of standing, and it is inconvenient to move. Her hobbies on weekdays are grow flowers, watch TV and read. In addition, she is a Christian. She usually reads the Bible and writes reading thoughts in her free time. Therefore, she hopes to have a quiet space for reading. 


\section{B. Based on the functions}

\section{Lighting:}

1. Do you have sufficient light to undertake daily tasks (e.g., cooking, reading, doing the dishes, washing clothes)? Expand as you need to answer this.

\section{Answer:}

Need to turning on the lights when they are reading.

The toilets and storage rooms are very dark.

2. Do you have enough natural light from windows?

\section{Answer:}

Windows are enough. But some windows did not play a role in light transmission.

For example, the small window of the toilet is basically used to ventilate.

3. Which rooms or spaces in your home do you think are well- 
lit?

Answer:

There is plenty of natural light in the bedroom and living room.

Especially in the bedroom, there is no need to turn on the lights during the day.

4. Which rooms or spaces in your home do you think are poorlylit?

Answer:

Toilet and storage.

5. What would you change about the lighting if you could?

\section{Answer:}

They hope to add some warm colours to make the atmosphere warmer.

6. Do you like the colors in your home?

Answer:

Yes. They like wood texture and colour 
7. Do the colors in your home make it easy to see the different surfaces, for example, different steps?

Answer:

No.

Kitchen:

1. Is the kitchen large enough for preparing and cooking food? Answer:

The kitchen cannot accommodate two people at the same time

2. Is there sufficient storage space in your kitchen?

Answer:

Yes.

3. Is there enough space in your kitchen for appliances and 
cooking utensils and equipment, such as a refrigerator and oven?

Answer:

Yes

4. Can you do all the activities you need to in your kitchen?

Answer:

Yes.

5. Is it easy to clean the kitchen?

Answer:

No, some corners are difficult to clean.

6. Is there anything about how your kitchen is designed that makes it difficult to use?

Answer:

The gaps between the workbench and the wall are too large, making it difficult to clean. Items on the upper level of the top cabinet are not easily to catch. 
7. Is there anything you would change about the kitchen if you could?

Answer:

I hope the kitchen has more space.

Bathroom and Toilet:

1.Is there enough space in the bathroom and toilet spaces for washing and using the toilet?

Answer:

No.

2. Is there sufficient storage space in your bathroom?

Answer:

No.

3. Is there enough space in your bathroom for appliances such 
as a washing machine and clothes dryer?

Answer:

No.

4. Can you do all the activities you need to in your bathroom?

Answer:

No. Need to keep standing when they are taking shower.

5. Is it easy to clean the bathroom and toilet?

Answer:

Yes.

6. Is there anything about how your bathroom is designed that makes it difficult to use?

Answer:

The space is too small.

7. Is there anything you would change about your bathroom if 
you could?

Answer:

They want a space to install a bathtub

General function:

1.Is there enough storage in your home?

Answer:

Yes.

2. Is the layout or organization of space appropriate for your needs?

Answer:

The storage space is too concern traded in one place.

3. Is there anything you would change about the way the space 
is organized in your home if you could change it?

Answer:

Hope to divided the storage into small space in various areas

4. What can you see from your windows? Is there anything you wish you could see from your windows that you can't see?

Answer:

Streets and other flats.

5. Have you ever tripped over in your home? are there things that you think would make your home safer to be in if they were changed?

\section{Answer:}

Yes. The kitchen floor is very slippery when it gets wet, and there is a height difference between the corridor floor and kitchen floor. There is high possibility of causing injury due to this slippery floor.

6. Is your home a good place to invite family to stay and to look 


\section{after visitors?}

Answer:

No.

7. Is there anything difficult about how the space in your home is organized?

\section{Answer:}

The kitchen and dining room are separate. Hope to strengthen the connection between these two.

8. Do you find your home comfortable to live in?

Answer:

Not too bad.

9. Is there anything that could be changed to make your home 
more comfortable to live in?

\section{Answer:}

The storage can be removed. Increase the bathroom area. 


\section{Design Considerations}

1. Do you think that old age home construction should have separate design codes addressing the comfort parameters?

Answer:

Yes. User B has some trouble with walk for a long time, so she hopes that everything can be placed within easy reach

2. In concern with medical grounds, does the new design of buildings should include specific medication room with equipment's like (Nebulizer, physiotherapy, acupuncture \& etc.)

\section{Answer:}

User B has heart disease and high blood pressure. Although she doesn't need to go to the hospital often, but she needs to take medicine every day. She thinks she needs an emergency rescue device

3. Do you feel, having private room with having accessible with your own belongings is required?

a. 1. Agree 2. Strongly agree 3. strongly disagree 4. disagree 


\section{N/A}

b. If required what could be the desired size of the private room

\section{Answer:}

Not applicable. Because the internal space is small, there is no too much private space.

Fortunately, their hobbies are reading, so they think both of them are used to sharing one reading area. The only requirement is that the reading area needs to be sufficiently quiet.

4. Are you aware of smart technologies evolved recent days, are you happy of adopting features (automatic power on/off of home utilities) can improve standard of living?

Answer:

A quite space for two people to read and rest.

5. Can you address any specific issue you were facing, that can 
be treated as a major requirement for the present day leaving?

Answer:

Yes. Both of them believe that smart technology can be added to better assist daily life.

6. Did you feel of having specific colours that can improve peace of mind and to reduce visual impact?

\section{Answer:}

They both like warm colors and prefer wood furniture.

7. Based on the present location of your residence, do you feel any discomfort to access the nearby medical supplies?

Answer:

The hospital is opposite the community. It is convenient to see doctors.

8. In specific with the furniture with in the house, do you feel of 
having light weight furniture or heavy weight?

Answer:

Both of them prefer to use wooden furniture.

9. In connection with emergency services, do you consider of having so systems like alarms etc should be incorporated as a mandatory feature?

Answer:

Both of them think that it is necessary to have emergency services. 


\section{The Practical Application of Universal Design Principles}

This part's basic design principles are derived from the indoor dimensions and layout principles for older people mentioned by Yanmin Zhou (2018) in the Housing for the Elderly. The book introduces in detail the general design ideas for older people's residences based on China's home care background for older people. It comprehensively explains the size standards of each space.

In the Housing for the elderly, Zhou summarizes the basic principles and elements that should be followed in older people's living space. Zhou analyzes the floor plans of typical Chinese dwellings from the perspectives of safety, practicality, health, and flexibility, and gives design suggestions from a practical point of view. This chapter analyzes the application of universal design principles to each living space from a typical Chinese dwelling design perspective. 


\subsection{Kitchen}

There are several design principles to follow in kitchen. These relate to sufficient space, bench layout, door location and ventilation and lighting.

\section{a. Provide reasonable operating space}

The dimension of $1800 \times 3100 \mathrm{~mm}$ (figure 2.1) is usually appropriate for an occupant who is not in a wheelchair. The narrow passage, however, is not suited for a person in a wheelchair. When considering User B's potential health deterioration, it is critical to include a design for people in a wheelchair.

Figure 2.1 also shows the appropriate design for a kitchen with features that allow wheelchair movement. The main factors considered in the design are sufficient space between the utilities, movement, and access to the shelves. The area is a bit more spacious to accommodate a wheelchair.

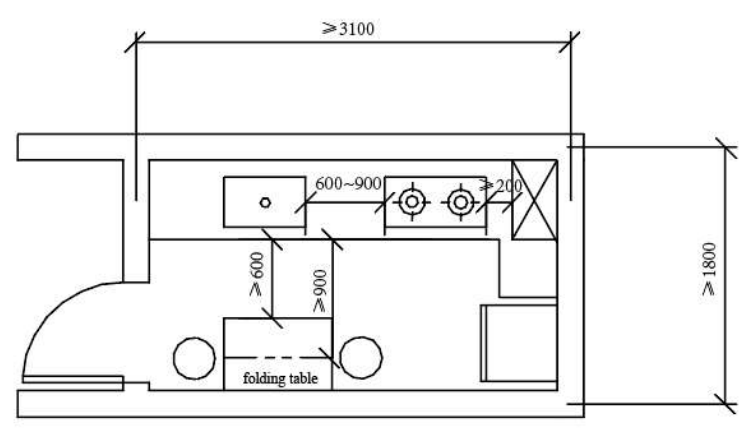

Kitchen for healthy elderly

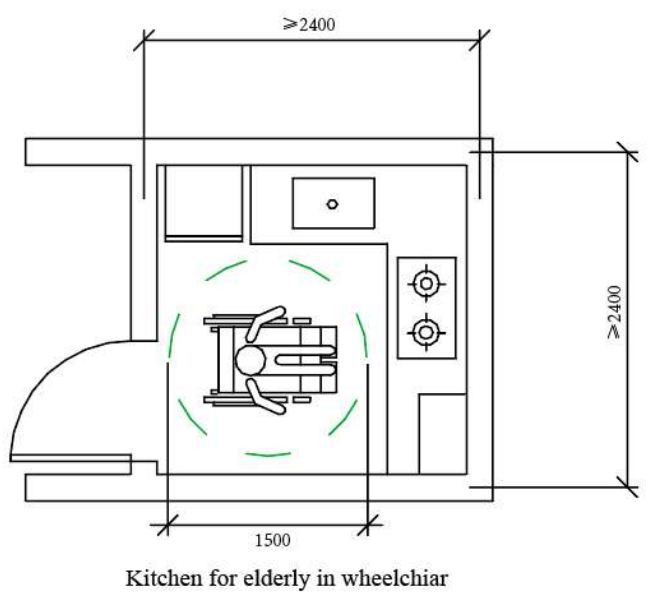




\section{b. A reasonable layout of the kitchen bench}

The console can be U- or L-shaped, which ensures that the user only needs to rotate in a 90-degree range to switch between multiple operations.

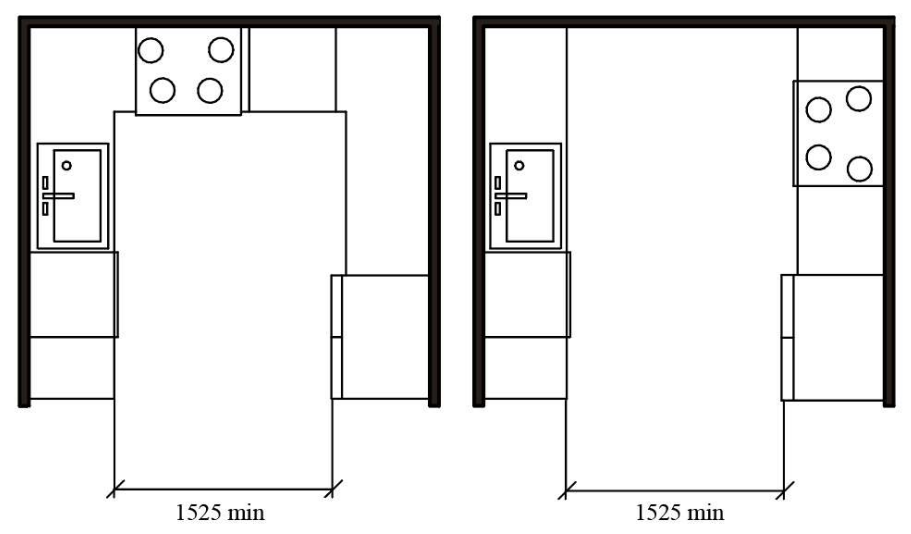

Figure 7.2 The required layout of kitchen bench

\section{c. The location of the kitchen door}

As Figure 2.3 shows, the door needs to be positioned at a sufficient distance from the console to avoid interference with the console caused by the opening action.

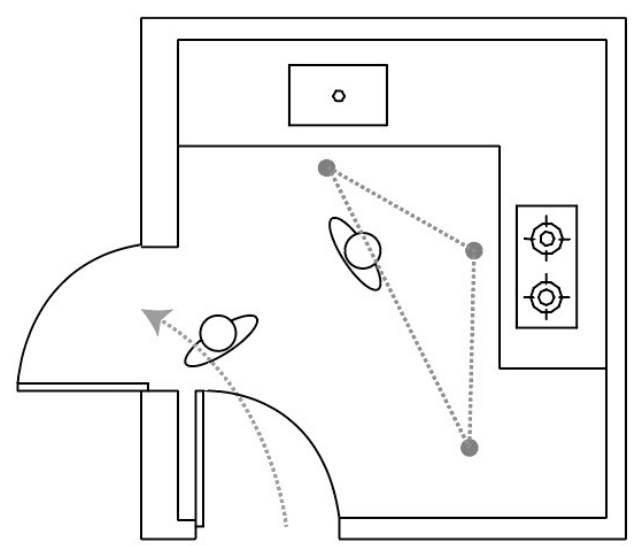

Figure 7.3 The location of kitchen door 


\section{d. Provide effective ventilation and lighting.}

According to the Residential Design Code, kitchens need to have openings that maintain direct light and natural ventilation. For older people, the main operating area of the kitchen needs to have a good range of light and ventilation. The effective area of the kitchen window should not be less than $0.6 \mathrm{~m}^{2}$.

\subsection{Bedroom}

There are several design principles to follow in bedroom:

\section{a. Provide reasonable space dimensions}

For older people's needs, the bedroom's width needs to be more than $3600 \mathrm{~mm}$, and the distance between the bed and the furniture should be greater than $800 \mathrm{~mm}$ to allow for wheelchair access.

The length of the bedroom should be in the range of 3600 to $4200 \mathrm{~mm}$. On the one hand, it is convenient to set aside an entire space as an activity area, and on the other hand, it is also convenient to change the position of the furniture at any time.

\section{b. Creating a concentrated space for activities}

As figure 2.4 shows, the bed needs to be set away from the walls to allow users move around them. In addition to allowing the user to move around the bed on a regular basis, sufficient space should also be available for wheelchairs and stretchers.

The activity space needs to be located close to windows so that the user can enjoy the sunshine or the outdoor view from the activity area. Alternatively, it can be located at the exit, leaving enough space for the wheelchair to turn. 


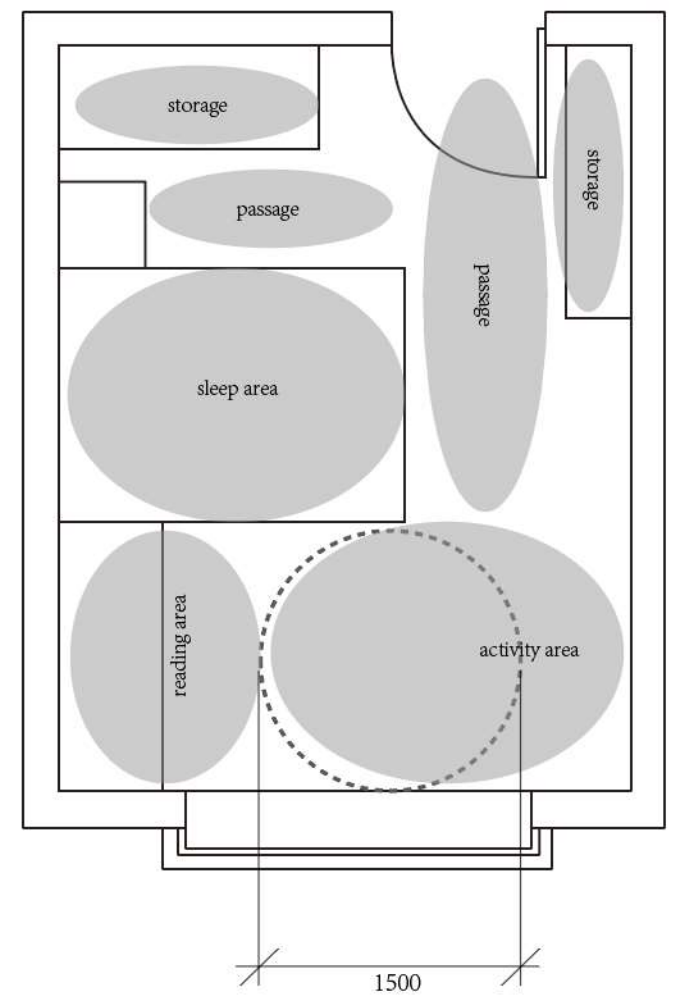

Figure 7.4 Layout of functional space in a bedroom

\section{c. Ensure the flexibility of furniture placement}

The shape and size of the bedroom space should allow for flexibility in the arrangement of the furniture so occupants can arrange the furniture according to their preferences. Therefore, more small and lightweight furniture is used. Also, avoid excessive use of fixed furniture that users can move the furniture at any time according to their preferences.

\section{d. Provide a comfortable resting space}

The sleeping area needs to be close to air circulation and sunlight. And there should be space around the bed that is convenient for older people to pass, organize and store things. The width of the channel needs to be kept above $600 \mathrm{~mm}$. For wheelchair users, the width needs to be maintained at $1500 \mathrm{~mm}$ and above to allow the wheelchair turn around. 


\subsection{Multi-functional areas}

There are several design principles to follow Multi-functional areas:

\section{a. The variability of functions}

Multi-functional space should preferably be no less than $2100 \mathrm{~mm}$, with an area of about 5-10m. Usually, the width of the aisle should be kept at least $900 \mathrm{~mm}$. For wheelchair users, the space of $1500 \mathrm{~mm}$ should be maintained to allow wheelchair turn around.

When the user is in good health, the multi-functional space can be used as a study room, a lounge, etc. The multi-functional space can be used as a study room or a lounge. When the user's health declines, the multi-purpose space can be used as a rehabilitation room.

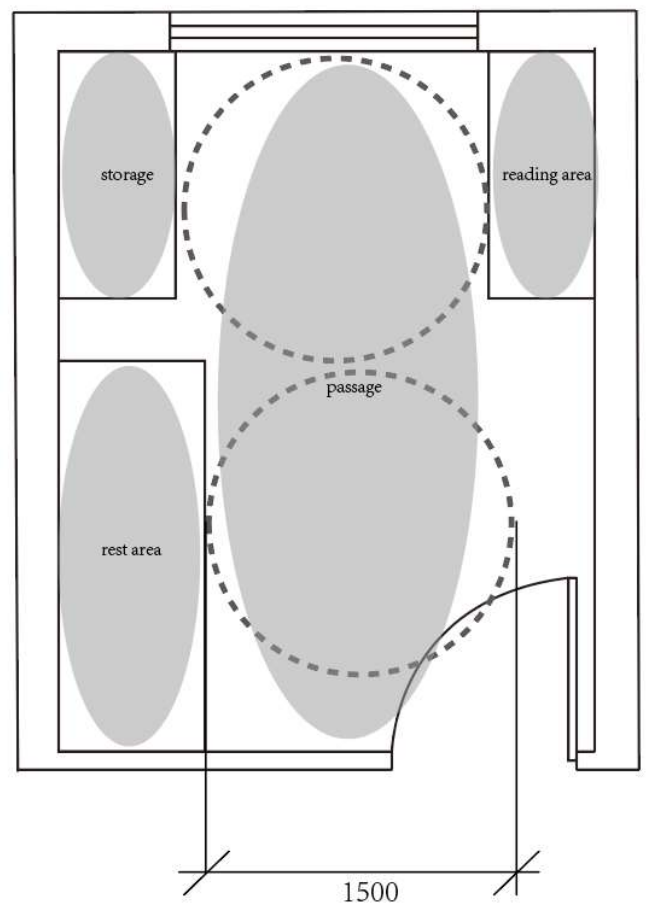

Figure 7.5 Layout of functional space in a Multi-functional area 


\section{b. Improve space utilization}

It is recommended for wheelchair-based occupants to have the room size bit bigger

than a regular room size. The bigger dimensioned room can provide 360 degrees access for people who use wheelchairs. 


\subsection{Living Room and Front lobby}

The living room design needs to follow these principles:

\section{a. Provide reasonable space dimensions}

Space issues are a significant factor for most of the residential design. It is recommended to join two rooms together if possible when there is insufficient space.

The lobby needs to meet the necessary activities of users such as changing shoes, dressing, and getting keys, but also space for receiving guests and medical staff and for using stretchers during first aid.

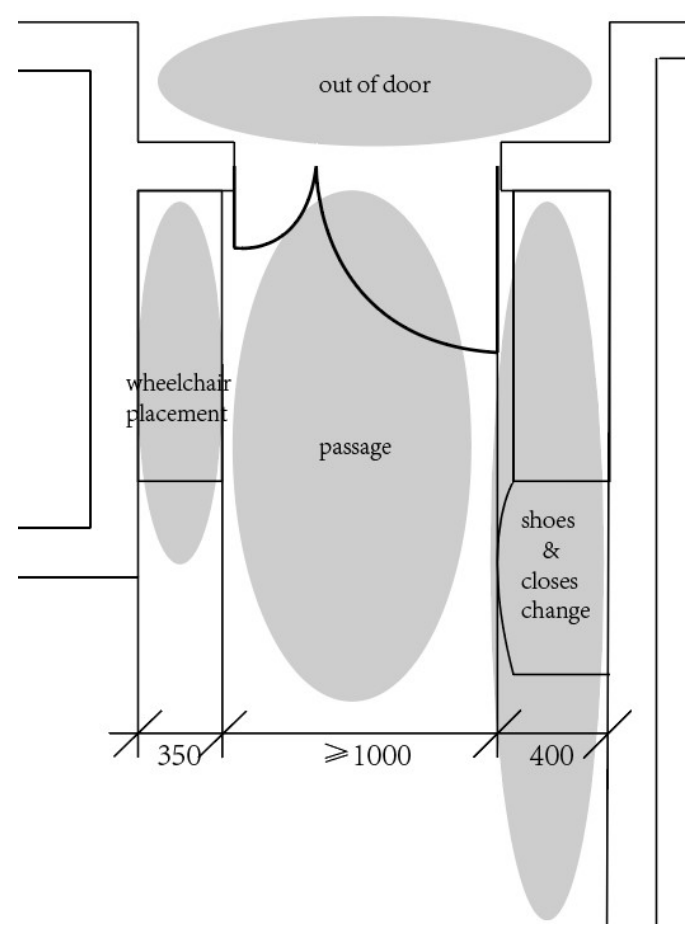

Figure 7.6 Layout of functional space in a front lobby

The living room needs to have enough width for wheelchairs to pass through without barriers. In addition, the living room should create an open, bright atmosphere and have a wide view, so that users can understand the space at first sight. 


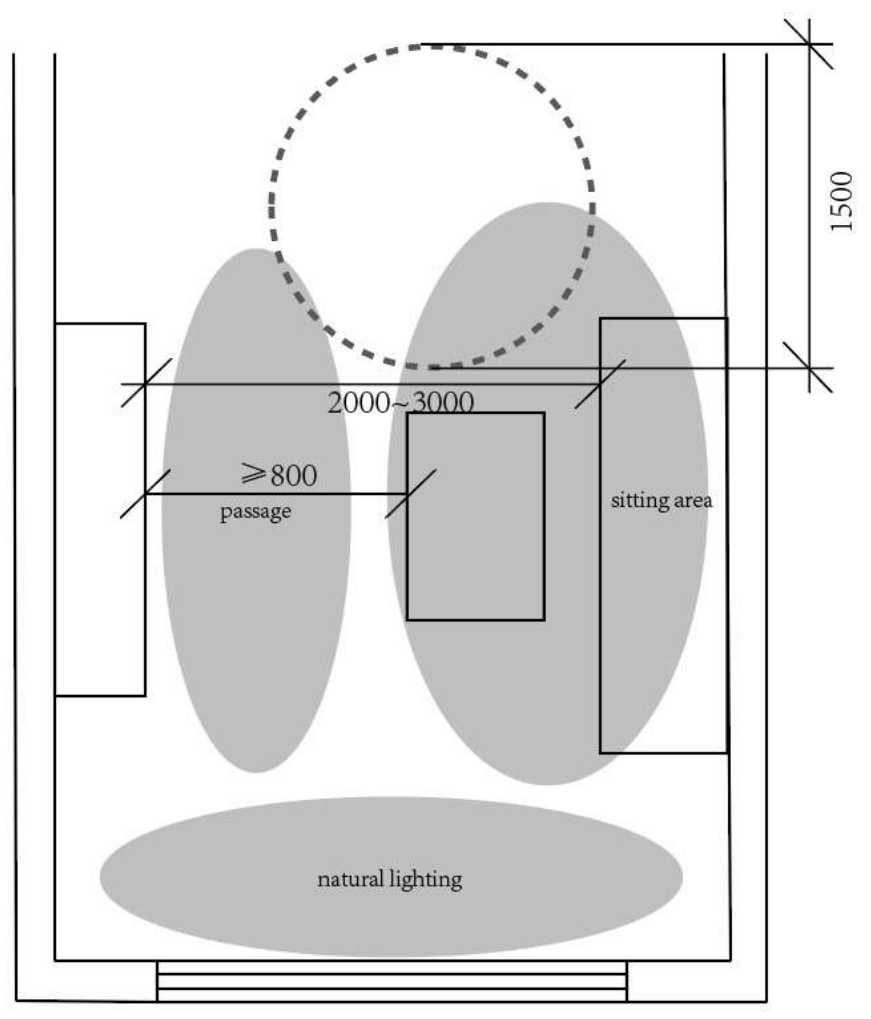

Figure 7.7 Layout of functional space in a living room

\section{b. Organizing effective traffic trajectories}

The living room, as the center of the house, should connect the various spaces. Leave a wide enough passageway as the main circulation route, and separate the activity areas from the passageway to avoid disturbing each other.

\section{c. Keep sightlines open.}

For older people, spaces with many activities, such as foyers and living rooms, need to be kept open for a sense of psychological security. Older people in living rooms, for example, need to be aware of their surroundings at all times, allowing sufficient reaction time for movement. 


\section{d. Focus on material selection for flooring}

The floor should be made of non-slip and waterproof material, and the junction of the materials should avoid height differences. 


\subsection{Dining room}

Restaurant design needs to follow these principles

a. Provide reasonable space dimensions.

As shown in the figure 2.8, the seat and the space behind the seat, each need to be $450 \mathrm{~mm}$ wide. The dining table needs to be at least $800 \mathrm{~mm}$ wide. The space at the other end of the table should consider whether it can accommodate a wheelchair user.

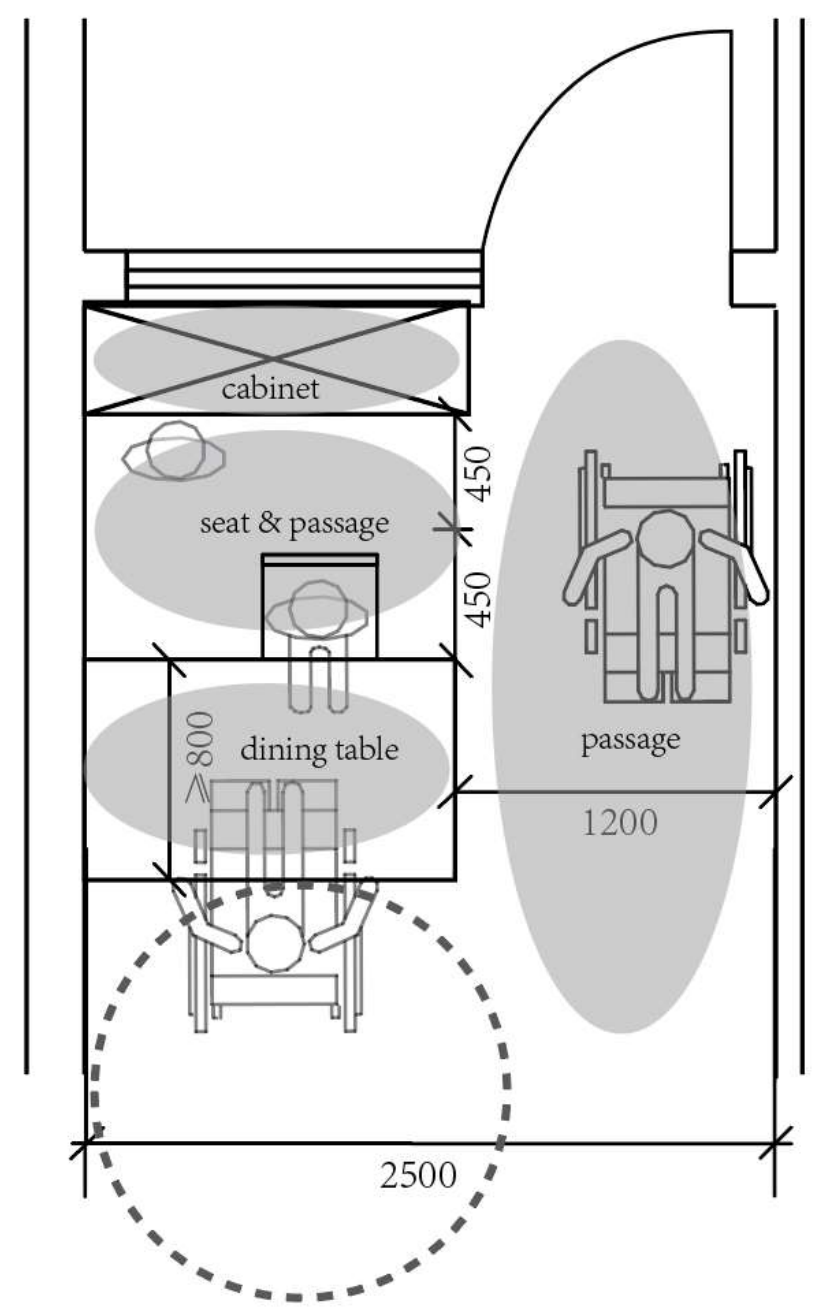

Figure 7.8 Layout of functional space in a dining room 


\section{b. The connection between kitchen and dining room}

Older people should be prevented from walking long distances with utensils in their hands, so the dining room to the kitchen should be close. In addition, a visual link between the dining room and the kitchen should be maintained so that people moving around in the dining room and kitchen can communicate with each other. 


\subsection{Bathroom and Laundry}

Bathroom design needs to follow several principles

\section{a. Dividing wet and dry areas}

The design should be separated into two areas the dry area and the wet area. During the design process, the bathing area should be separated from the toilet, sink, and other dry areas to reduce the likelihood of wet floors in dry areas. Often the shower and bathtub can be placed close together with the dry area located close to the door so that the user does not need to walk through the wet area to reach the dry area.

\section{b. Safety precautions}

Safety features like an emergency alarm should be included for safety, and handrails placed in the toilet and bathtub. A dual shower enables users to bathe comfortably in both seated and standing positions.

Lighting in the bathroom is important. During the day artificial lighting may be needed. 


\section{Initial list}

Figure 3.1 Entrance foyer

Institute for Human Centered Design. 2016. Entrance foyer. Retrieved from: https://universaldesigncasestudies.org/housing/private-single-family/baldwin$\underline{\text { residence/exterior-view }}$

Figure 3.2 Bathroom

Institute for Human Centered Design. 2016. Bath with Lavatory. Retrieved from: https://universaldesigncasestudies.org/housing/private-single-family/baldwin$\underline{\text { residence/removable-base-cabinets }}$

Figure 3.3 Removeable cabinets: Author

Figure 3.4 Dining adjacent with kitchen

Institute for Human Centered Design. 2016. Dining adjacent with kitchen. Retrieved from: $\quad \underline{\text { https://universaldesigncasestudies.org/housing/private-single-family/baldwin- }}$ residence/dining-area

Figure 3.5 Front foyer

Institute for Human Centered Design. 2016. Front foyer. Retrieved from: https://universaldesigncasestudies.org/housing/private-single-family/baldwin$\underline{\text { residence/front-foyer }}$ 
Figure 3.6 Reading room and stair

Institute for Human Centered Design. 2016. Reading room and stair. Retrieved from: https://universaldesigncasestudies.org/housing/private-single-family/baldwin$\underline{\text { residence/stacked-closet }}$

Figure 3.7 Front door

Institute for Human Centered Design. 2016. Front door. Retrieved from: https://universaldesigncasestudies.org/housing/private-single-family/taubatéhouse/front-view

Figure 3.8 Double rails

Institute for Human Centered Design. 2016. Double Rails. Retrieved from: https://universaldesigncasestudies.org/housing/private-single-family/taubaté$\underline{\text { house/stairs }}$

Figure 3.9 Laundry

Institute for Human Centered Design. 2006. Laundry. Retrieved from: https://universaldesigncasestudies.org/housing/private-single-family/taubatéhouse/laundry-room

Figure 3.10 Bathroom

Institute for Human Centered Design. 2016. Bathroom. Retrieved from: https://universaldesigncasestudies.org/housing/private-single-family/taubatéhouse/bathroom-1 
Figure 3.11 Backyard

Institute for Human Centered Design. 2016. Backyard. Retrieved from: https://universaldesigncasestudies.org/housing/private-single-family/taubaté$\underline{\text { house/rear-view }}$

Figure 3.12 Sliding Door to the terrace

Institute for Human Centered Design. 2016. Sliding door to the terrace. Retrieved from: https://universaldesigncasestudies.org/housing/private-single-family/siple-house/living$\underline{\text { room-sliding-doors }}$

Figure 3.13 The terrace (13) connect the surrounding rooms: Author

Figure 3.14 Built-in coffee dispenser in cabinet

Institute for Human Centered Design. 2016. Built-in coffee dispenser in cabinet. Retrieved from: $\underline{\text { https://universaldesigncasestudies.org/housing/private-single- }}$ family/siple-house/refrigerator

Figure 3.15 Tile shower

Institute for Human Centered Design. 2016. Tile shower. Retrieved from: https://universaldesigncasestudies.org/housing/private-single-family/siplehouse/shower

Figure 3.16 Kitchen Unities

Institute for Human Centered Design. 2016. Kitchen Unities. Retrieved from: https://universaldesigncasestudies.org/housing/private-single-family/siple$\underline{\text { house/kitchen }}$ 
Figure 3.17 Standard of door size for wheelchair

Figure 3.18 Outside of house

Institute for Human Centered Design. 2016. Outside of house. Retrieved from: https://universaldesigncasestudies.org/housing/multi-family/egebakken-communityhousing/rear-view

Figure 3.19 Sidewalks in house

Institute for Human Centered Design. 2016. Sidewalks in house. Retrieved from: https://universaldesigncasestudies.org/housing/multi-family/egebakken-communityhousing/clubhouse

Figure 3.20 Slope

Institute for Human Centered Design. 2016. Slope. Retrieved from: https://universaldesigncasestudies.org/housing/multi-family/egebakken-communityhousing/front-view

Figure 3.21 Kitchen unit

Institute for Human Centered Design. 2016. Kitchen. Retrieved from: https://universaldesigncasestudies.org/housing/multi-family/egebakken-communityhousing/kitchen

Figure 3.22 U-shaped kitchen: Author

Figure 3.23 Original plan: Author

Figure 3.24 The plan after redesign: Author

Figure 3.25 Redesign of Storage: Author 
Figure 3.26 and 3.27 Visual design: Author

Figure 3.28

Housing for the elderly. 2018. Page 293

Figure 3.29

Housing for the elderly. 2018. Page 293

Figure 3.30

Housing for the elderly. 2018. Page 293

Figure 3.31

Housing for the elderly. 2018. Page 294

Figure 3.32

Housing for the elderly. 2018. Page 294

Figure 4.1 to 4.9: Author

Figure 5.1 to 5.27: Author

Figure 6.1 to 6.9: Author

Figure 7.1 to 7.8 : Author 